\title{
Supramolecular Interactions between $\beta$-Cyclodextrin and the Nucleobase Derivatives of Ferrocene
}

\section{Supplementary Information}

Artur Kasprzak $^{\mathrm{a} *}$, Mariola Koszytkowska-Stawińska ${ }^{\mathrm{a} *}$, Anna M. Nowicka ${ }^{\mathrm{b}}$, Włodzimierz Buchowicz $^{\mathrm{a}}$, Magdalena Poplawska ${ }^{\mathrm{a}}$

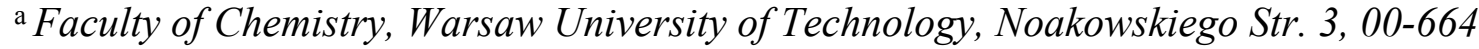
Warsaw, Poland

${ }^{\mathrm{b}}$ Faculty of Chemistry, University of Warsaw, Pasteura Str. 1, 02-093Warsaw, Poland

* Corresponding authors; e-mails: akasprzak@ch.pw.edu.pl (A. Kasprzak), mkoszyt@ch.pw.edu.pl (M. Koszytkowska-Stawińska)

\section{Table of Contents}

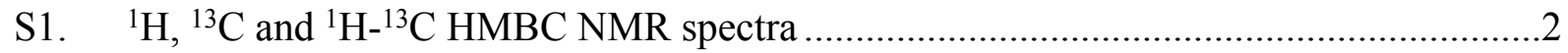

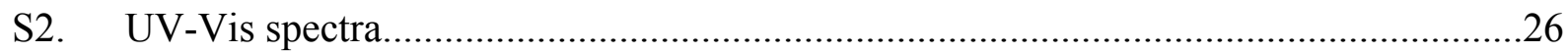

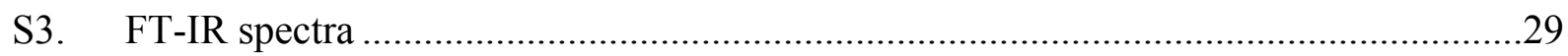

S4. Electrochemical characterization of compounds Fc-1-Fc-5 - data ...............................33

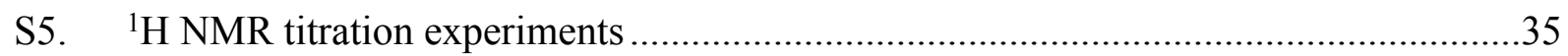

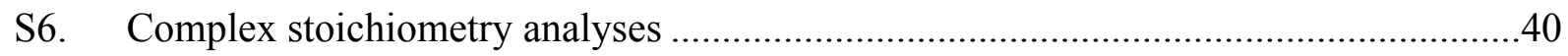

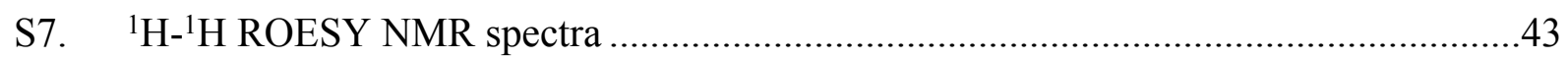

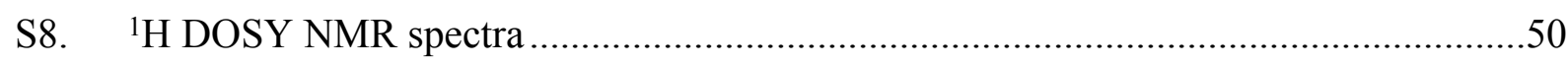

S9. Calculation method for errors of measured diffusion coefficients and association

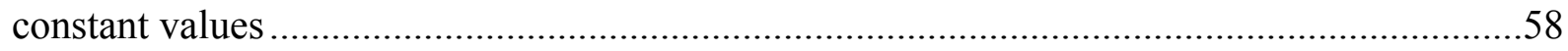

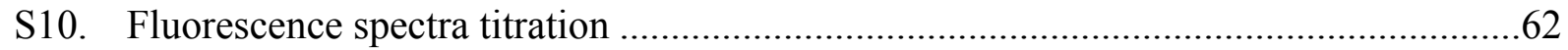

S11. Tracking the complexation phenomenon with FT-IR ...............................................67

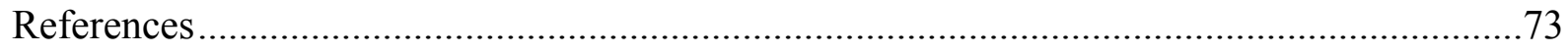




\section{S1. ${ }^{1} \mathrm{H},{ }^{13} \mathrm{C}$ and ${ }^{1} \mathrm{H}-{ }^{13} \mathrm{C}$ HMBC NMR spectra}

cdcl3, 1H, 499.93, 25.0

STANDARD PROTON PARAMETERS 2015-02-27T12:46:12
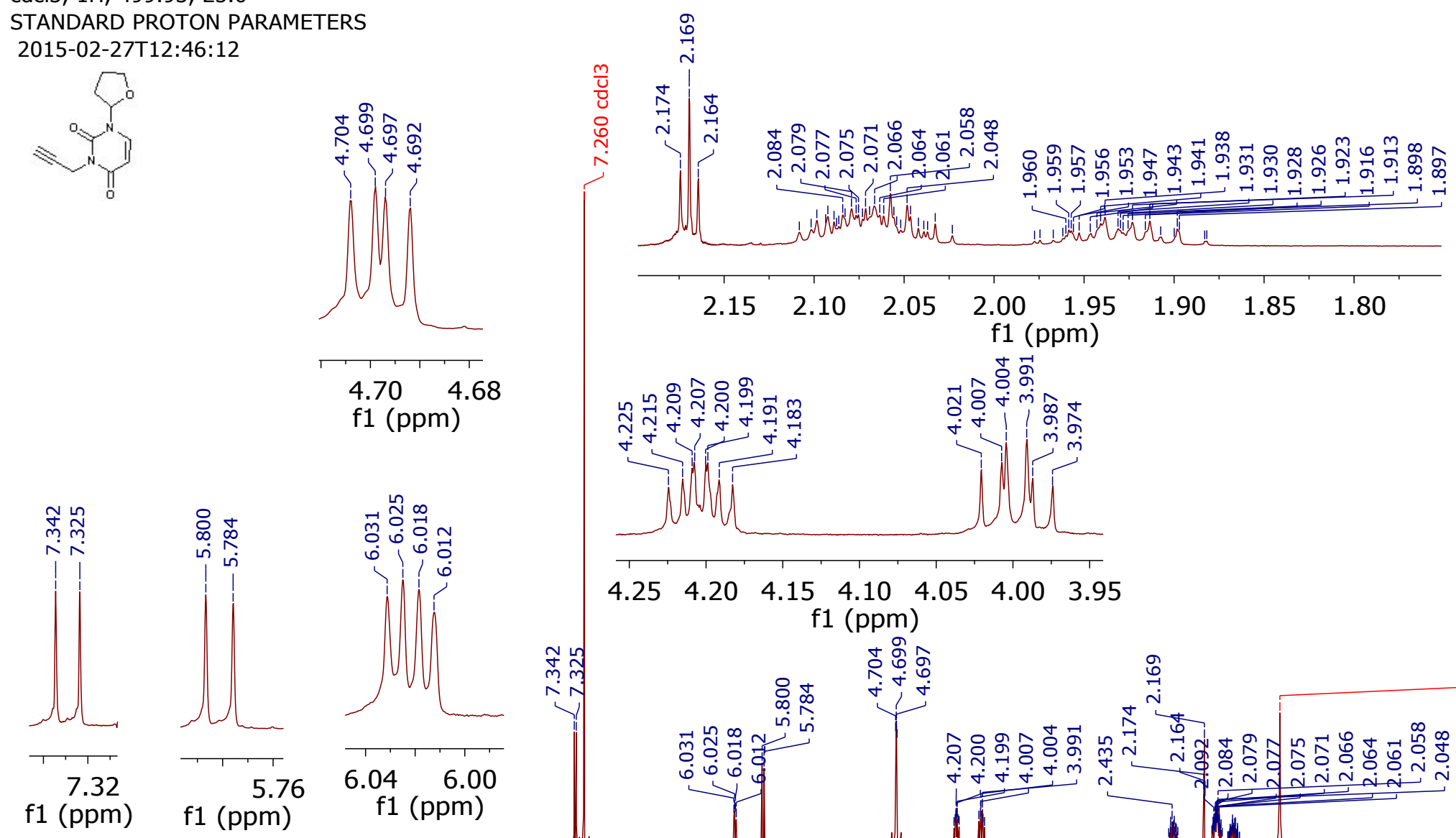

$\begin{array}{lllllll}4.25 & 4.20 & 4.15 & 4.10 & 4.05 & 4.00 & 3.95\end{array}$ f1 (ppm)

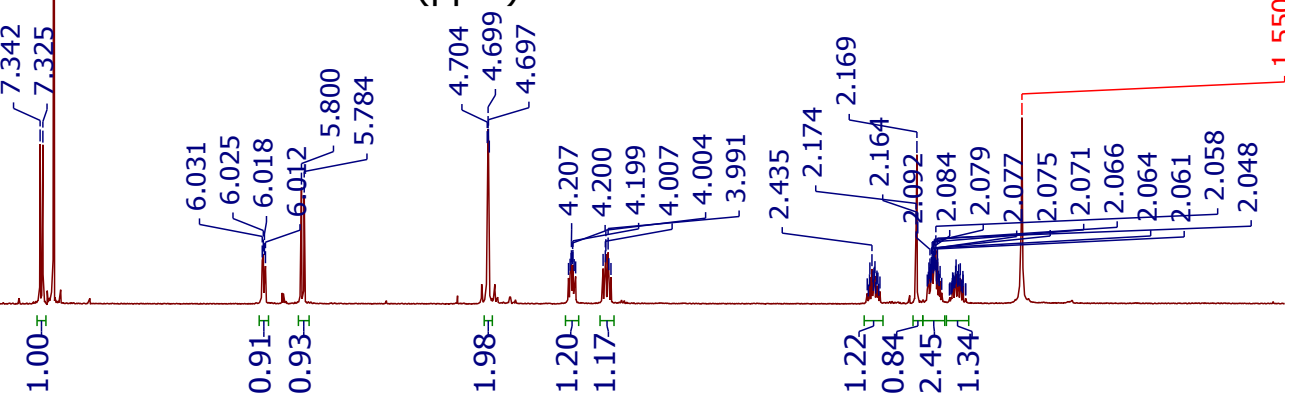

$\begin{array}{lllll}2.0 & 11.0 & 10.0 & 9.0 & 8.0\end{array}$

7.0 f1

Figure S1. ${ }^{1} \mathrm{H}$ NMR spectrum $\left(\mathrm{CDCl}_{3}, 500 \mathrm{MHz}\right)$ of compound 2 a. 
cdcl3, 13C, 125.72, 25.0

STANDARD CARBON PARAMETERS

2015-03-02T12:57:03

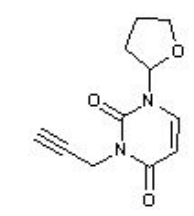

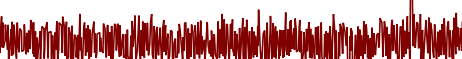

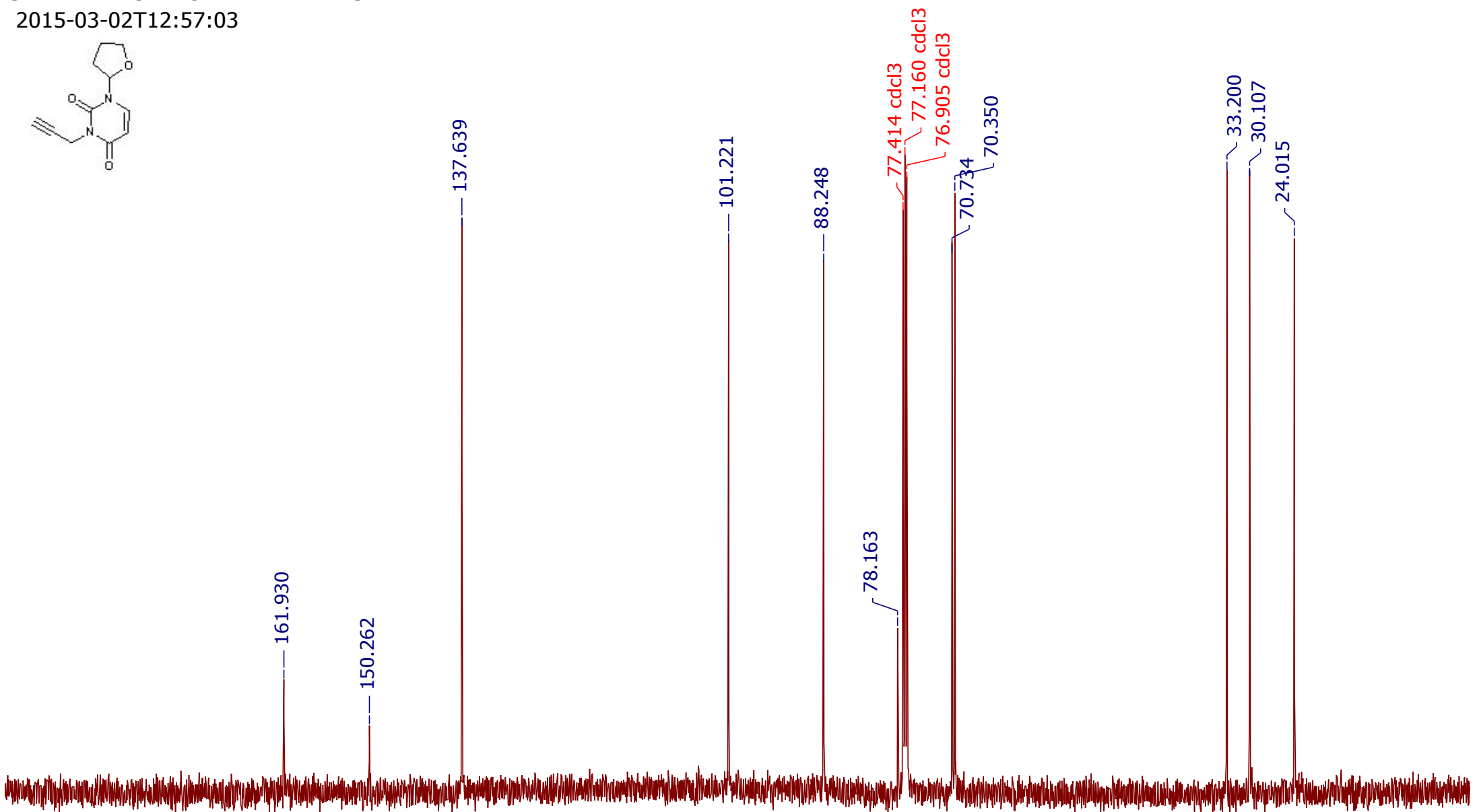

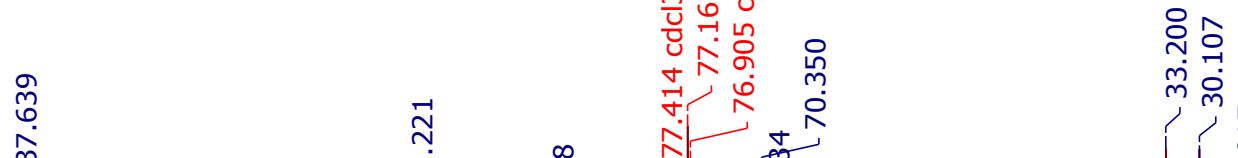

$\stackrel{m}{\rightarrow}$

$\stackrel{\stackrel{0}{\sim}}{\stackrel{0}{\dot{d}}}$

$00 \quad 190 \quad 180 \quad 170$

160

$150 \quad 140$

130

120

$110 \quad 100 \quad 90$

80

70

6050

40

3020

101

Figure S2. ${ }^{13} \mathrm{C}$ NMR spectrum $\left(\mathrm{CDCl}_{3}, 125 \mathrm{MHz}\right)$ of compound 2 a. 
cdcl3, $1 \mathrm{H}, 499.93,25.0$

STANDARD PROTON PARAMETERS

2017-06-09T11:45:51
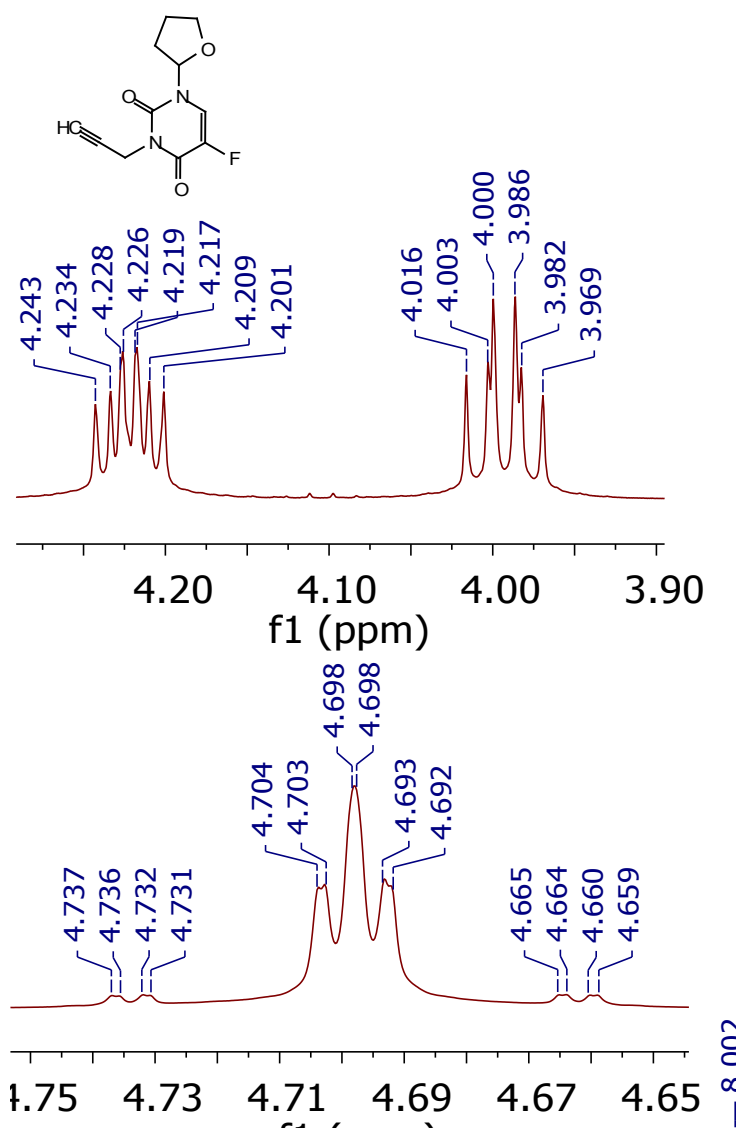

$$
\text { f1 (ppm) }
$$

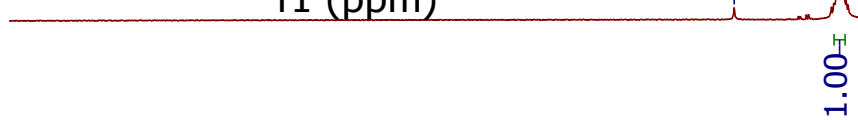

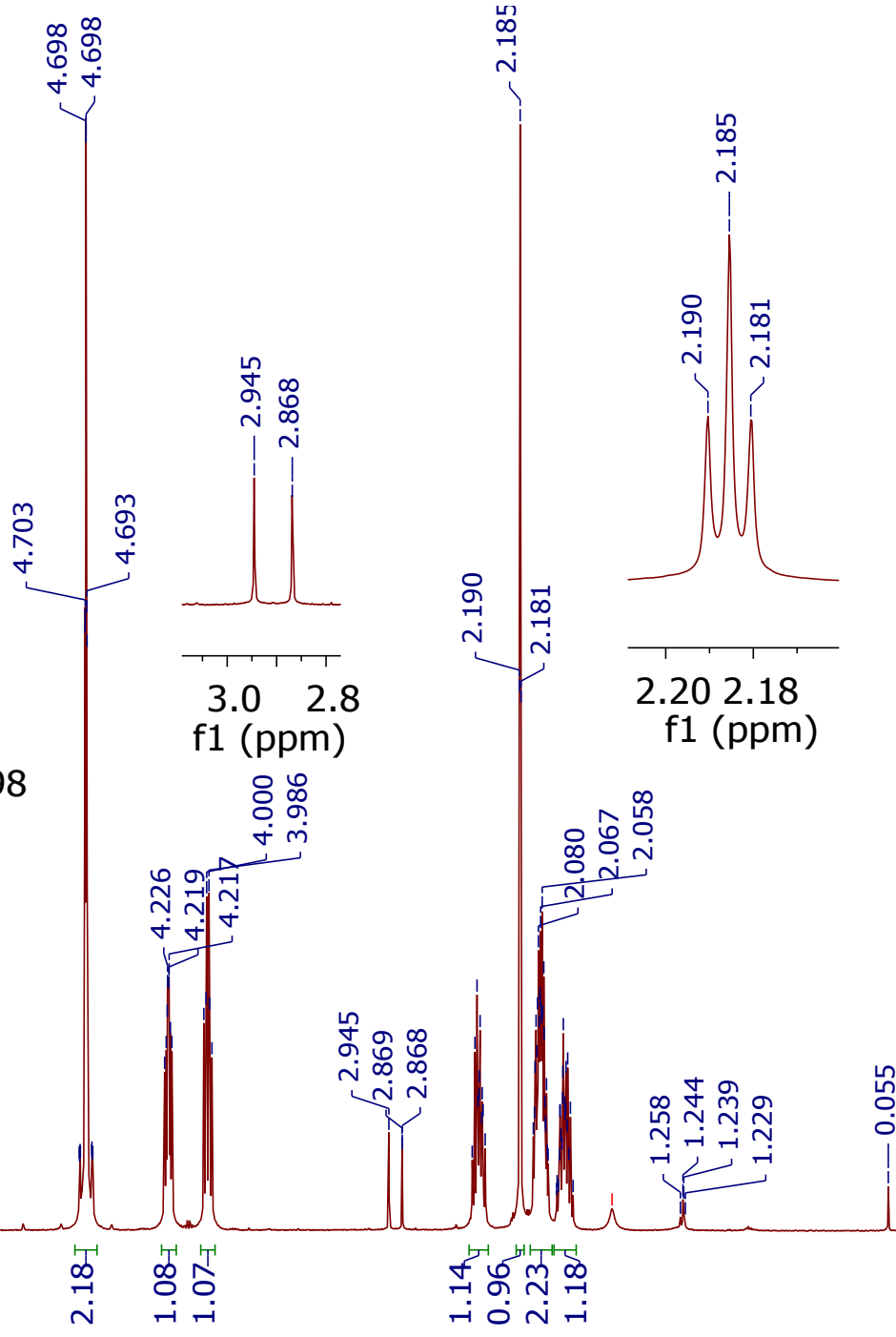

$\begin{array}{lllllllllllllllllllllll}11.5 & 11.0 & 10.5 & 10.0 & 9.5 & 9.0 & 8.5 & 8.0 & 7.5 & 7.0 & 6.5 & 6.0 & 5.5 & 5.0 & 4.5 & 4.0 & 3.5 & 3.0 & 2.5 & 2.0 & 1.5 & 1.0 & 0.5\end{array}$ f1 (ppm)

Figure S3. ${ }^{1} \mathrm{H}$ NMR spectrum $\left(\mathrm{CDCl}_{3}, 500 \mathrm{MHz}\right)$ of compound $\mathbf{2 b}$. 
cdcl3, 13C, 125.72, 25.0

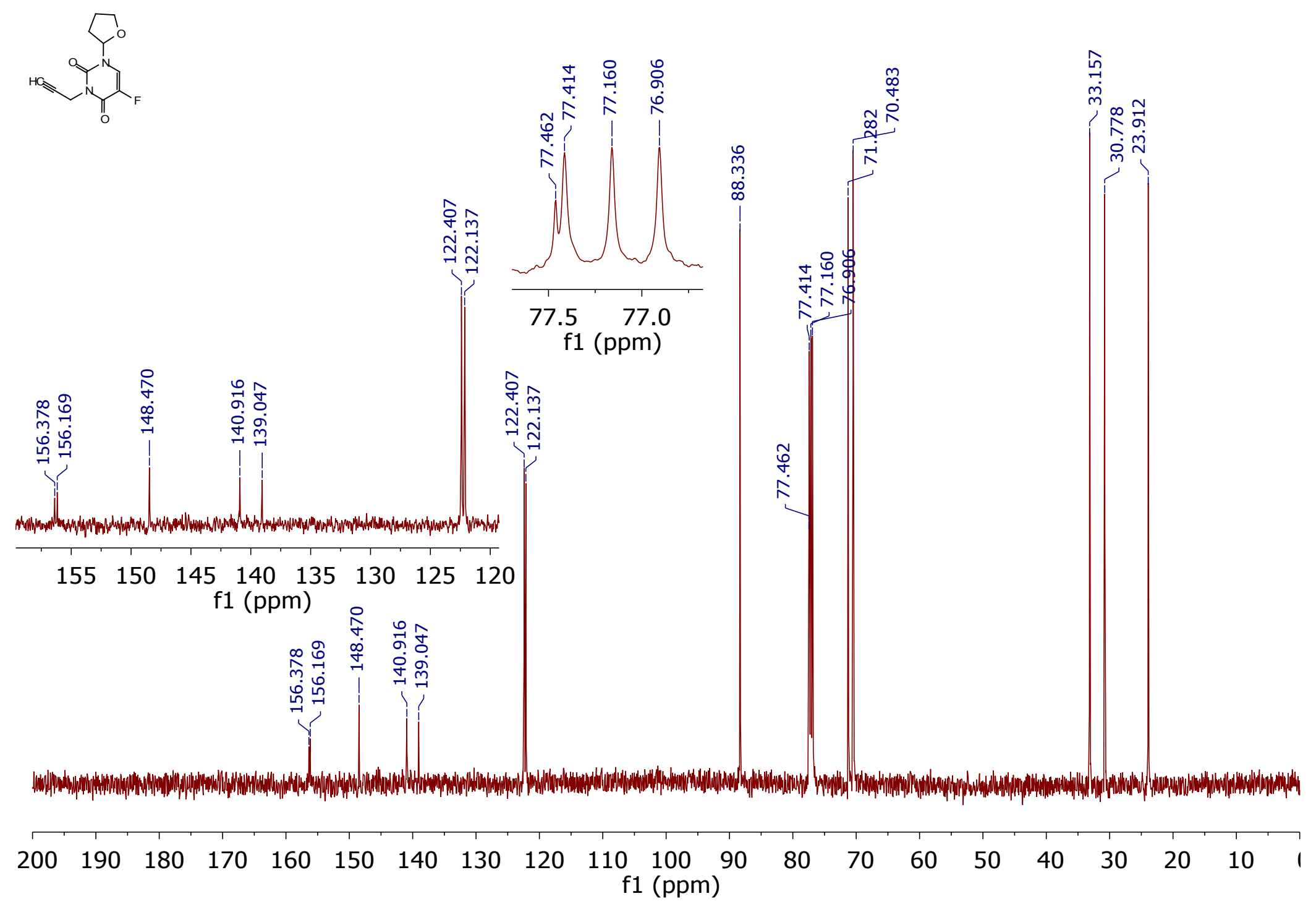

Figure $44 .{ }^{13} \mathrm{C}$ NMR spectrum $\left(\mathrm{CDCl}_{3}, 125 \mathrm{MHz}\right)$ of compound $\mathbf{2 b}$. 
dmso, 1H, 499.94, 25.0

STANDARD PROTON PARAMETERS

2015-06-18T10:47:47<smiles>C#CCn1c(=O)cc[nH]c1=O</smiles>
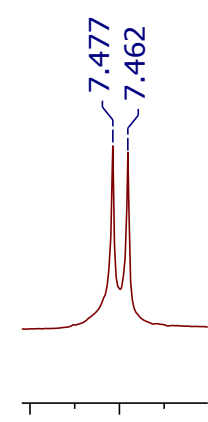

7.567 .47

f1 (ppm)

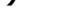

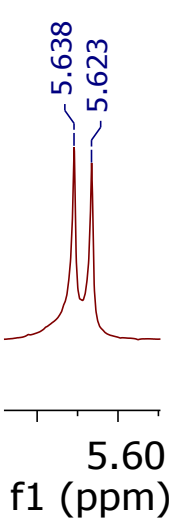

5.60
$(\mathrm{ppm})$

ำ $f 1(p p m)$

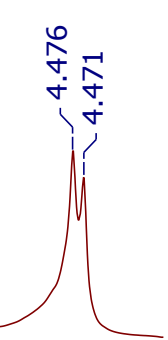

$$
44
$$
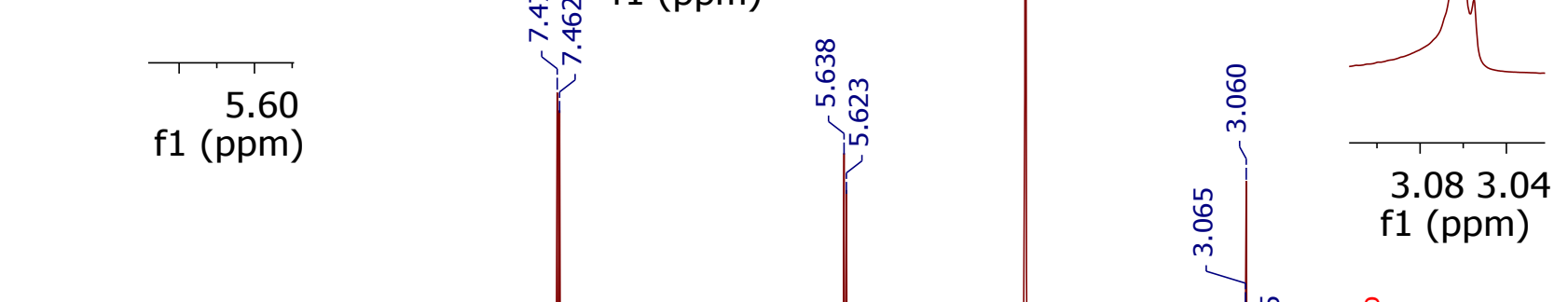
dmso, 13C, 125.72, 25.0

STANDARD CARBON PARAMETERS

2015-06-18T10:48:33
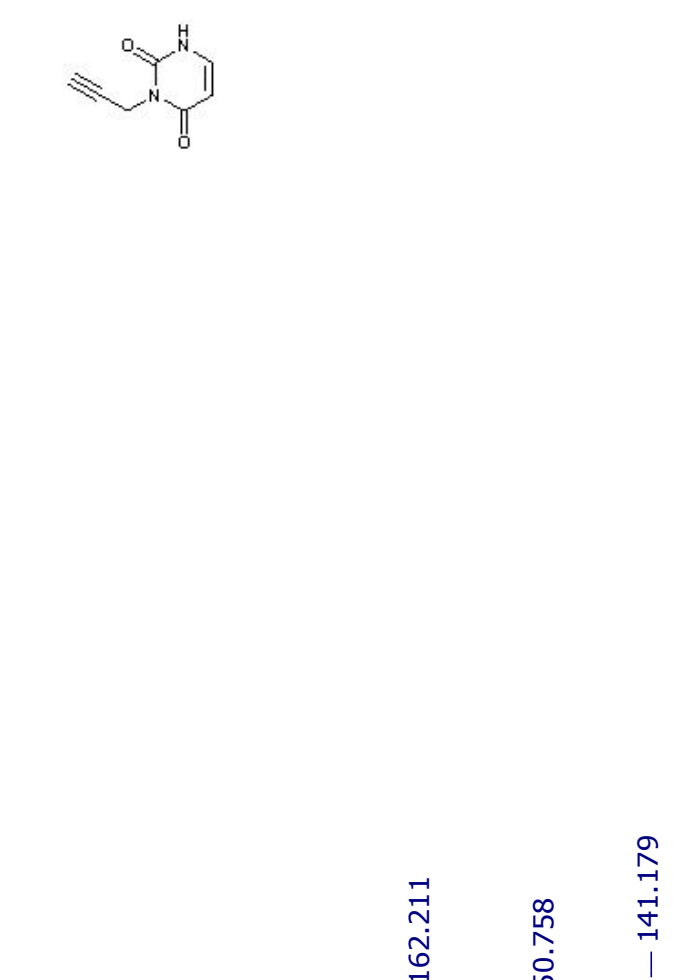

ตั

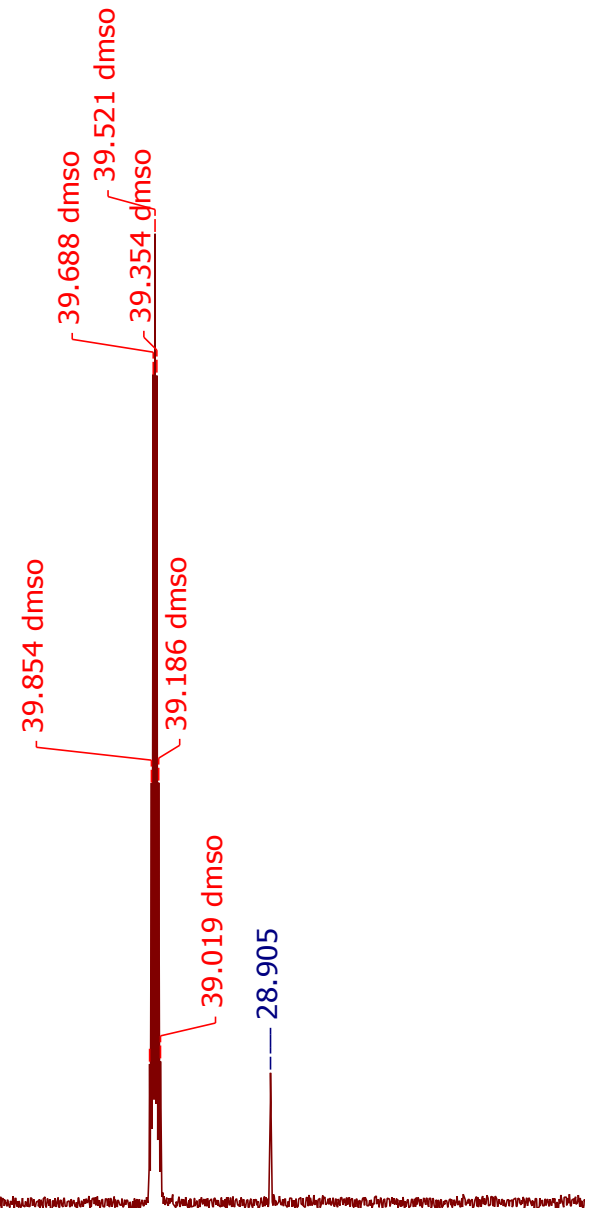

$00 \quad 190 \quad 180 \quad 170$

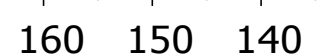

110100

90

80

$70 \quad 60$

50

40

3020

Figure S6. ${ }^{13} \mathrm{C}$ NMR spectrum (DMSO- $d_{6}, 125 \mathrm{MHz}$ ) of compound 3a. 
dmso, $1 \mathrm{H}, 499.88,25.0$

new experiment

2018-11-15T13:25:58
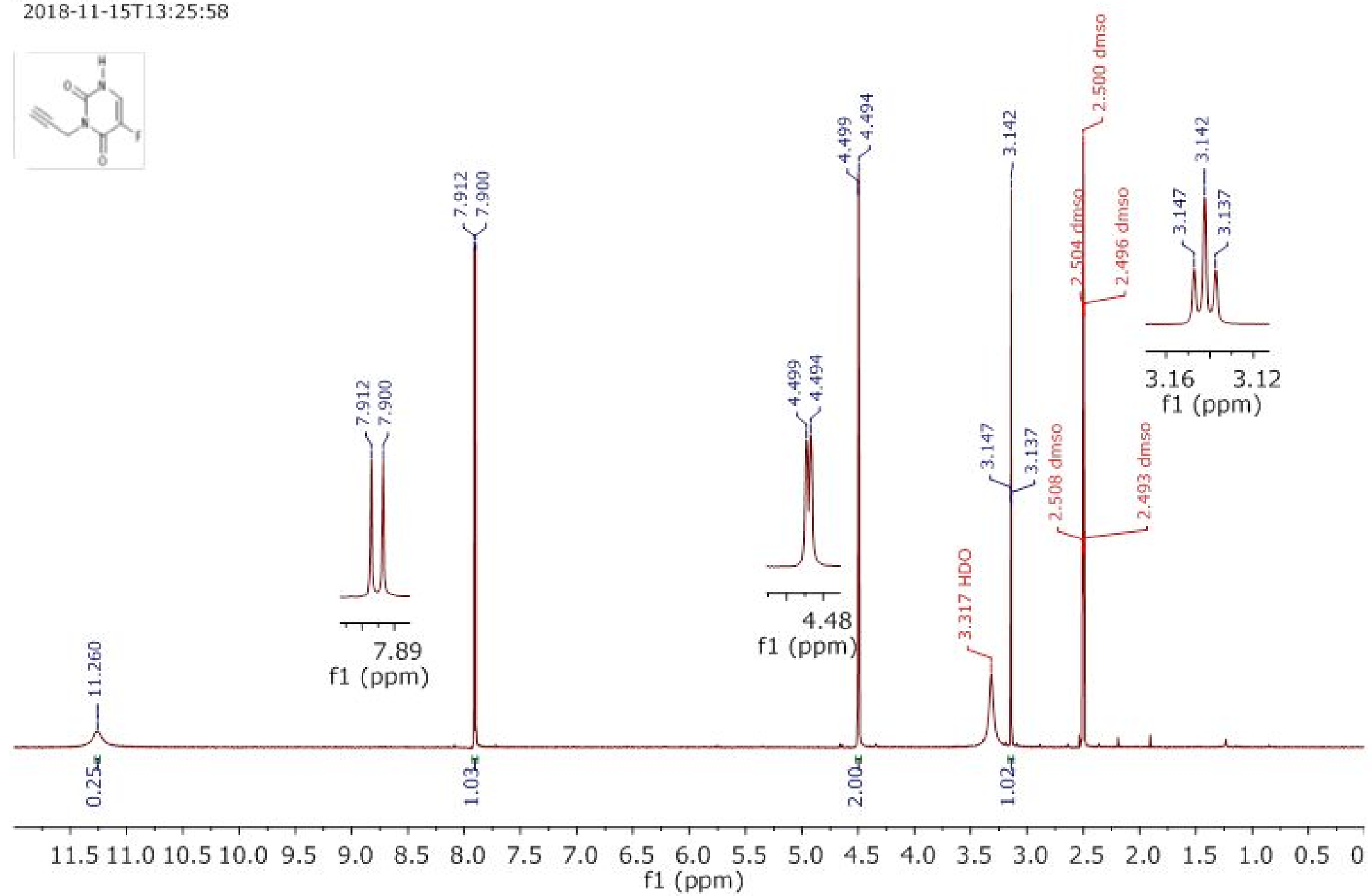

Figure S7. ${ }^{1} \mathrm{H}$ NMR spectrum (DMSO- $d_{6}, 500 \mathrm{MHz}$ ) of compound $\mathbf{3 b}$. 
dmso, 13C, 125.72, 25.0

STANDARD CARBON PARAMETERS

2017-11-28T15:10:43
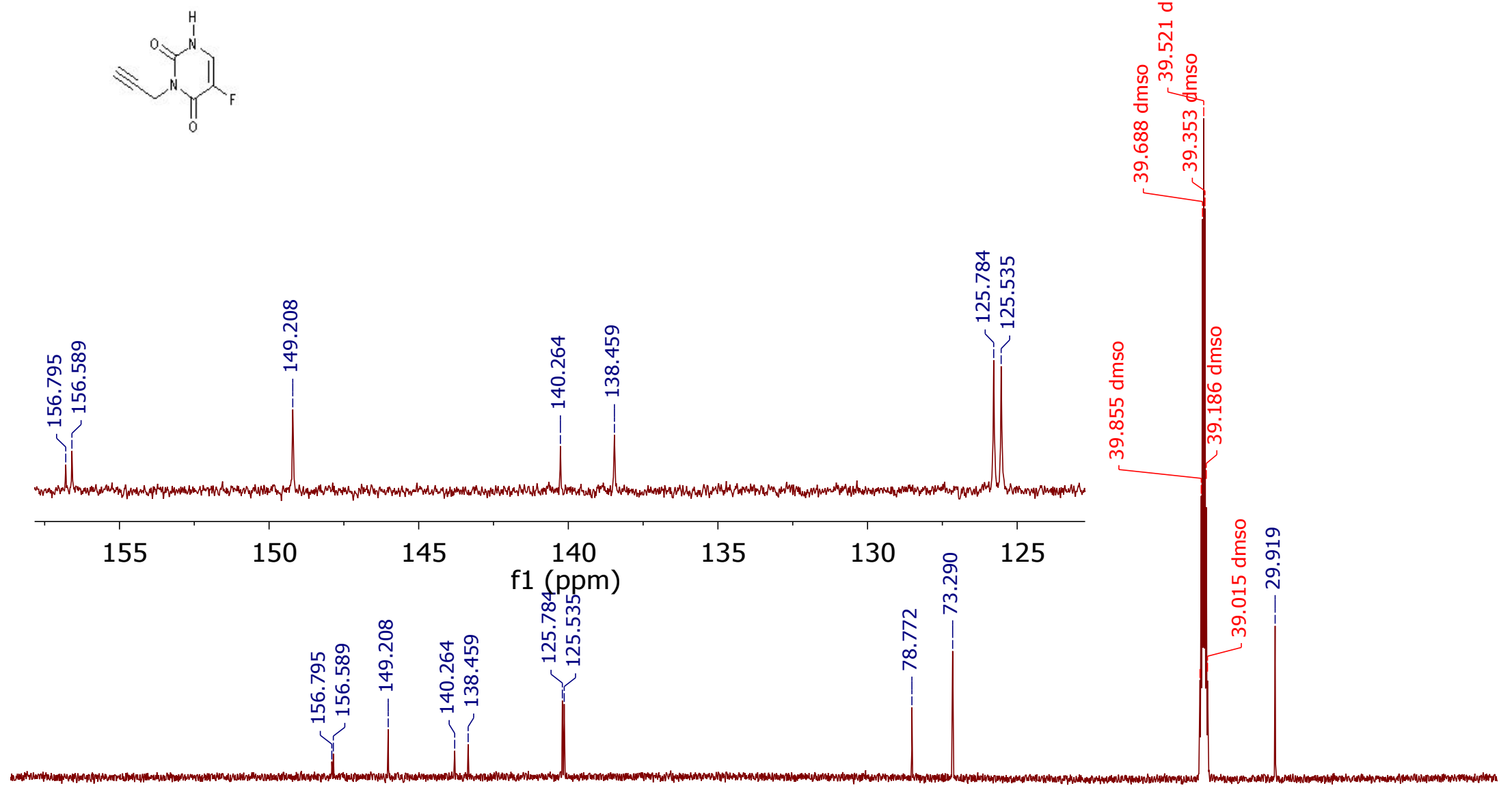

$\begin{array}{lllllllllll}00 & 190 & 180 & 170 & 160 & 150 & 140 & 130 & 120 & 110 & 100\end{array}$

$\begin{array}{lllllllll}80 & 70 & 60 & 50 & 40 & 30 & 20 & 10\end{array}$

Figure S8. ${ }^{13} \mathrm{C}$ NMR spectrum (DMSO-d $d_{6}, 125 \mathrm{MHz}$ ) of compound $\mathbf{3 b}$. 


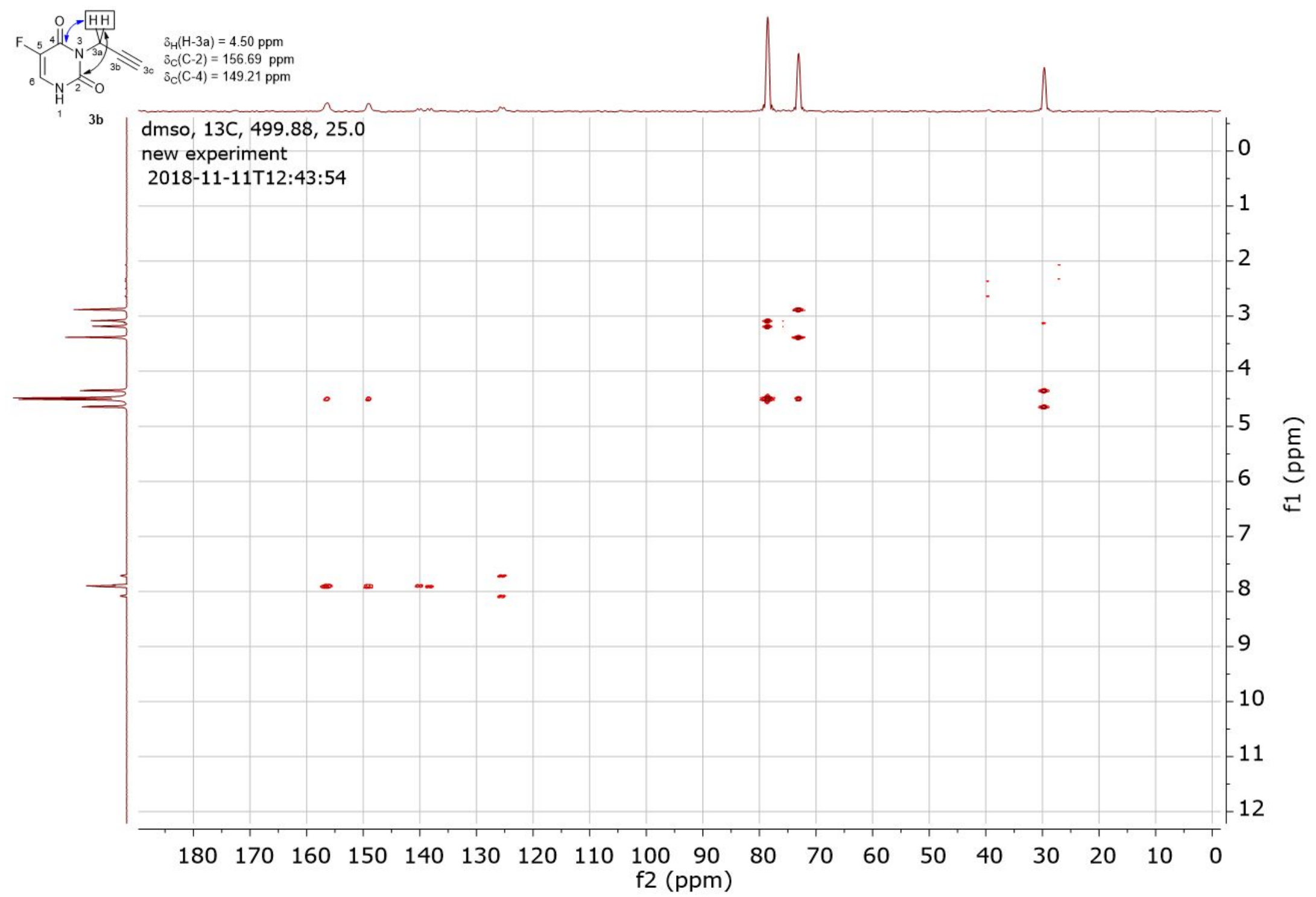

Figure S9. ${ }^{1} \mathrm{H}-{ }^{13} \mathrm{C}$ HMBC NMR spectrum (DMSO- $d_{6}, 500 \times 125 \mathrm{MHz}$ ) of compound $\mathbf{3 b}$. 
dmso, $1 \mathrm{H}, 499.88,25.0$

new experiment

2018-11-16T10:33:22
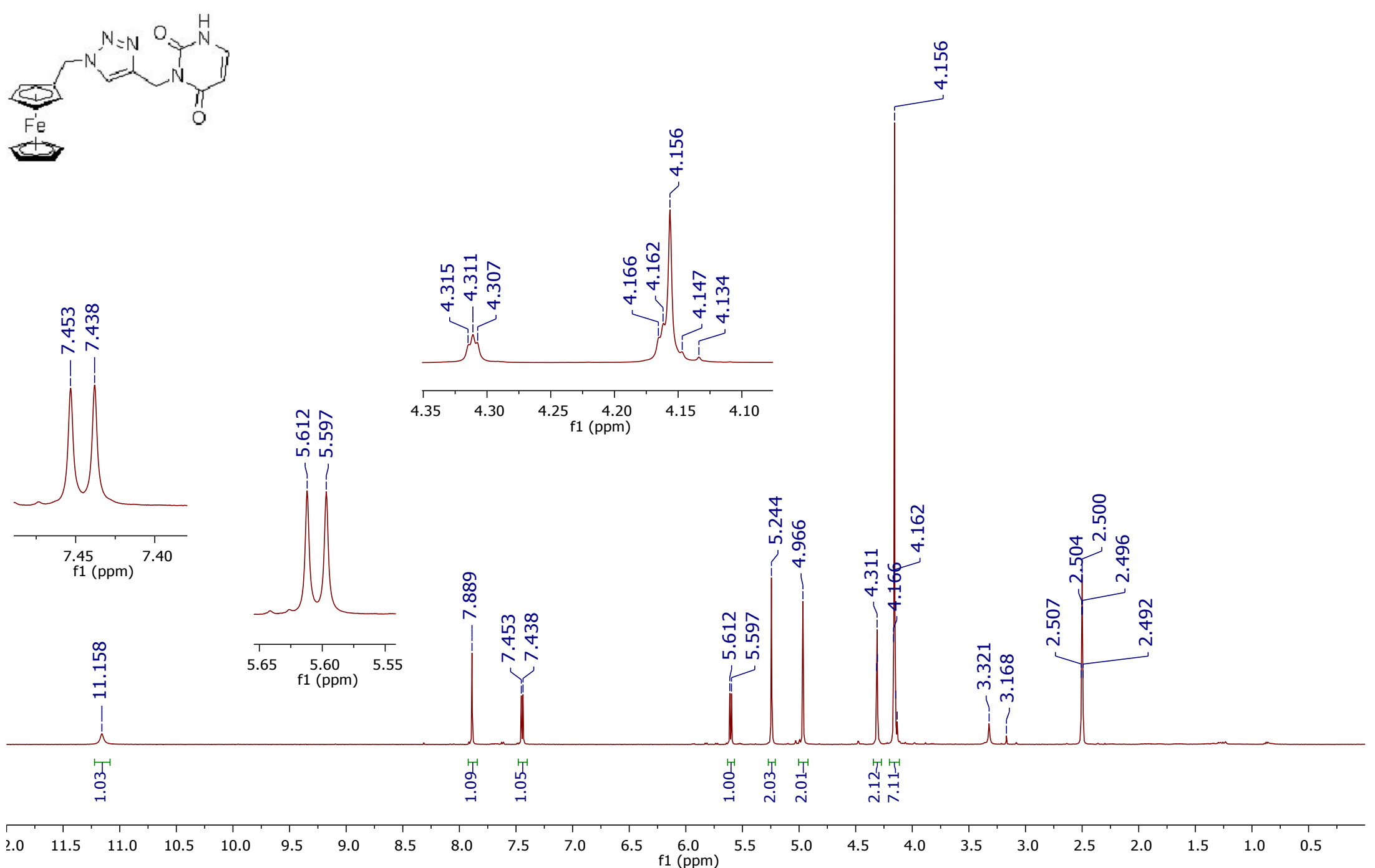

Figure S10. ${ }^{1} \mathrm{H}$ NMR spectrum (DMSO- $d_{6}, 500 \mathrm{MHz}$ ) of compound Fc-1. 
dmso, 13C, $125.71,25.0$

new experiment

2018-11-16T10:41:10
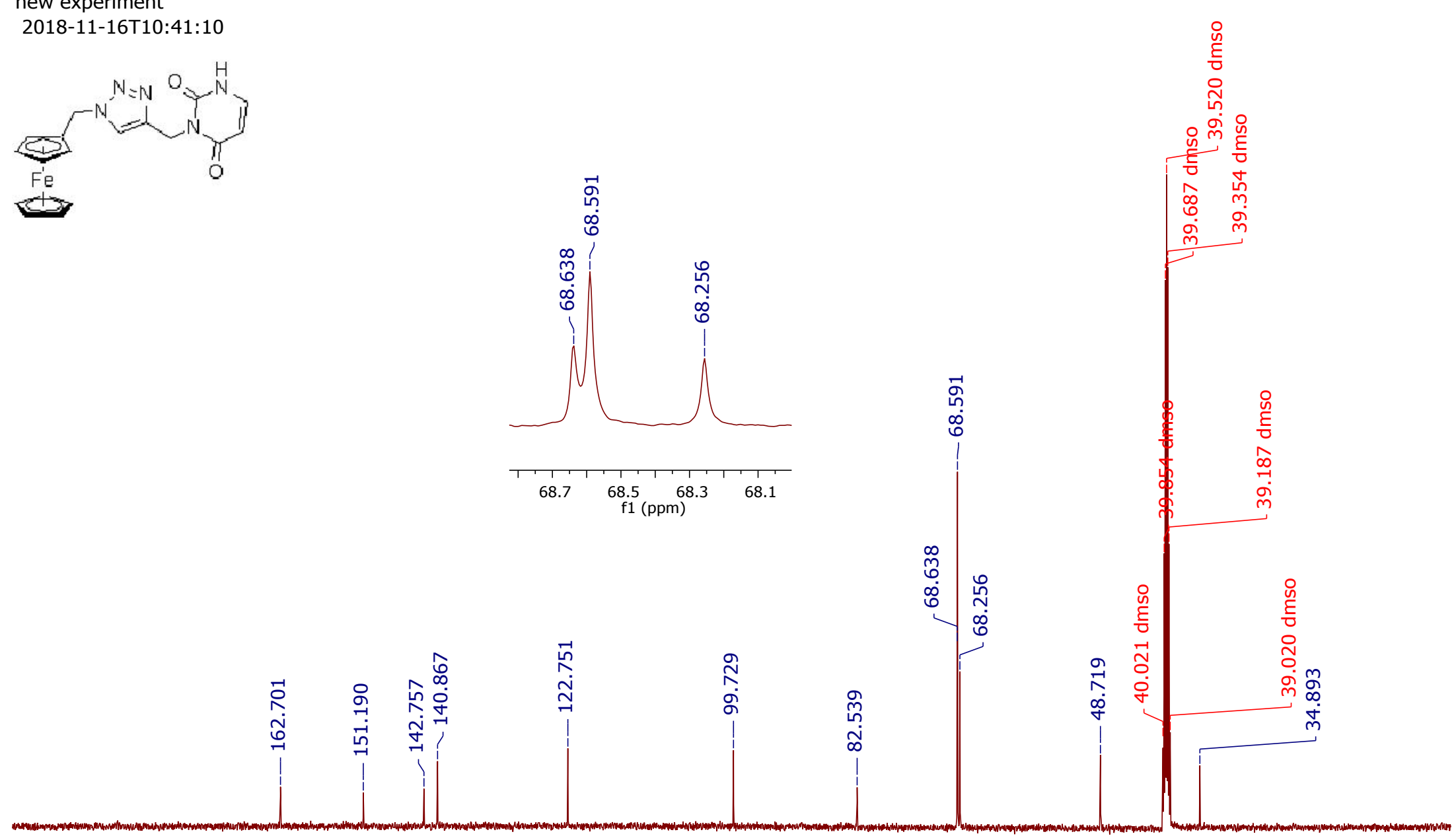

$\begin{array}{lllllllllll}00 & 190 & 180 & 170 & 160 & 150 & 140 & 130 & 120 & 110 & \begin{array}{c}100 \\ \mathrm{f} 1(\mathrm{ppm})\end{array}\end{array}$

Figure S11. ${ }^{13}$ NMR spectrum (DMSO- $d_{6}, 125 \mathrm{MHz}$ ) of compound Fc-1. 
dmso, 1H, 499.94, 25.0

STANDARD PROTON PARAMETERS

2018-01-11T13:27:28
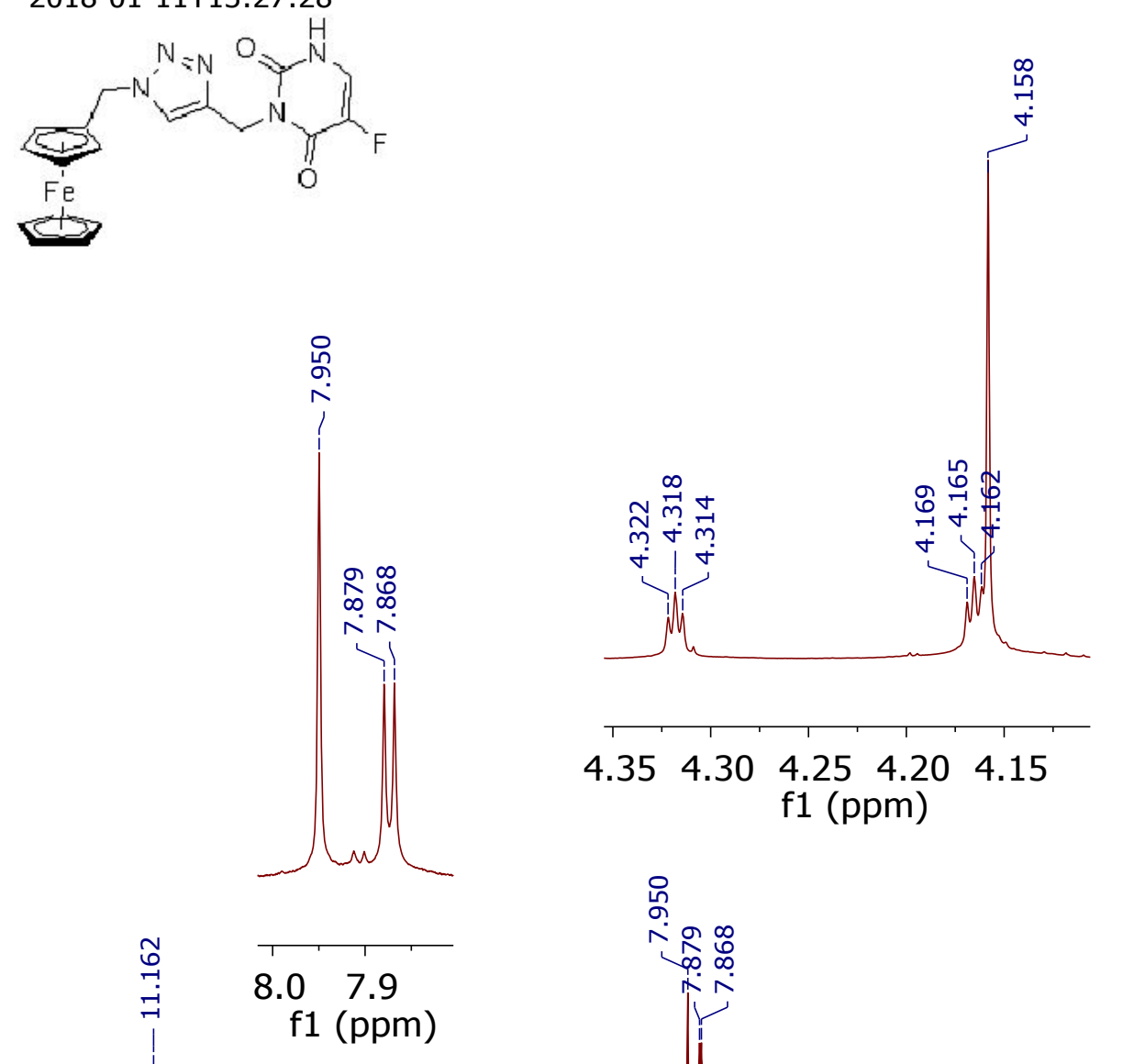

กิ
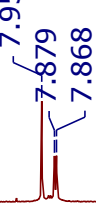

年

苫

배응

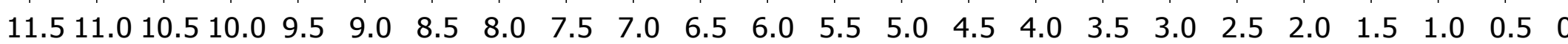
f1 (ppm)

Figure S12. ${ }^{1} \mathrm{H}$ NMR spectrum (DMSO- $d_{6}, 500 \mathrm{MHz}$ ) of compound Fc-2. 
dmso, 13C, 125.72, 25.0

STANDARD CARBON PARAMETERS

2018-01-05T10:48:49
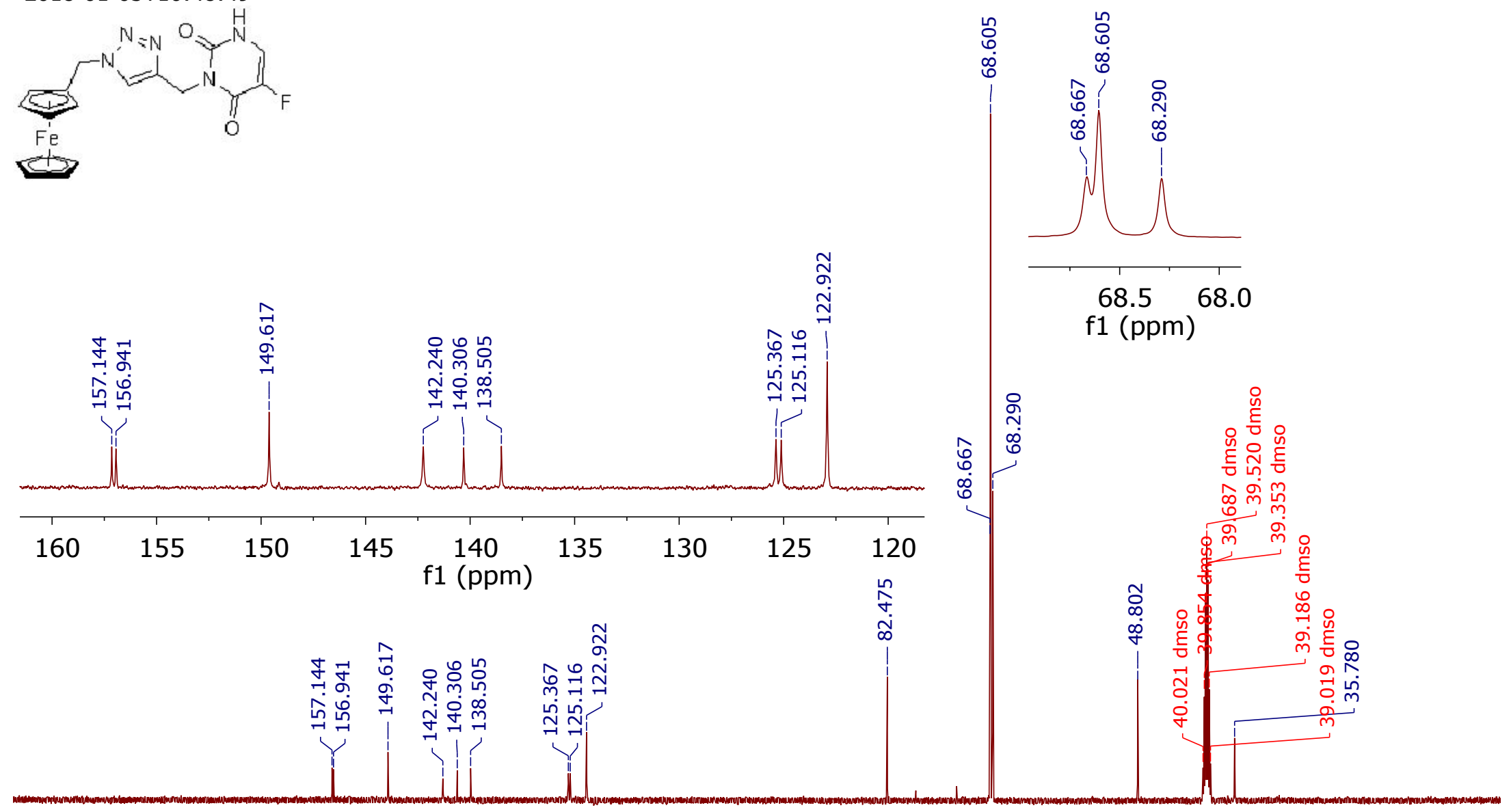

$\begin{array}{llllllllll}00 & 190 & 180 & 170 & 160 & 150 & 140 & 130 & 120 & 110 \\ \text { f1 (ppm) }\end{array}$ 
cdcl3, 1H, 499.93, 25.0

STANDARD PROTON PARAMETERS

2017-12-01T13:57:32

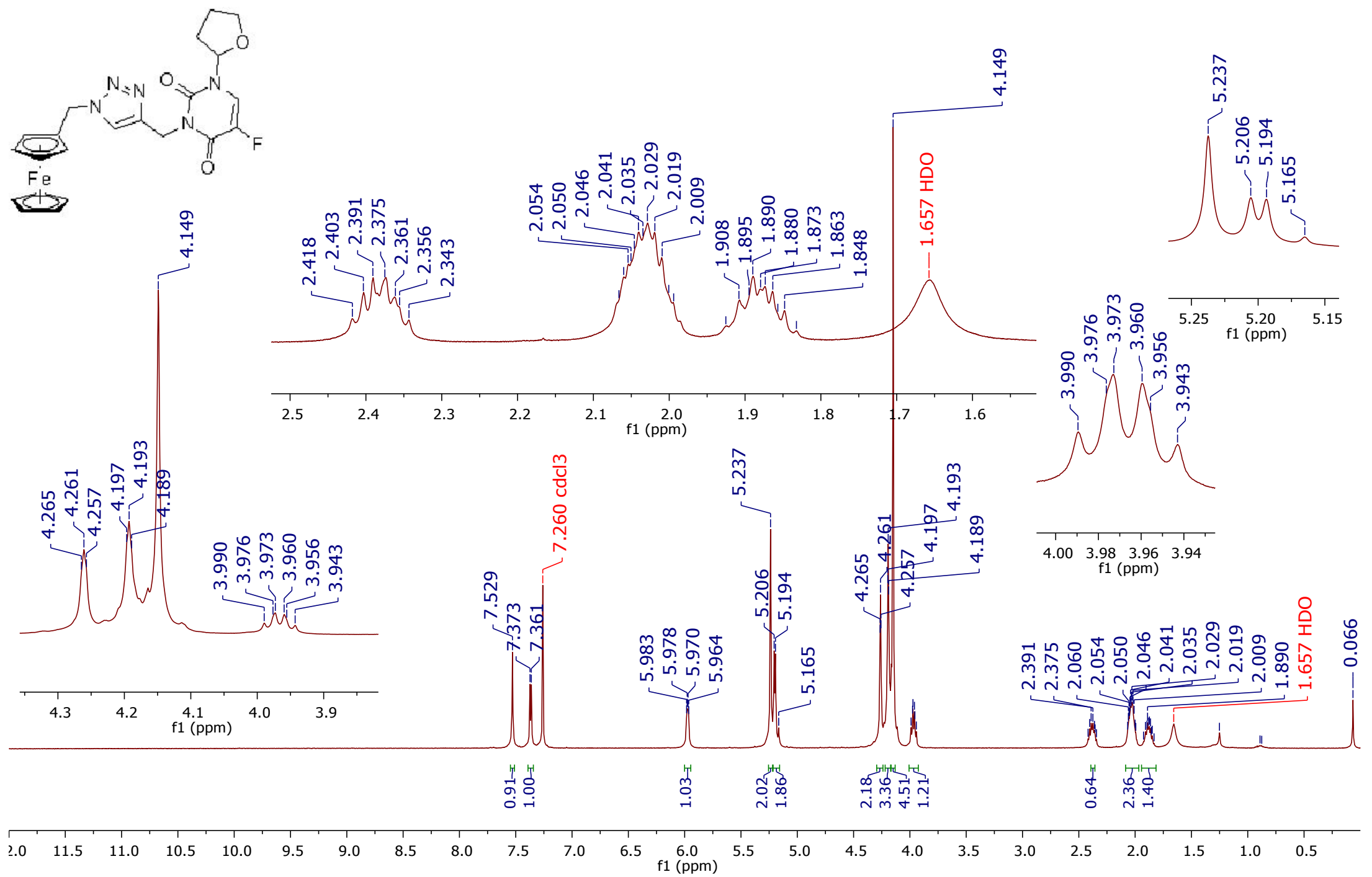

Figure S14. ${ }^{1} \mathrm{H}$ NMR spectrum $\left(\mathrm{CDCl}_{3}, 500 \mathrm{MHz}\right)$ of compound Fc-3. 
cdcl3, 13C, 125.72, 25.0

STANDARD CARBON PARAMETERS

2017-12-13T15:10:29
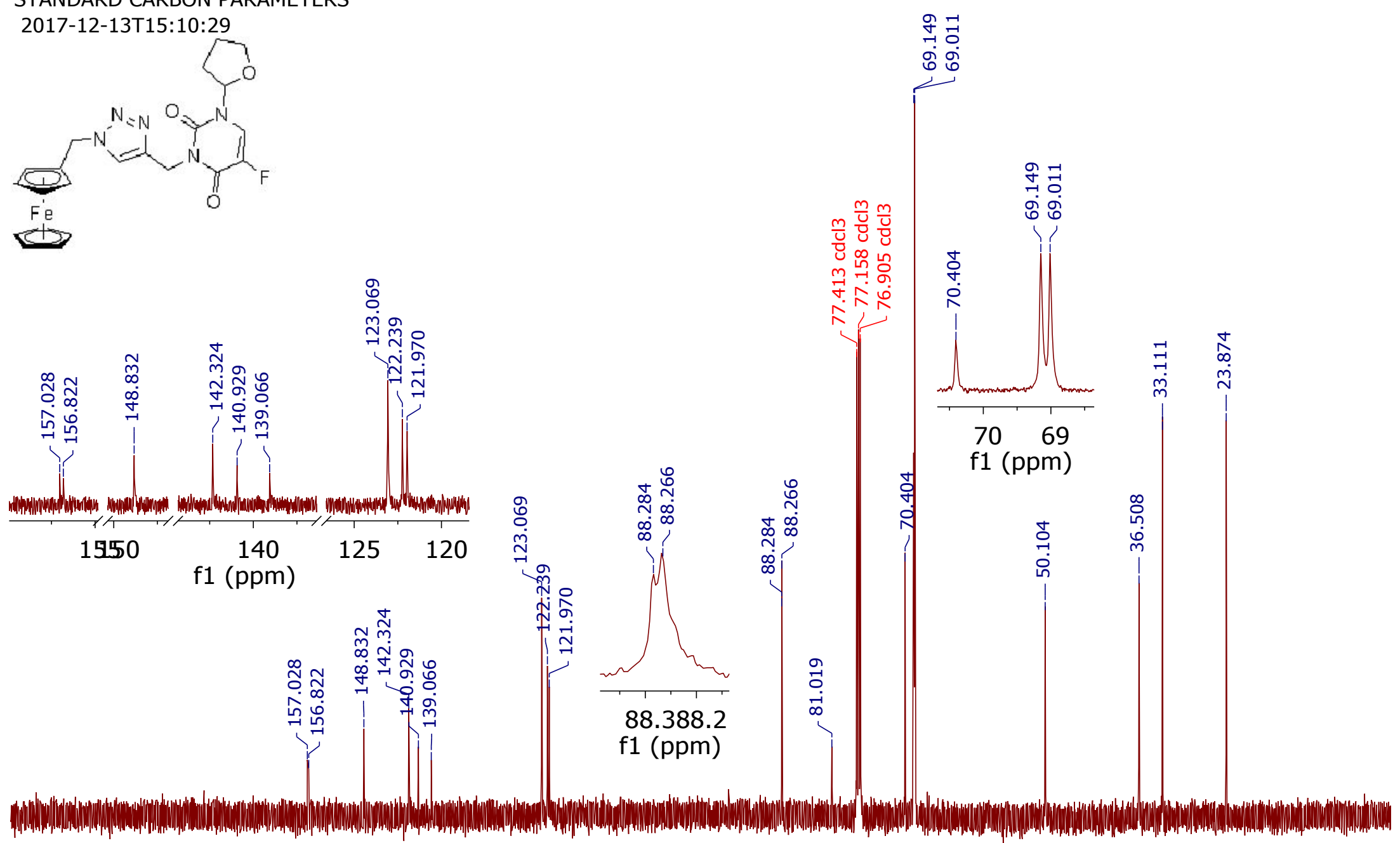

$\begin{array}{llllllllllll}00 & 190 & 180 & 170 & 160 & 150 & 140 & 130 & 120 & 110 & 100 & 90\end{array}$

$80 \quad 70$

$60 \quad 50$

40

20 101

Figure S15. ${ }^{13} \mathrm{NMR}$ spectrum $\left(\mathrm{CDCl}_{3}, 125 \mathrm{MHz}\right)$ of compound Fc-3. 
dmso, $1 \mathrm{H}, 499.88,25.0$

new experiment

2018-06-27T12:03:38
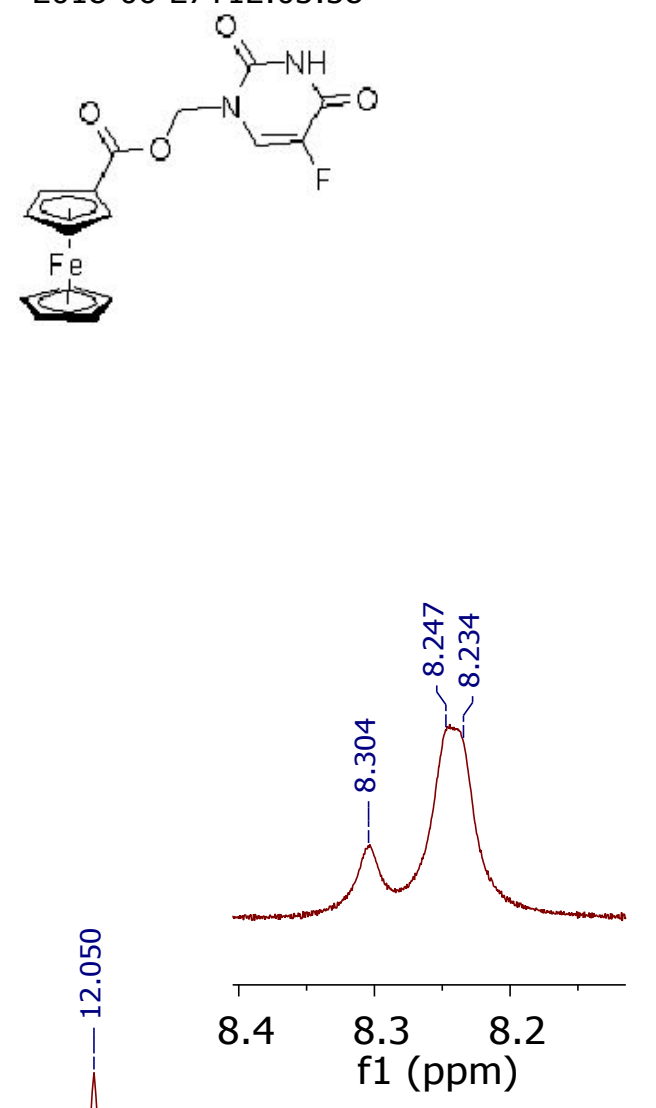

$\stackrel{\bullet}{0}$
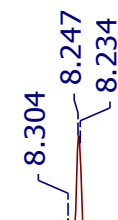

శึ:

岁

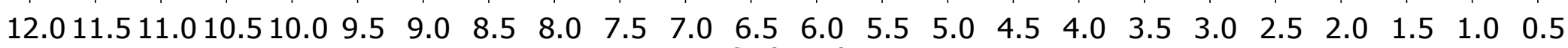
f1 (ppm)

Figure S16. ${ }^{1} \mathrm{H}$ NMR spectrum (DMSO- $d_{6}, 500 \mathrm{MHz}$ ) of compound Fc-4. 
dmso, 13C, 125.71, 25.0

new experiment

2018-06-27T12:56:05
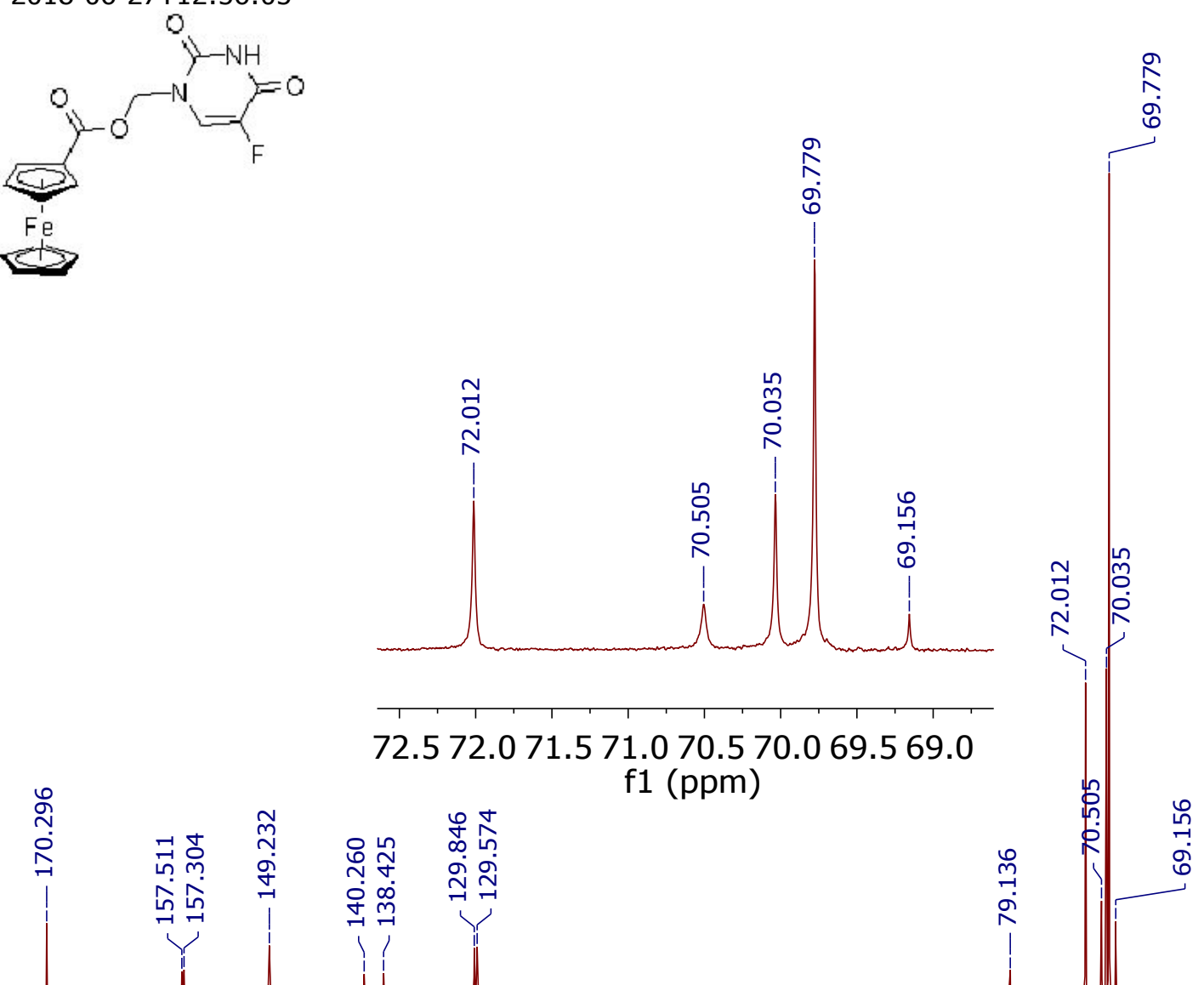

.

72.572 .071 .571 .070 .570 .069 .569 .0

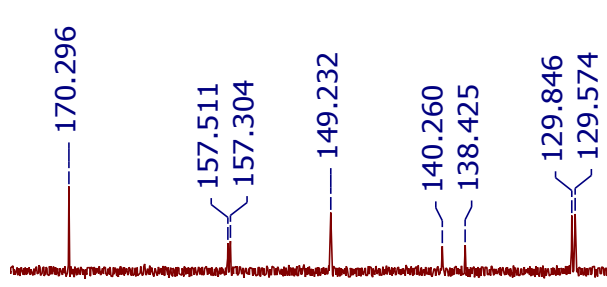

f1 (ppm)

$\begin{array}{lllllllll}170 & 160 & 150 & 140 & 130 & 120 & 110 & 100 & 90 \\ \mathrm{f} 1(\mathrm{ppm}) & 80\end{array}$

$\begin{array}{llllllll}70 & 60 & 50 & 40 & 30 & 20 & 10 & 1\end{array}$

Figure S17. ${ }^{13}$ NMR spectrum (DMSO- $d_{6}, 125 \mathrm{MHz}$ ) of compound Fc-4. 


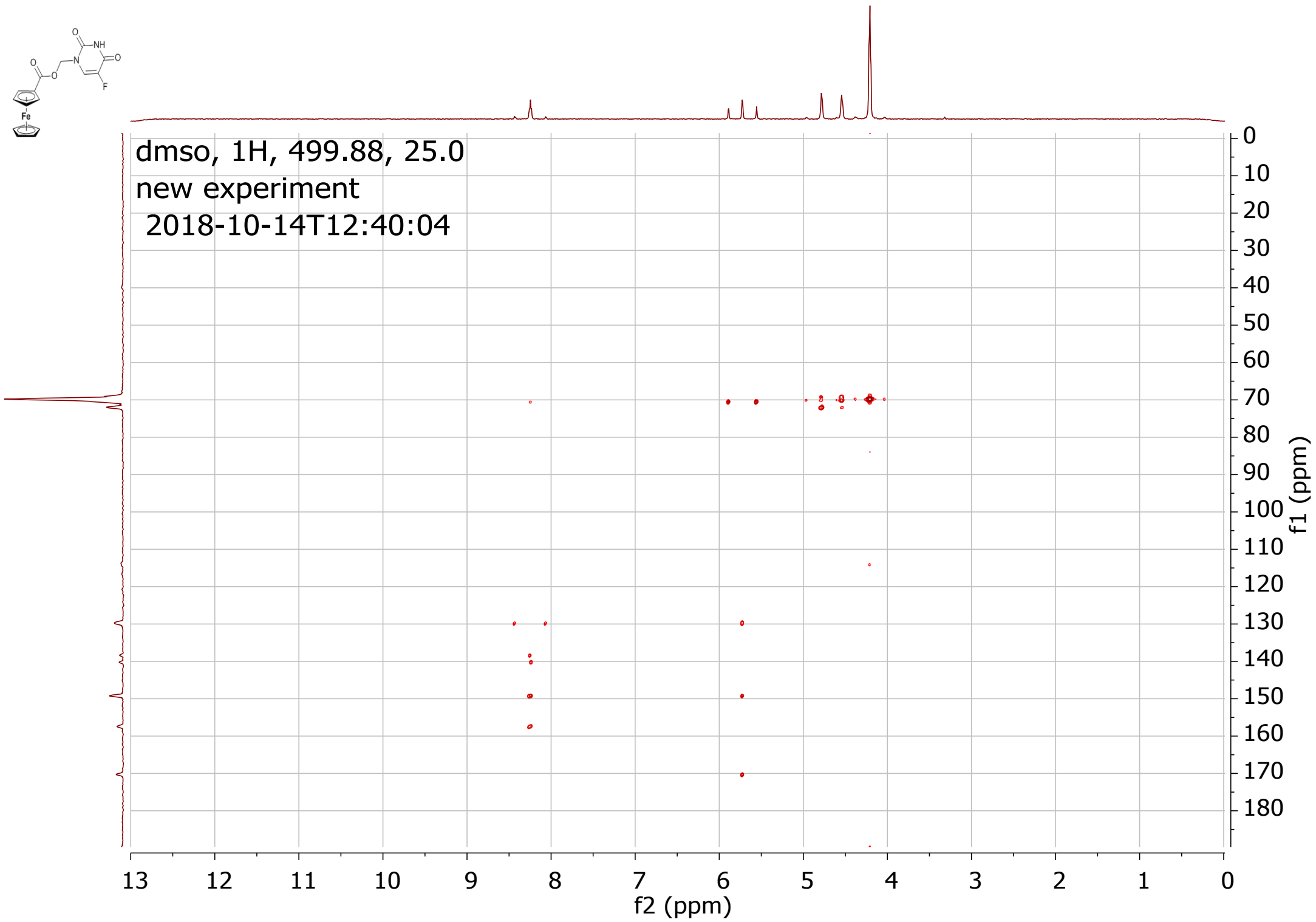

Figure S18. ${ }^{1} \mathrm{H}_{-}{ }^{13} \mathrm{C}$ HMBC NMR spectrum (DMSO- $d_{6}, 500 \times 125 \mathrm{MHz}$ ) of compound Fc-4. 
dmso, $1 \mathrm{H}, 499.88,25.0$

new experiment

2018-10-30T13:40:16

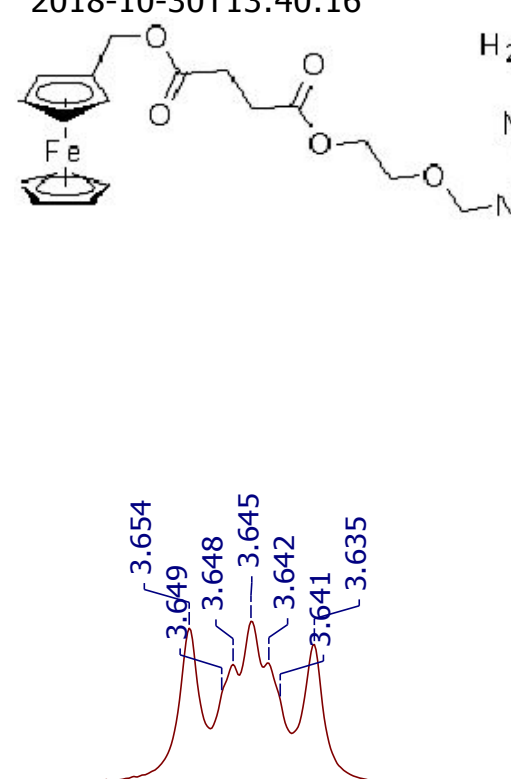

(n)
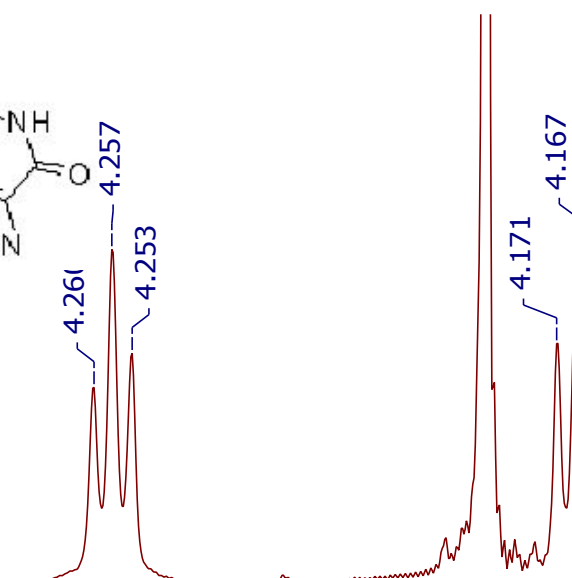

Then

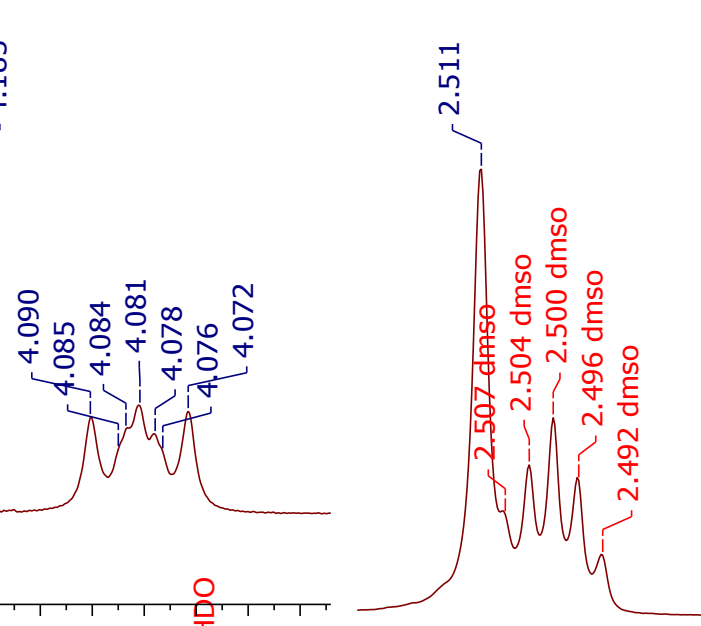

$\begin{array}{llllllllllll}4.27 & 4.25 & 4.23 & 4.21 & 4.19 & 4.17 & 4.15 & 4.13 & 4.11 & 4.09 & 4.07 & 4.05\end{array}$

f1 (ppm)

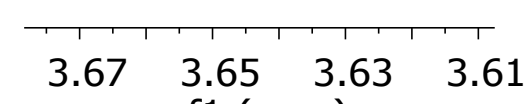

f1 (ppm)
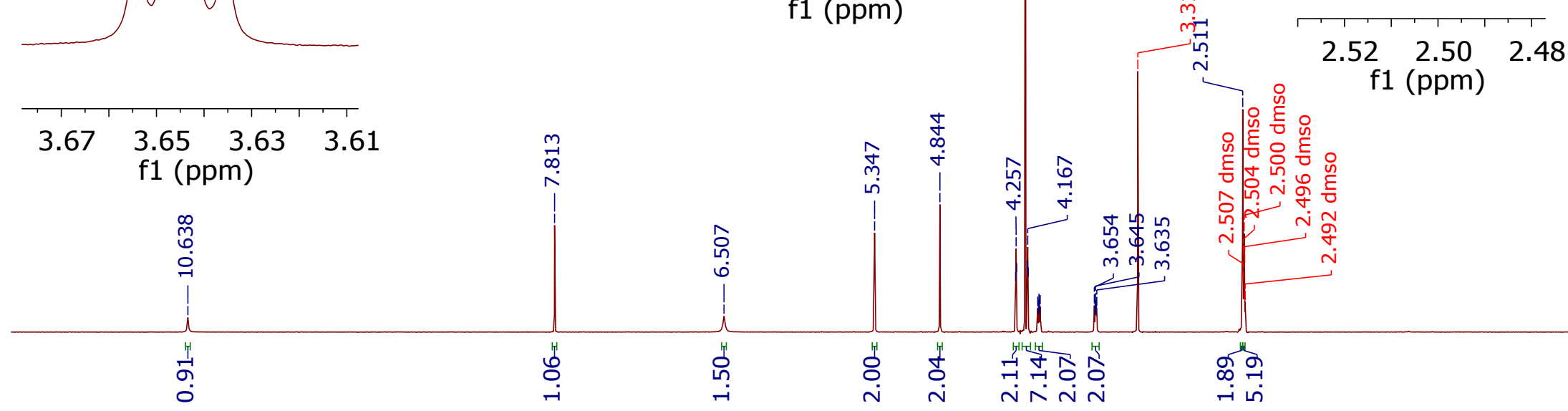

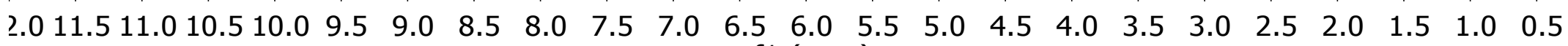

Figure S19. ${ }^{1} \mathrm{H}$ NMR spectrum (DMSO- $d_{6}, 500 \mathrm{MHz}$ ) of compound Fc-5. 
dmso, 13C, $125.71,25.0$

new experiment

2018-11-22T13:31:06

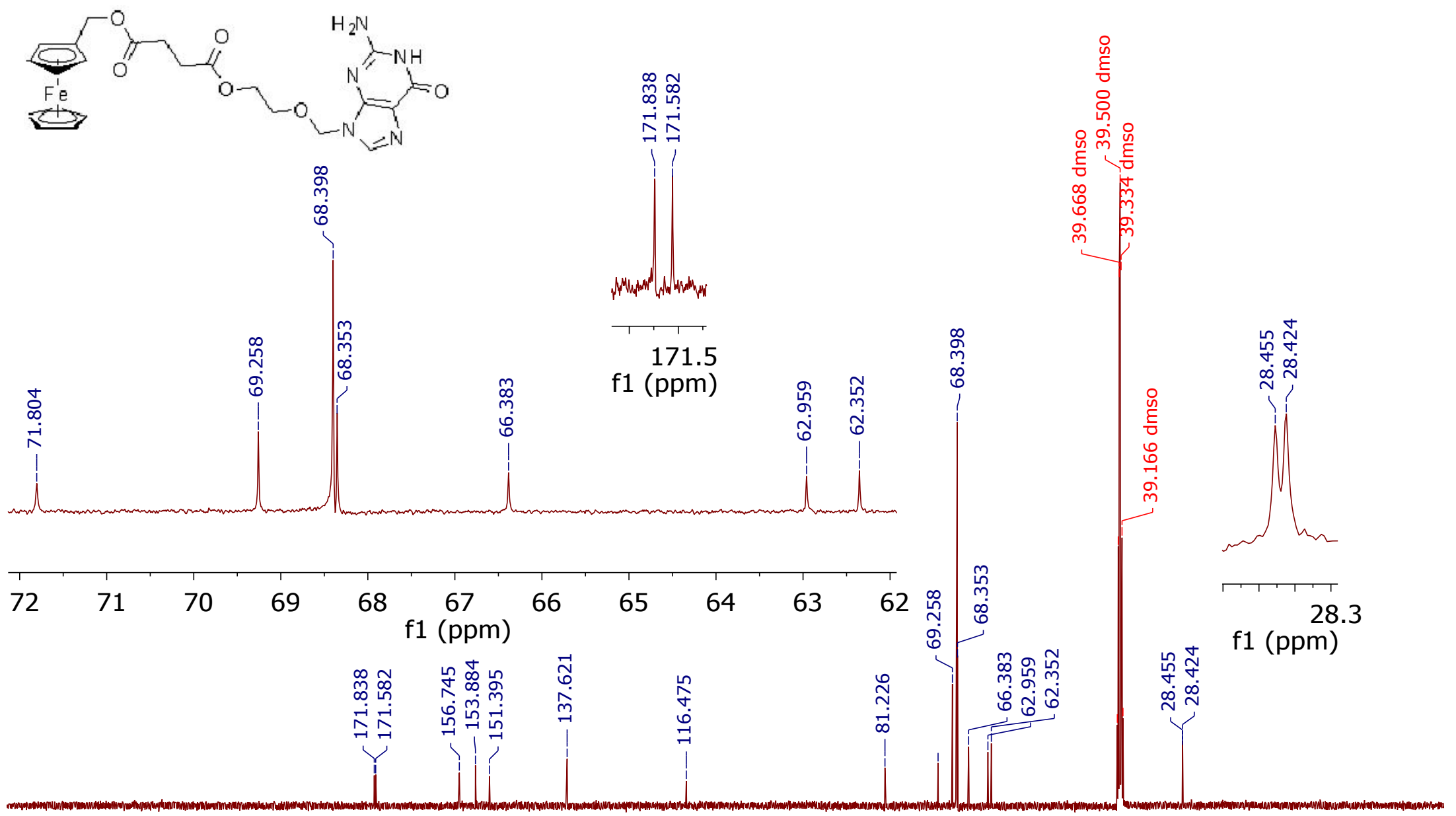

$230220210200190180170160150140130120110100 \quad 90 \quad 80 \begin{array}{lllllllllllllll}70 & 60 & 50 & 40 & 30 & 20 & 10 & 0 & -10\end{array}$

f1 (ppm)

Figure S20. ${ }^{13}$ NMR spectrum (DMSO- $d_{6}, 125 \mathrm{MHz}$ ) of compound Fc-5. 
dmso, $1 \mathrm{H}, 499.88,25.0$

new experiment

2018-06-27T13:37:08
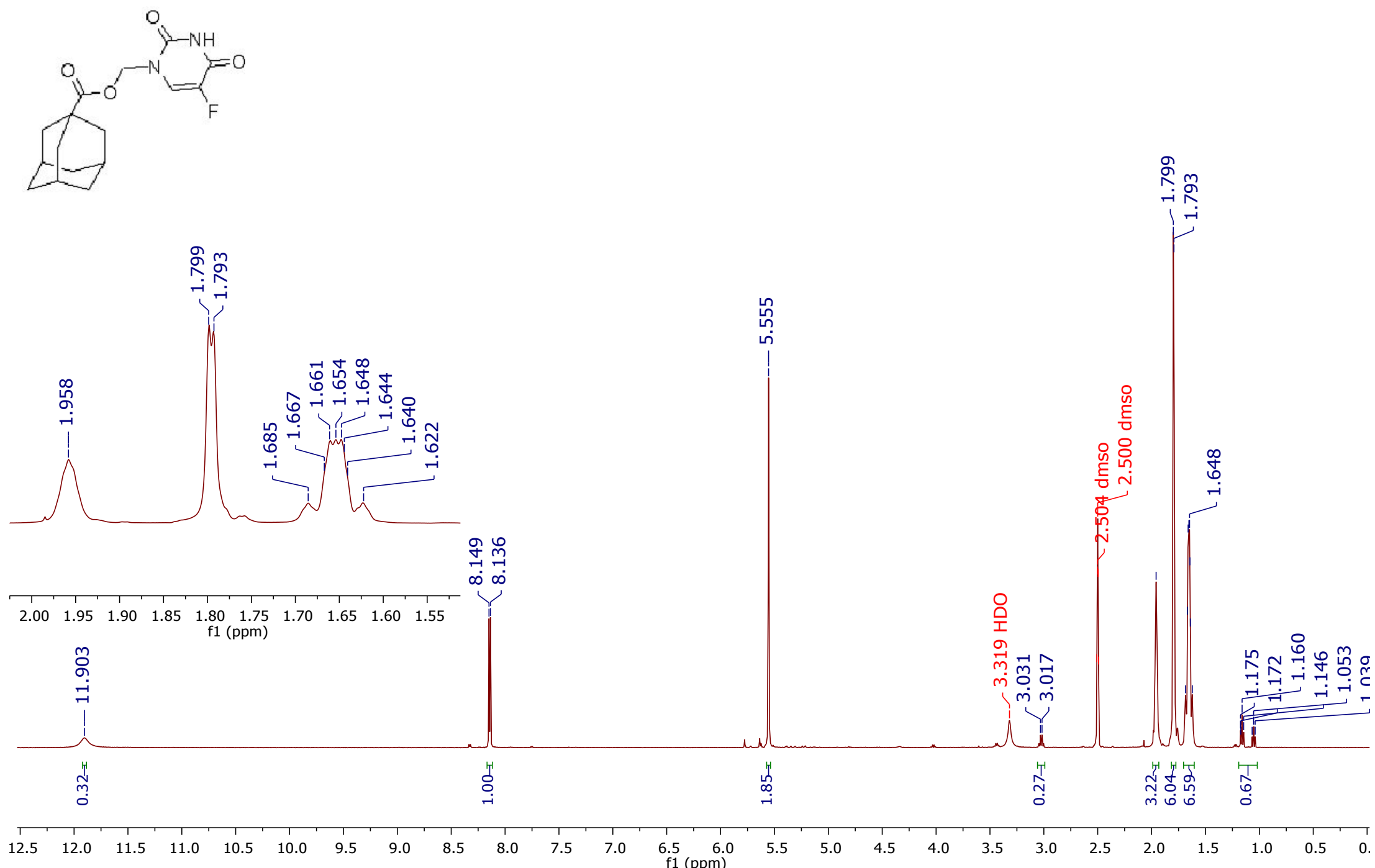

Figure S21. ${ }^{1} \mathrm{H}$ NMR spectrum (DMSO- $d_{6}, 500 \mathrm{MHz}$ ) of compound Ada-1. 
dmso, 13C, 125.71, 25.0

new experiment

2018-06-27T13:38:01

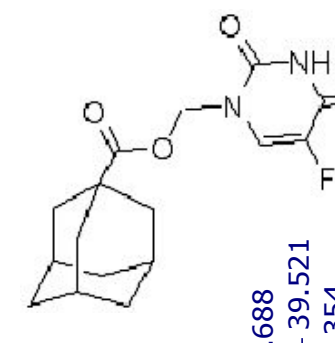

in-NH
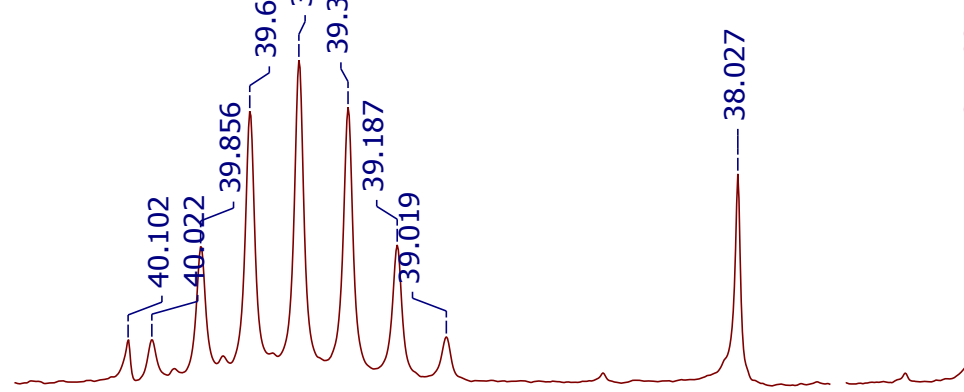

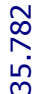

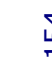



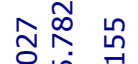
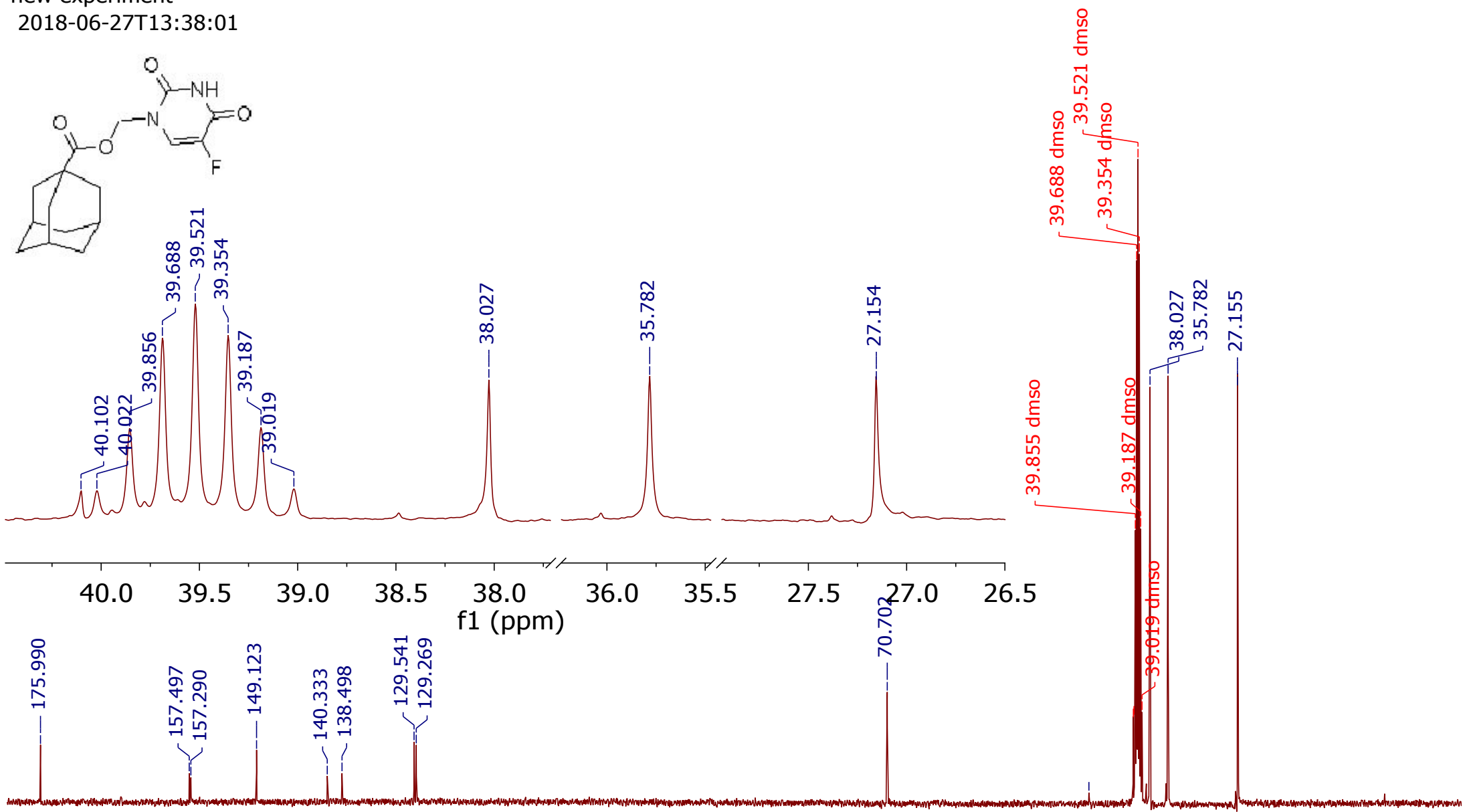

80170

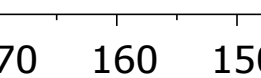

140

130

120

110100

$$
\text { f1 (ppm) }
$$

80

$60 \quad 50$

40

$\begin{array}{lll}30 & 20 & 10\end{array}$

Figure S22. ${ }^{13}$ NMR spectrum (DMSO- $d_{6}, 125 \mathrm{MHz}$ ) of compound Ada-1. 
dmso, $13 \mathrm{C}, 499.88,25.0$

new experiment

2018-09-07T05:40:29

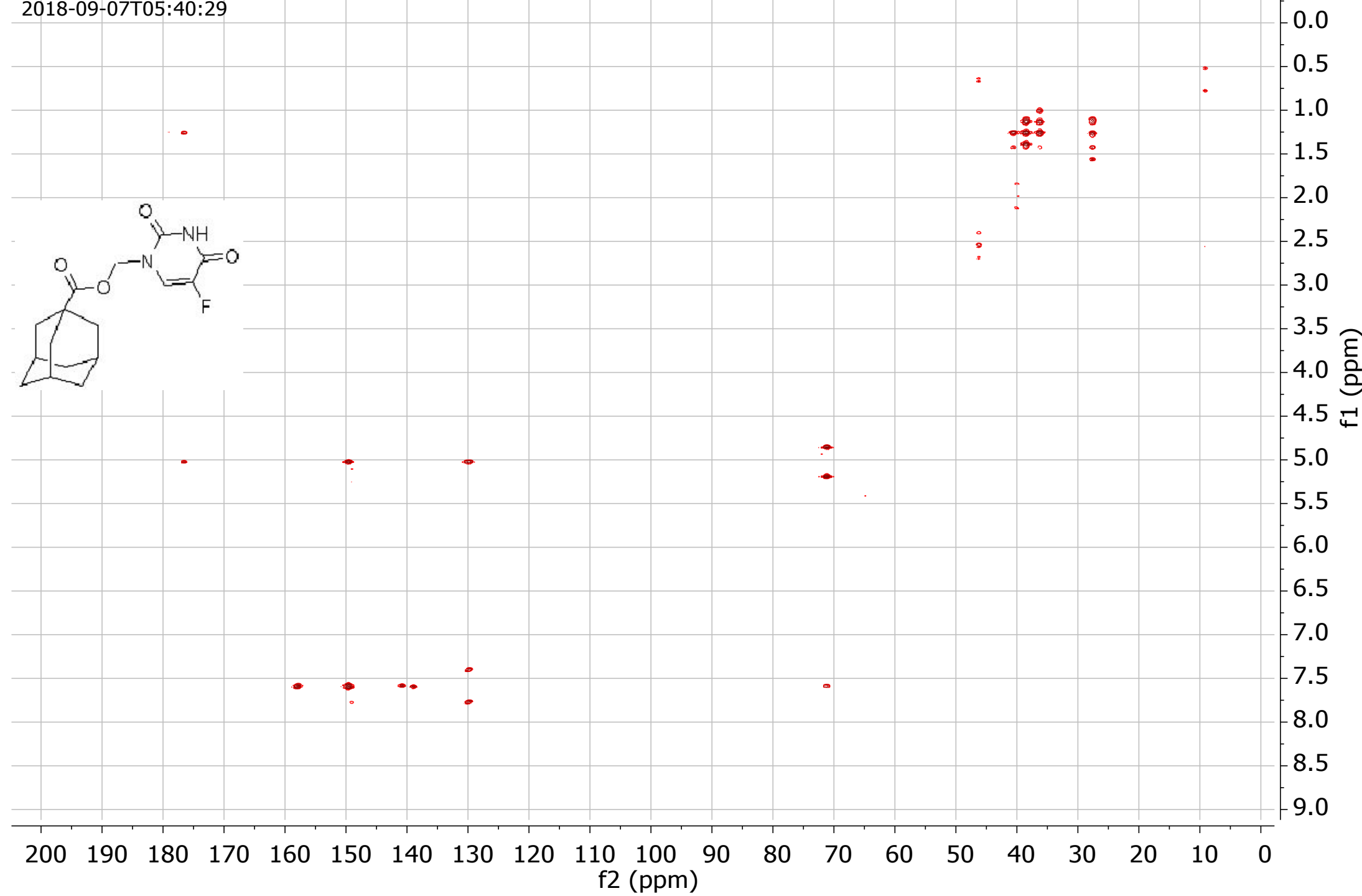

Figure S23. ${ }^{1} \mathrm{H}_{-}{ }^{13} \mathrm{C}$ HMBC NMR spectrum (DMSO- $d_{6}, 500 \times 125 \mathrm{MHz}$ ) of compound Ada-1. 
dmso, $1 \mathrm{H}, 499.94,25.0$

STANDARD PROTON PARAMETERS

2018-01-25T11:11:01

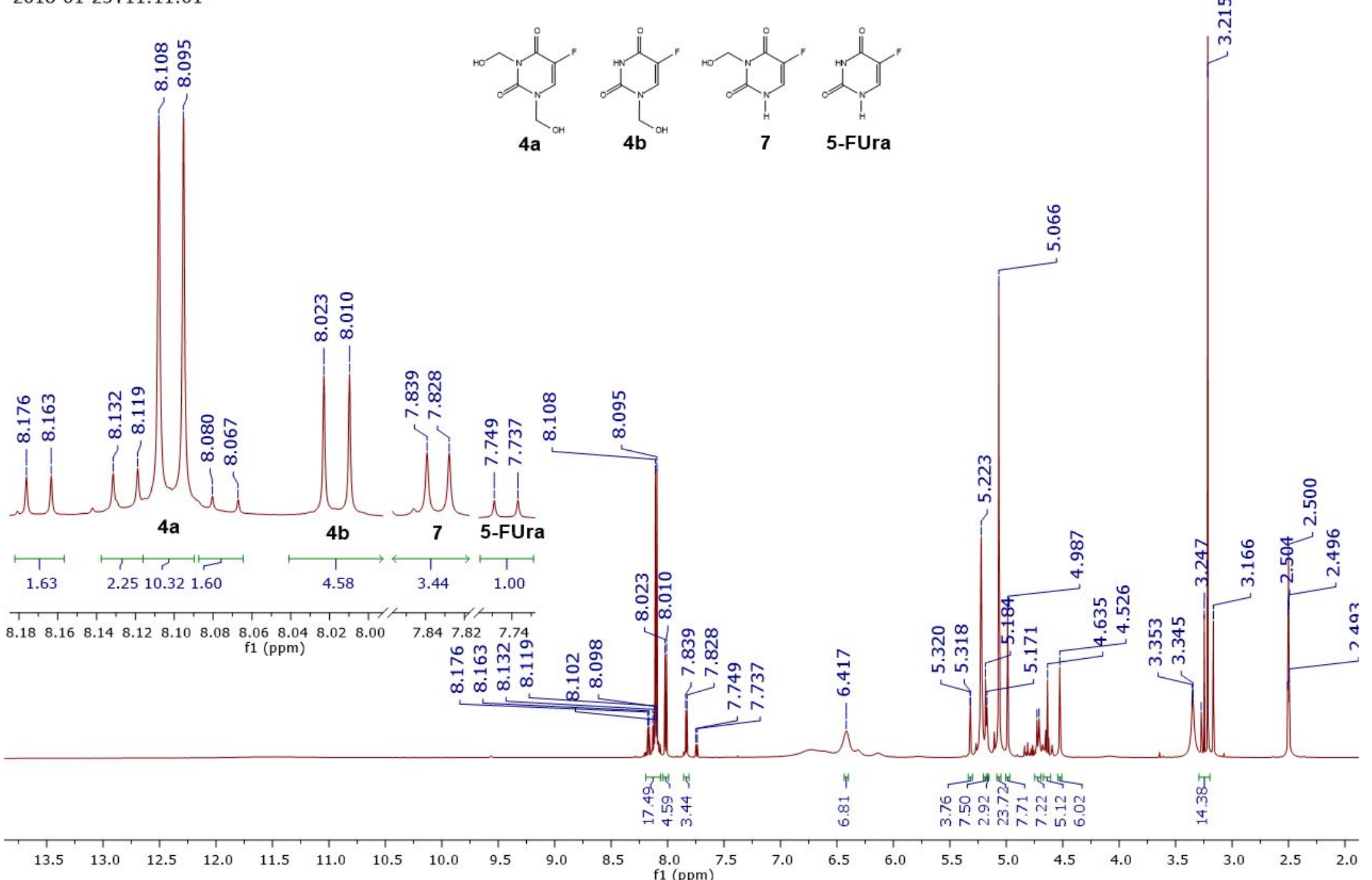

Figure S24. ${ }^{1} \mathrm{H}$ NMR spectrum (DMSO- $d_{6}, 500 \mathrm{MHz}$ ) of the reaction mixture from hydroxymethylation of 5-FUra. 
Table S1. Absorption maxima observed in the UV-Vis spectra of compounds Fc-1-Fc-5 (DMSO, $\left.2 \cdot 10^{-4} \mathrm{M}\right)$.

\begin{tabular}{l|lllll}
\hline Compound & Fc-1 & Fc-2 & Fc-3 & Fc-4 & Fc-5 \\
\hline Absorption maximum[nm] & 435 & 436 & 438 & 442 & 440 \\
\hline
\end{tabular}

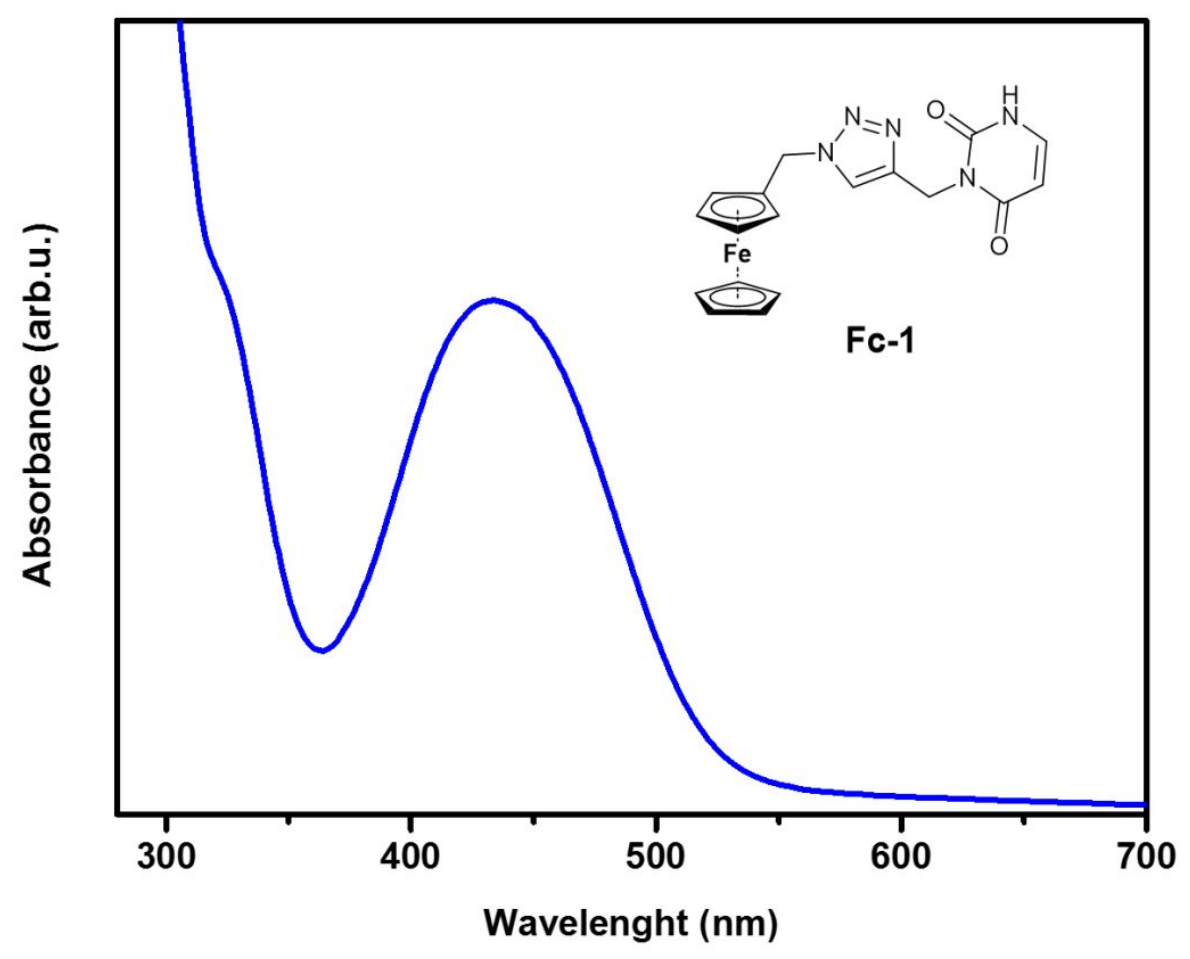

Figure S25. UV-Vis spectrum (DMSO, $2 \cdot 10^{-4} \mathrm{M}$ ) of compound Fc-1. 


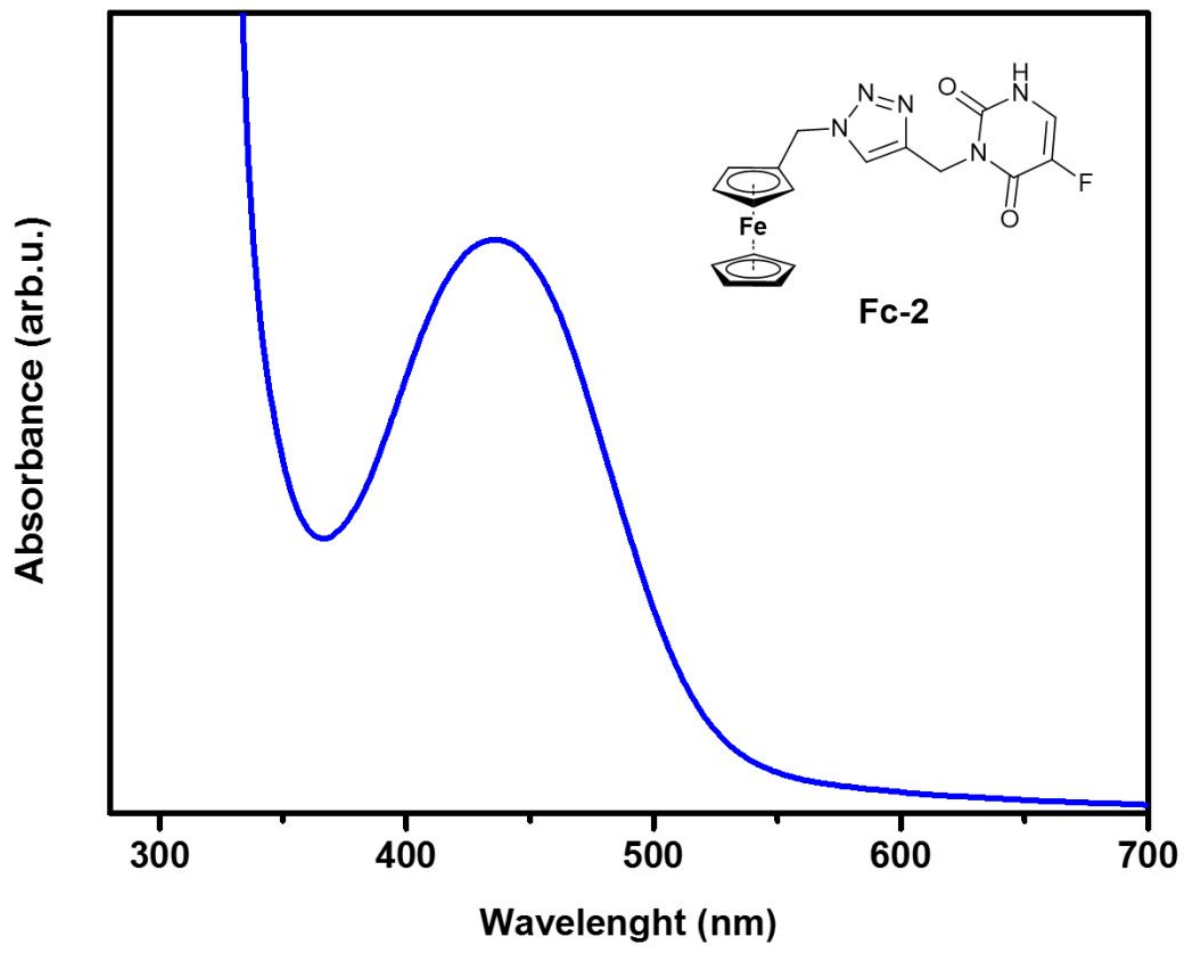

Figure S26. UV-Vis spectrum (DMSO, $2 \cdot 10^{-4} \mathrm{M}$ ) of compound Fc-2.

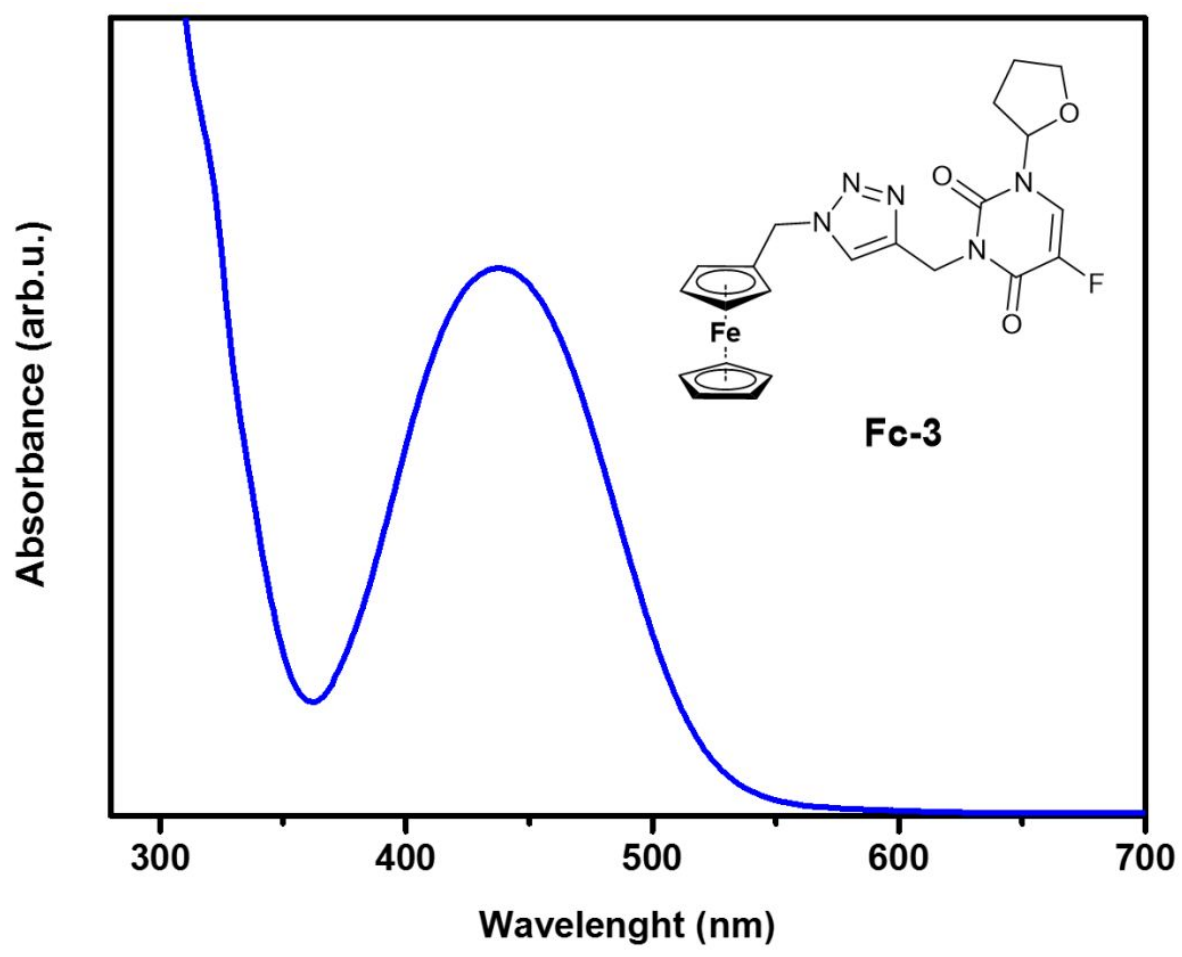

Figure S27. UV-Vis spectrum (DMSO, $2 \cdot 10^{-4} \mathrm{M}$ ) of compound Fc-3. 


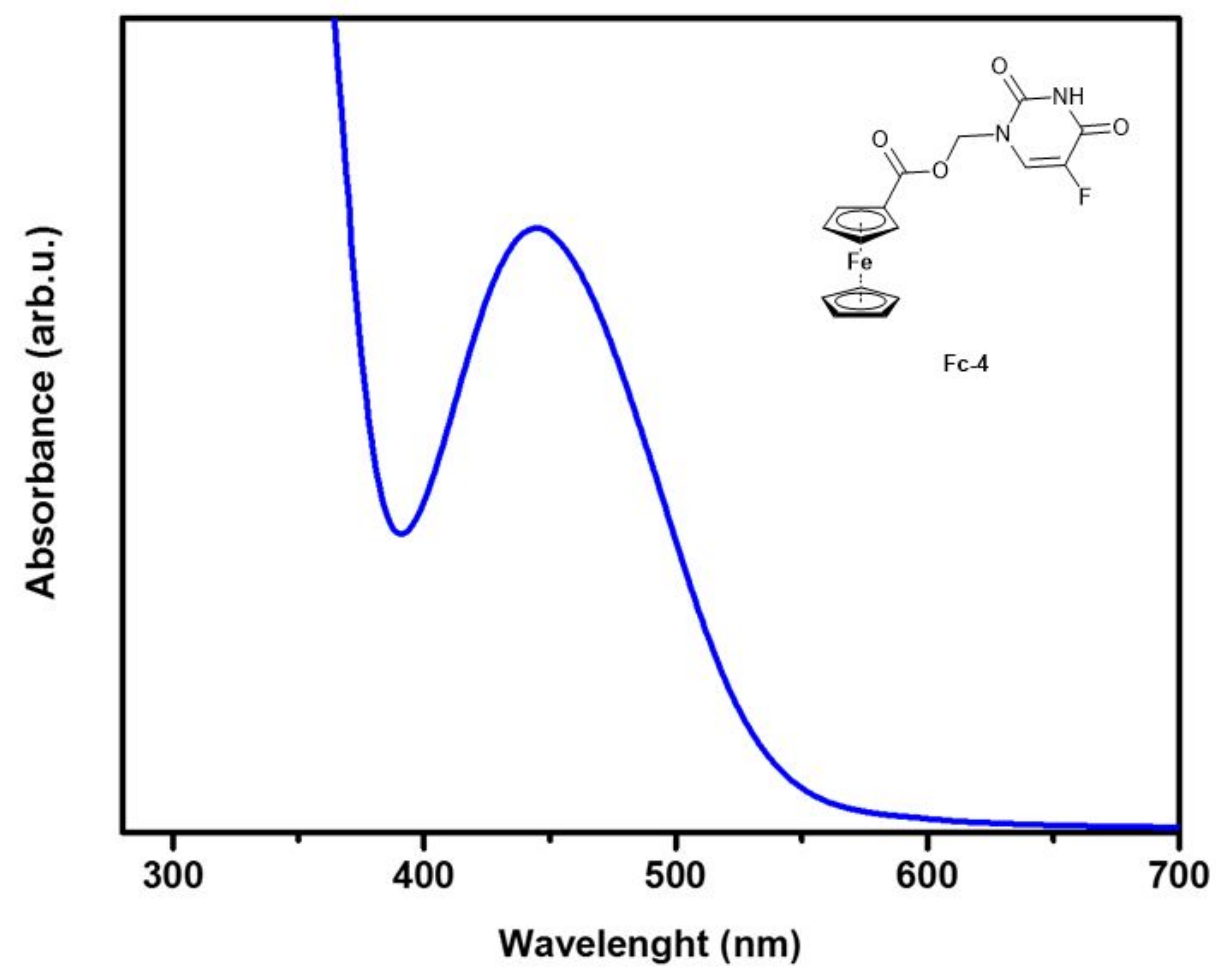

Figure S28. UV-Vis spectrum (DMSO, $2 \cdot 10^{-4} \mathrm{M}$ ) of compound Fc-4.

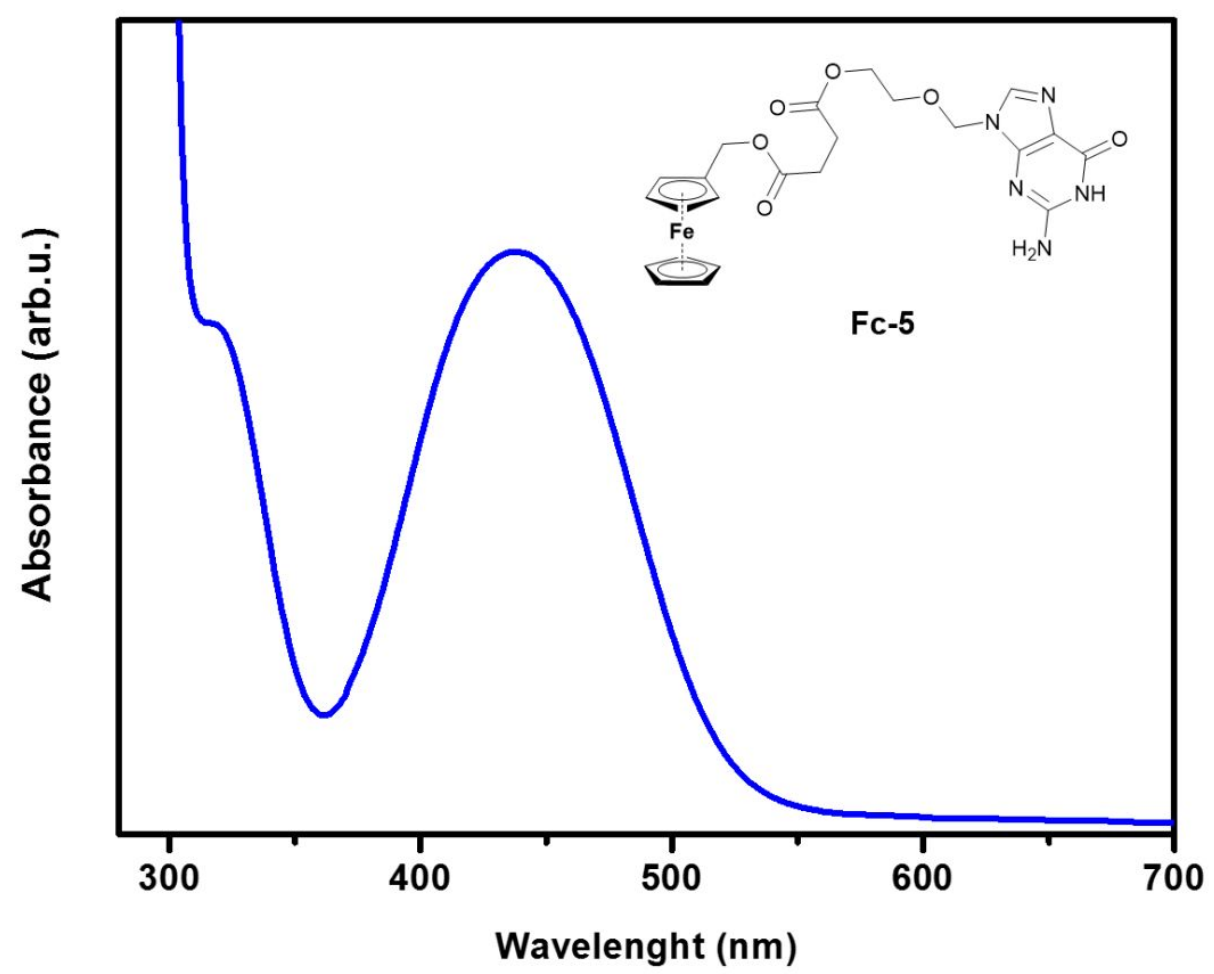

Figure S29. UV-Vis spectrum (DMSO, $2 \cdot 10^{-4} \mathrm{M}$ ) of compound Fc-5. 


\section{S3. FT-IR spectra}

Most of the characteristic absorption bands of the 1,2,3-triazole unit and the ferrocene unit were reported to be observed in similar regions. ${ }^{1}$ Owing to the presence of both these structural units in compounds Fc-1-Fc-3, the spectra of these compounds were rather complex.

Typically for the $\mathrm{Fc}$ derivatives, the spectra featured five strong absorption bands of the $\mathrm{Fc}$ unit at the range of 1440-1480, 1150-1200, 1045-1065, 795-800 and 510-550 $\mathrm{cm}^{-1} .^{2}$ The absorption band of a medium intensity was found in the $1320-1330 \mathrm{~cm}^{-1}$ region. This band was assigned to the 1,2,3-triazole unit because of its significant intensity compared with the spectra of the corresponding parent compound (i.e. uracil, 5-fluorouracil or tegafur). ${ }^{3}$ The characteristic absorption band assigned to the $\mathrm{N}_{3}$ group of the unreacted azide or the $\mathrm{C} \equiv \mathrm{C}$ group of the unreacted alkyne (both ca. 2200-2100 $\mathrm{cm}^{-1}$ ) was not observed.

Compared with the FT-IR spectra of uracil or 5-fluorouracil ${ }^{3}$, a significant increase in intensity of the absorption bands located at $1740-1745 \mathrm{~cm}^{-1}$ was observed in the spectra of esters Fc-4 and Fc-5. This fact was attributed to the presence of the ester linkage.

Table S2. Frequencies ( $v$ ) of the absorption bands assigned to the Fc skeleton, the Ada skeleton or the $\mathrm{C}=\mathrm{O}$ groups in compounds Fc-1-Fc-5 and Ada-1. ${ }^{\mathrm{a}}$

\begin{tabular}{|c|c|c|c|}
\hline Entry & Compound & skeleton $/ v\left[\mathrm{~cm}^{-1}\right]$ & $v(\mathrm{C}=\mathrm{O})\left[\mathrm{cm}^{-1}\right]^{\mathrm{b}}$ \\
\hline 1 & Fc-1 & $\begin{array}{l}\mathrm{Fc} / 1440,1175,1050,800,550 \\
\text { 1,2,3-triazole/1325 }\end{array}$ & $1740,1630^{c}$ \\
\hline 2 & Fc-2 & $\begin{array}{l}\mathrm{Fc} / 1445,1200,1065,800,510 \\
\text { 1,2,3-triazole/1320 }\end{array}$ & $1735,1640^{\mathrm{c}}$ \\
\hline 3 & Fc-3 & $\begin{array}{l}\mathrm{Fc} / 1480,1150,1045,795,510 \\
\text { 1,2,3-triazole/1330 }\end{array}$ & $1725,1665^{\mathrm{c}}$ \\
\hline 4 & Fc-4 & $\mathrm{Fc} / 1465,1120,1040,820,580$ & $1740,1670^{\mathrm{d}}$ \\
\hline 5 & Fc-5 & $\mathrm{Fc} / 1390,1165,1100,845,595$ & $1745,1640^{\mathrm{e}}$ \\
\hline 6 & Ada-1 & Ada/2915-2850 & $1740,1695,1655^{\mathrm{c}}$ \\
\hline
\end{tabular}

$\mathrm{n} / \mathrm{a}=$ not applicable. ${ }^{\mathrm{a}}$ For the FT-IR spectra, see Section S3 in Supplementary Information. ${ }^{\mathrm{b}}$ For the

numbering system in compounds Fc-1-Fc-4 and Ada-1, see Table 1. ${ }^{c}$ Assigned to $C(2)=O$ and $C(4)=O$. ${ }^{d}$ Assigned to $\mathrm{C}(2)=\mathrm{O}, \mathrm{C}(4)=\mathrm{O}$ and $\mathrm{C}(1 \mathrm{~b})=\mathrm{O} .{ }^{\mathrm{e}}$ Assigned to the ester $\mathrm{C}=\mathrm{O}$ and the guanine $\mathrm{C}=\mathrm{O}$. 

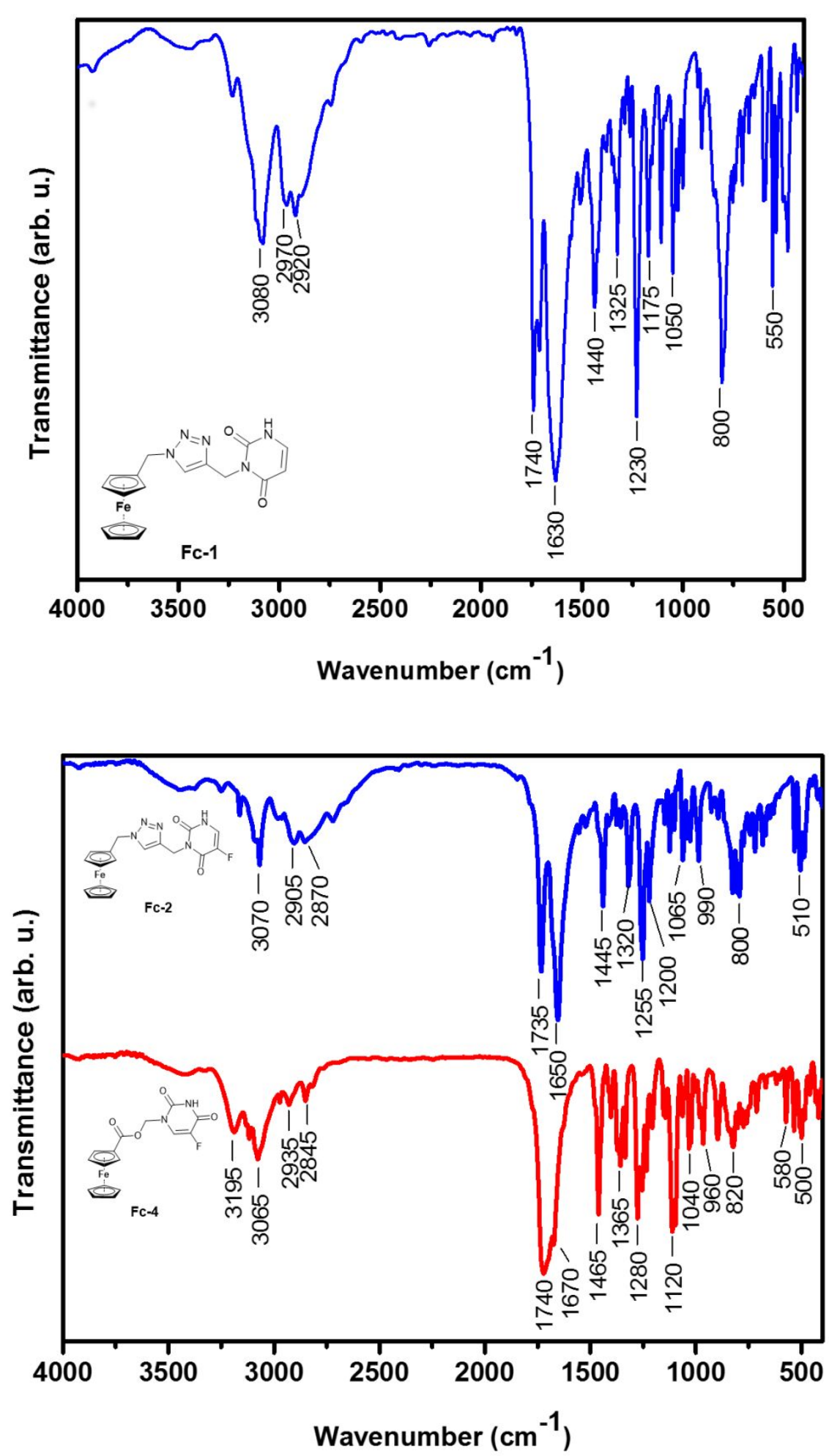

Figure S30. FT-IR spectrum (KBr) of compound Fc-1 (top) and Fc-2 and Fc-4 (bottom). 


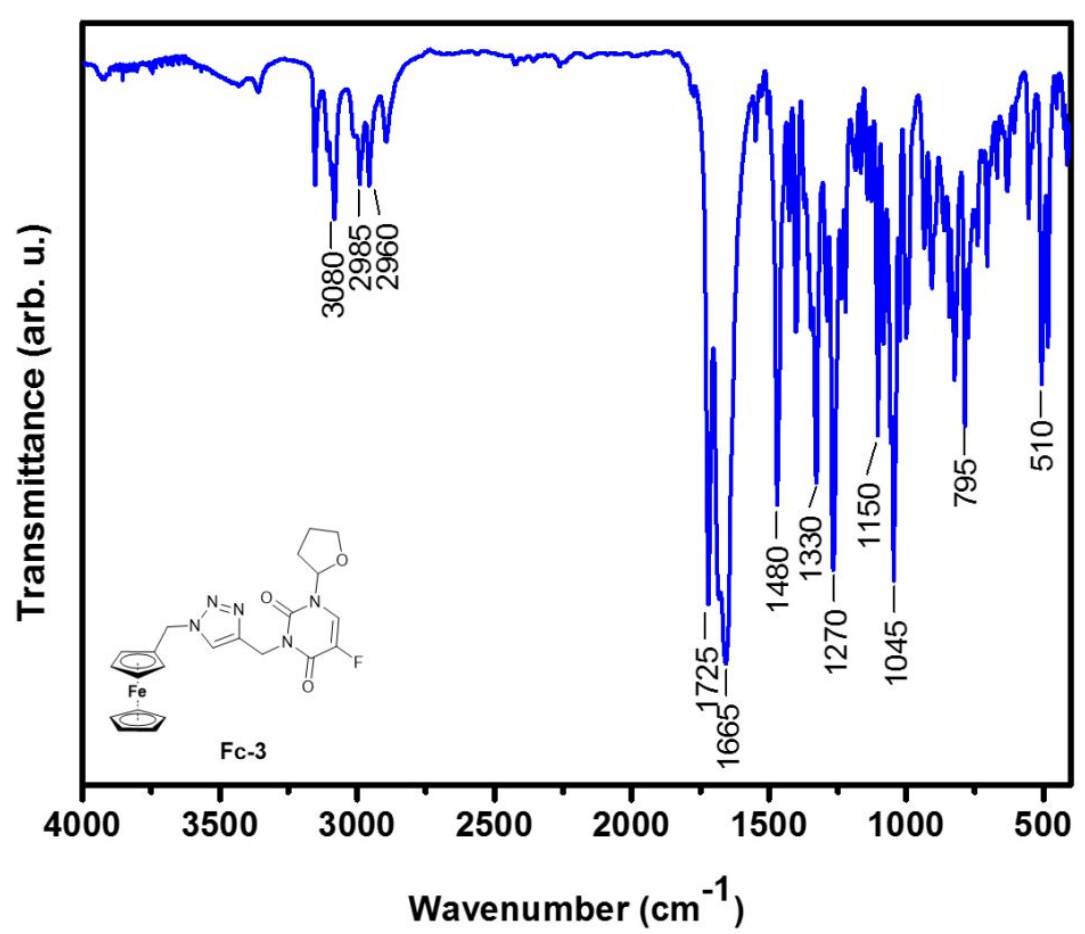

Figure S31. FT-IR spectrum (KBr) of compound Fc-3.

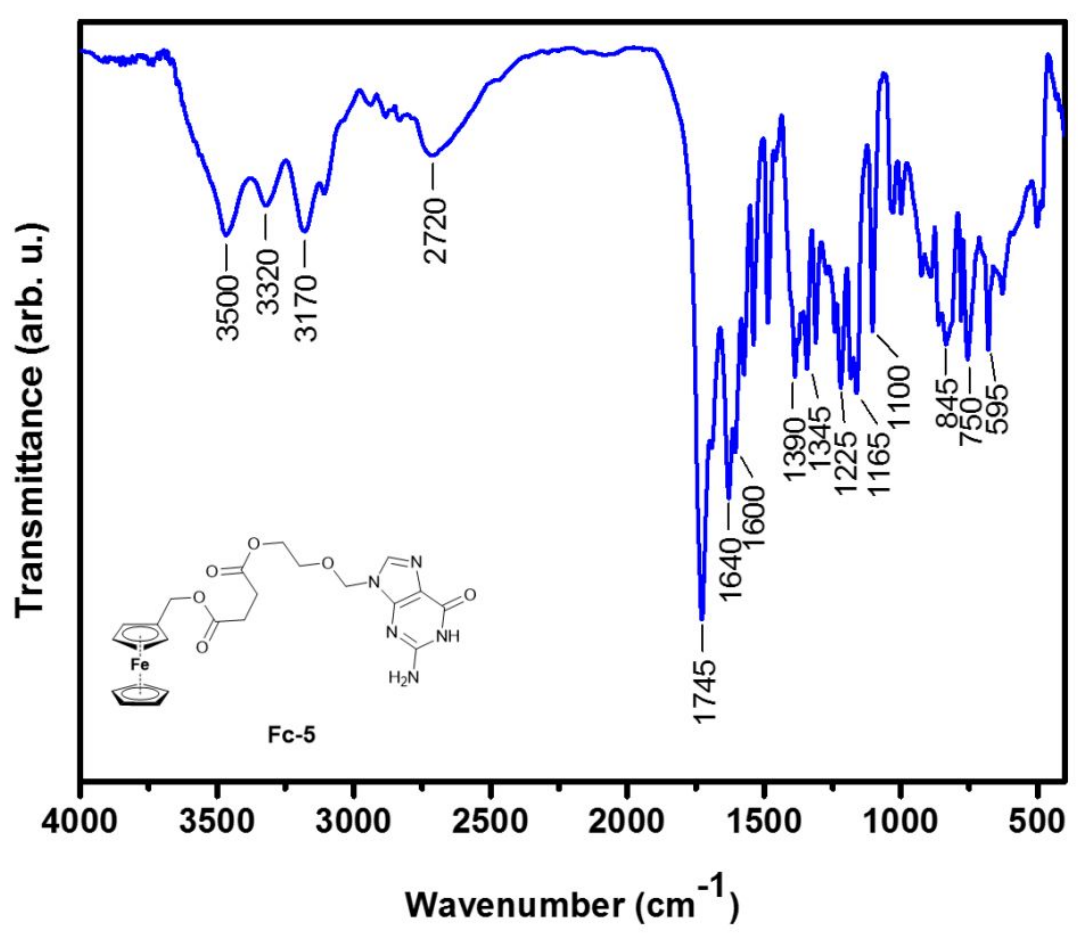

Figure S32. FT-IR spectrum ( $\mathrm{KBr})$ of compound Fc-5. 


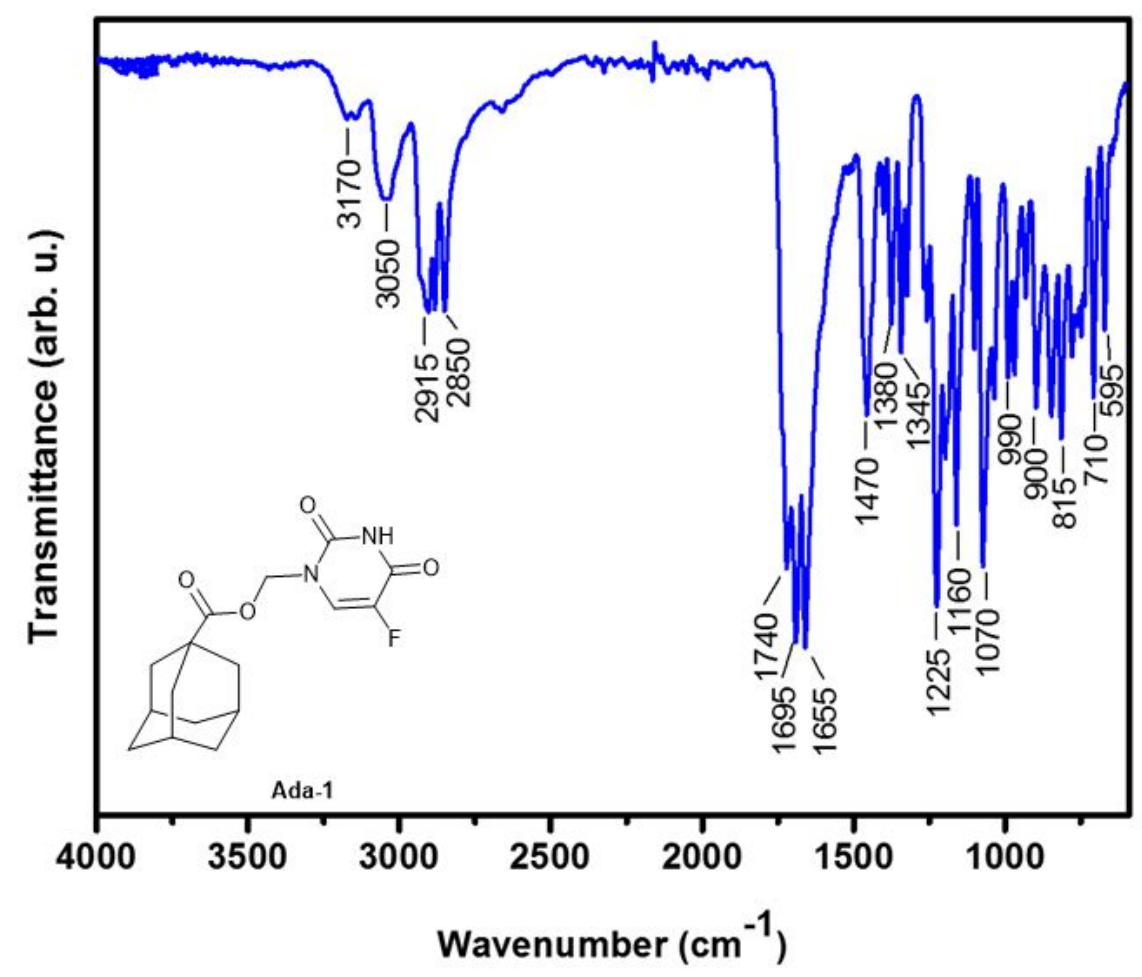

Figure S33. FT-IR spectrum (KBr) of compound Ada-1. 


\section{S4. Electrochemical characterization of compounds Fc-1-Fc-5 - data}

Table S3. Diffusion coefficient $\left(D_{\mathrm{S}}\right)$, formal potential $\left(E_{\mathrm{f}}\right)$, electron-transfer rate constant $\left(k_{0}\right)$, and regression coefficients: slope $(a)$, intercept $(b)$, correlation coefficient $\left(r^{2}\right)$ of linearized $\ln \left(I_{\mathrm{pa}}\right)$ vs. $\left(E_{\mathrm{pa}}-E_{\mathrm{f}}\right)$.

\begin{tabular}{|c|c|c|c|c|c|c|}
\hline Compound & $a \pm s(\mathbf{a})$ & $b \pm s(\mathbf{b})$ & $r^{2}$ & $\begin{array}{c}k_{0} \cdot 10^{3} \\
{\left[\mathrm{~cm} \cdot \mathrm{s}^{-1}\right]}\end{array}$ & $\begin{array}{c}D_{\mathrm{S}} \cdot 10^{5} \\
{\left[\mathrm{~cm}^{2} \cdot \mathrm{s}^{-1}\right]}\end{array}$ & $\begin{array}{l}E_{\mathrm{f}} \\
{[\mathrm{V}]}\end{array}$ \\
\hline Fc-1 & $10.23 \pm 1.12$ & $-12.67 \pm 0.20$ & 0.995 & $2.03 \pm 0.12$ & $0.34 \pm 0.06$ & 0.573 \\
\hline Fc-2 & $10.67 \pm 0.81$ & $-12.49 \pm 0.11$ & 0.989 & $2.43 \pm 0.25$ & $0.39 \pm 0.02$ & 0.568 \\
\hline Fc-3 & $22.92 \pm 2.45$ & $-12.87 \pm 0.21$ & 0.991 & $1.67 \pm 0.14$ & $0.43 \pm 0.05$ & 0.569 \\
\hline Fc-4 & - & - & - & $0.97 \pm 0.10$ & $0.29 \pm 0.02$ & - \\
\hline Fc-5 & $7.94 \pm 1.20$ & $-13.41 \pm 0.40$ & 0.984 & $0.97 \pm 0.10$ & $0.16 \pm 0.05$ & 0.544 \\
\hline
\end{tabular}



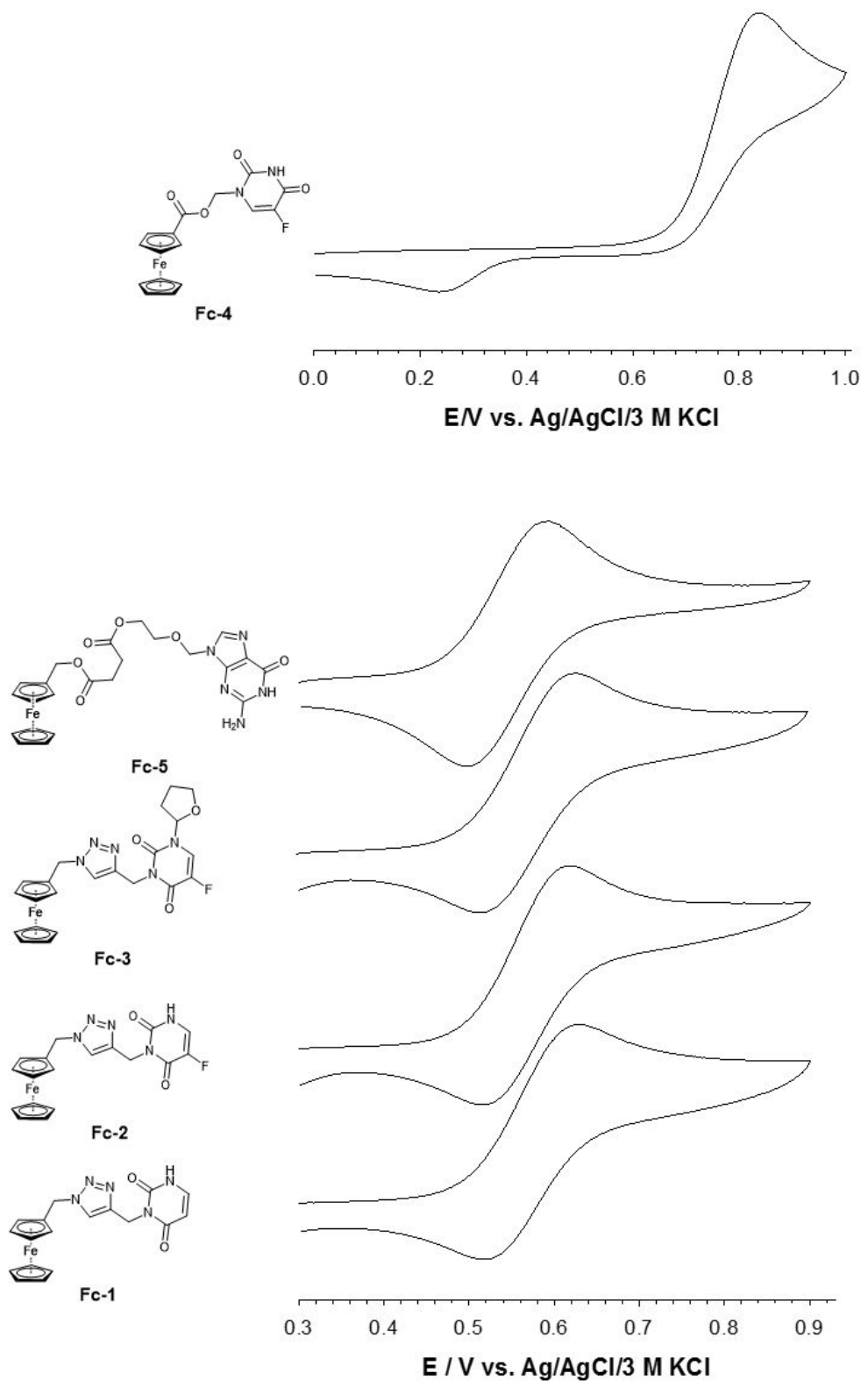

Figure S34. Normalized (versus peak current) cyclic voltammograms (CV) of compounds Fc1-Fc-5 (1 mM) on GC electrode in DMSO with $50 \mathrm{mM}$ TBAHFP. 


\section{S5. ${ }^{1} \mathrm{H}$ NMR titration experiments}

a)

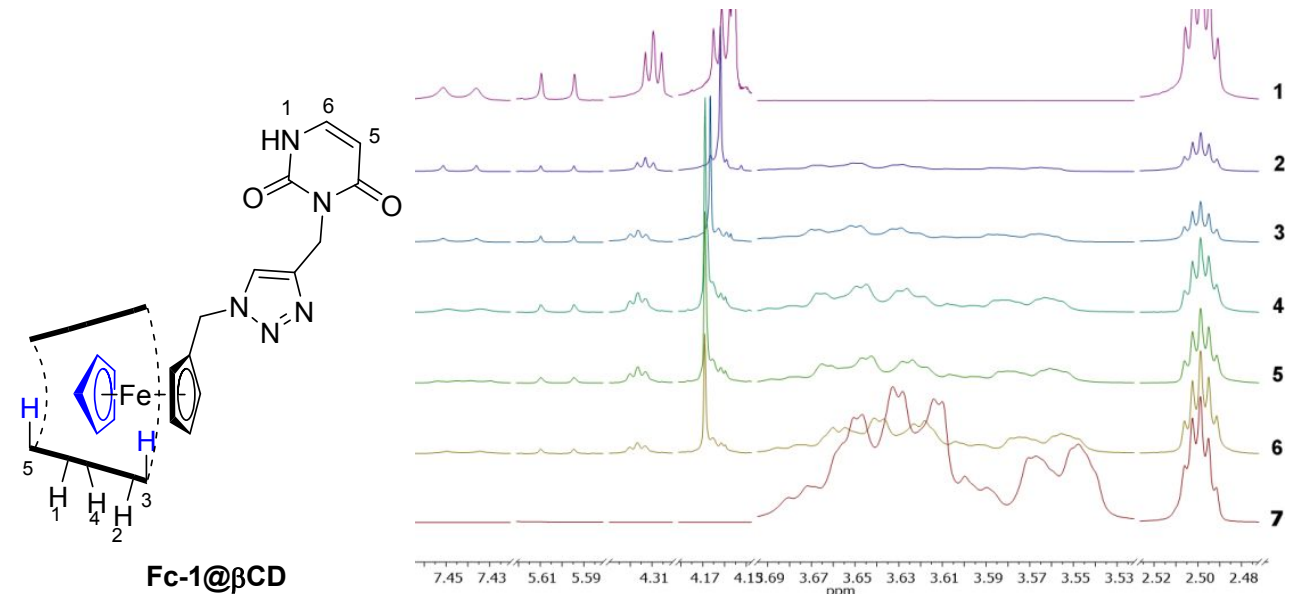

\begin{tabular}{|c|c|c|c|c|c|c|c|c|}
\hline Spectrum & $\mathrm{x}(\mathbf{F c}-1)^{\mathrm{a}}$ & $\begin{array}{c}\text { H-6 } \\
(\mathbf{F c - 1}) \\
\end{array}$ & $\begin{array}{c}\mathrm{H}-5 \\
(\mathbf{F c}-1) \\
\end{array}$ & $\begin{array}{c}\text { H-Fc } \\
(\text { Fc-1 })^{b}\end{array}$ & $\begin{array}{c}\text { H-Fc } \\
(\text { Fc-1 })^{b}\end{array}$ & $\begin{array}{c}\text { H-Fc } \\
(\text { Fc-1) }\end{array}$ & $\begin{array}{c}\mathrm{H}-3 \\
(\beta C D) \\
\end{array}$ & $\begin{array}{c}\mathrm{H}-5 \\
(\beta \mathrm{CD}) \\
\end{array}$ \\
\hline 1 & 1.0 & 7.443 & 5.608 & 4.309 & 4.162 & 4.157 & - & - \\
\hline 2 & 0.7 & 7.443 & 5.608 & \multicolumn{2}{|c|}{$4.310-4.164^{\mathrm{e}}$} & 4.162 & 3.642 & 3.565 \\
\hline 3 & 0.6 & 7.443 & 5.608 & \multicolumn{2}{|c|}{$4.311-4.164^{\mathrm{e}}$} & 4.166 & 3.642 & 3.565 \\
\hline $4^{\mathrm{d}}$ & 0.5 & 7.443 & 5.608 & \multicolumn{2}{|c|}{$4.312-4.164^{\mathrm{e}}$} & 4.169 & 3.642 & 3.565 \\
\hline & & & & \multicolumn{2}{|c|}{$\begin{array}{c}(\Delta \delta=0.003-0.002 \\
\mathrm{ppm})\end{array}$} & $\begin{array}{c}(\Delta \delta=0.012 \\
\mathrm{ppm})\end{array}$ & $\begin{array}{c}(\Delta \delta=0.009 \\
\mathrm{ppm})\end{array}$ & $\begin{array}{c}(\Delta \delta=0.007 \\
\mathrm{ppm})\end{array}$ \\
\hline 5 & 0.4 & 7.443 & 5.608 & \multicolumn{2}{|c|}{$4.312-4.164^{\mathrm{e}}$} & 4.169 & 3.640 & 3.563 \\
\hline 6 & 0.3 & 7.443 & 5.608 & \multicolumn{2}{|c|}{$4.312-4.164^{\mathrm{e}}$} & 4.169 & 3.636 & 3.562 \\
\hline 7 & 0.0 & - & - & - & - & - & 3.633 & 3.558 \\
\hline
\end{tabular}

${ }^{a}$ Mole fraction of compound Fc-1 in the examined sample. ${ }^{b}$ The chemical shift of signals assigned to the protons of the substituted cyclopentadienyl ring. ${ }^{c}$ The chemical shift of signals assigned to the protons of the unsubstituted cyclopentadienyl ring (marked in blue). ${ }^{\mathrm{d}} \Delta \delta=\delta$ (entry 4$)$ - $\delta$ (entry 1 ) for signals of compound Fc-1 or $\Delta \delta=\delta($ entry 4$)-\delta($ entry 7$)$ for the $\beta C D$ signals. ${ }^{e}$ Overlapped with $\mathrm{H}-\mathrm{Fc}\left(\mathrm{C}_{5} \mathrm{H}_{5} ; 4.169-4.162 \mathrm{ppm}\right)$

b)

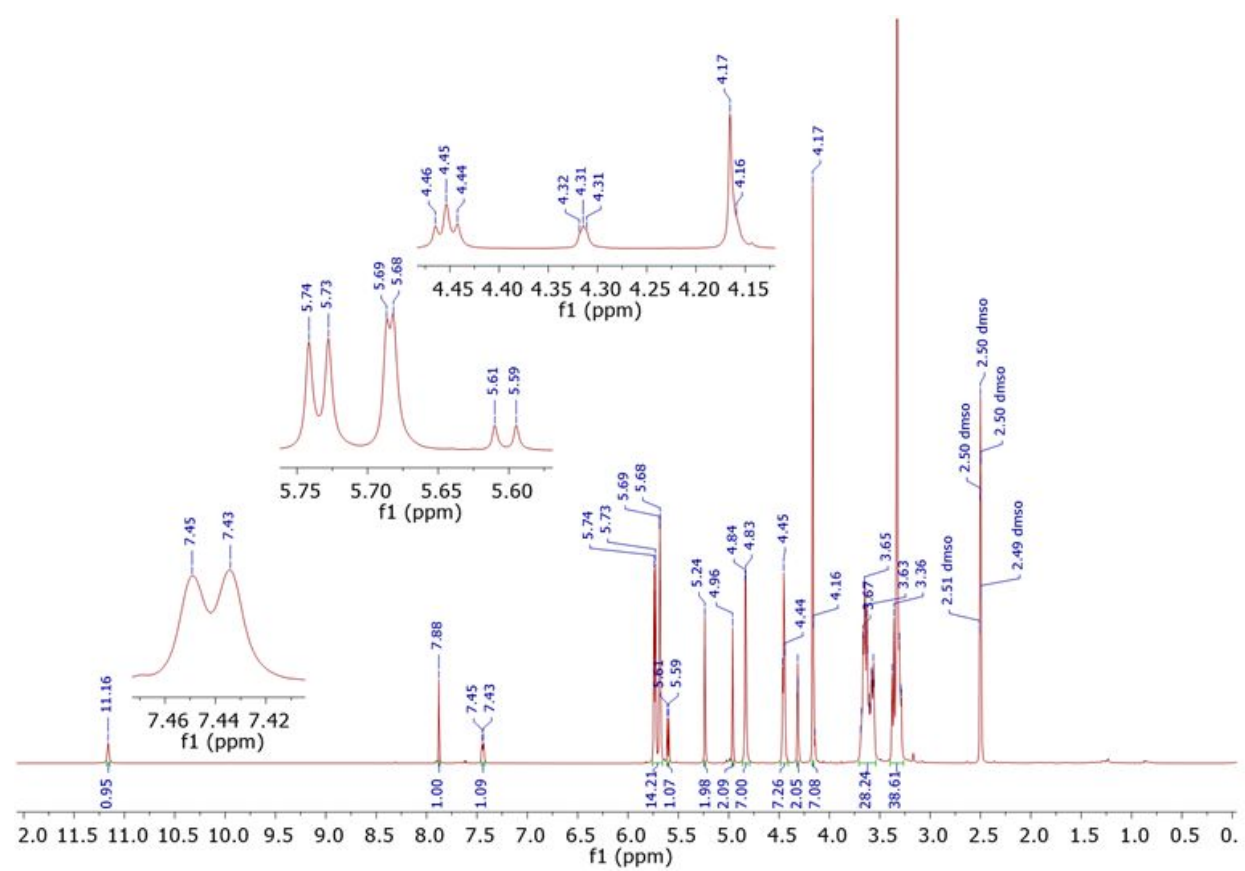

Figure S35. (a) Schematic representation of complex Fc-1@BCD, the selected insets of the spectra obtained from the ${ }^{1} \mathrm{H}$ NMR titration of compound Fc-1 with $\beta \mathrm{CD}$ (DMSO- $d_{6}$, $500 \mathrm{MHz}$ ) and the chemical shifts of signals shown in the insets (in ppm for the center of the signal). (b) The ${ }^{1} \mathrm{H}$ NMR spectrum of complex Fc-1@BCD (DMSO- $d_{6}, 500 \mathrm{MHz}$ ). 
a)

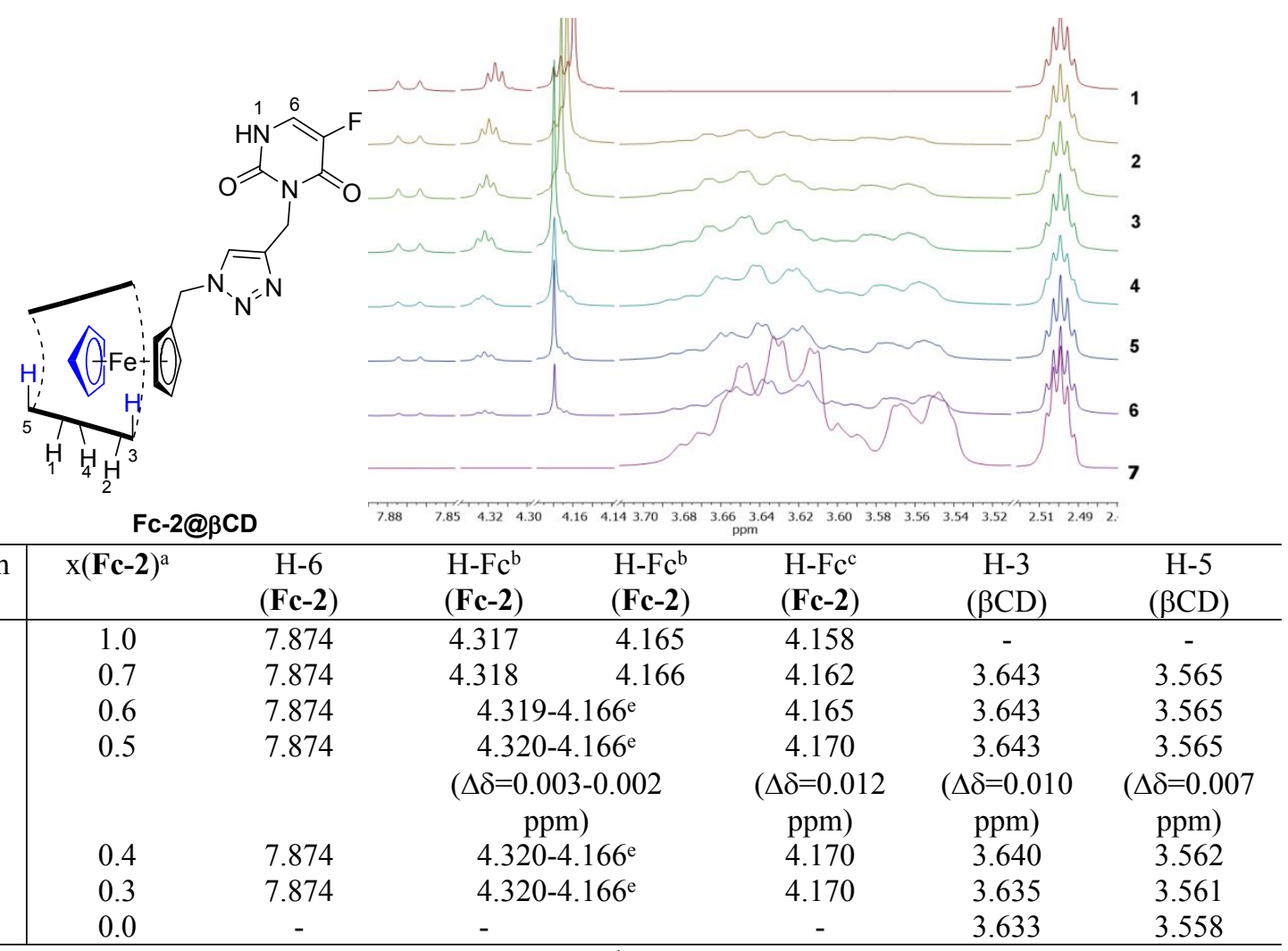

${ }^{a}$ Mole fraction of compound $\mathbf{F c - 2}$ in the examined sample. ${ }^{\mathrm{b}}$ The chemical shift of signals assigned to the protons of the substituted cyclopentadienyl ring. ${ }^{\mathrm{c}}$ The chemical shift of signals assigned to the protons of the unsubstituted cyclopentadienyl ring (marked in blue). ${ }^{\mathrm{d}} \Delta \delta=\delta$ (entry 4$)$ - $\delta$ (entry 1 ) for signals of compound $\mathbf{F c}-2$ or $\Delta \delta=\delta$ (entry 4$)-\delta$ (entry 7$)$ for the $\beta C D$ signals. ${ }^{e}$ Overlapped with $\mathrm{H}-\mathrm{Fc}\left(\mathrm{C}_{5} \mathrm{H}_{5} ; 4.170-4.165 \mathrm{ppm}\right)$

b)

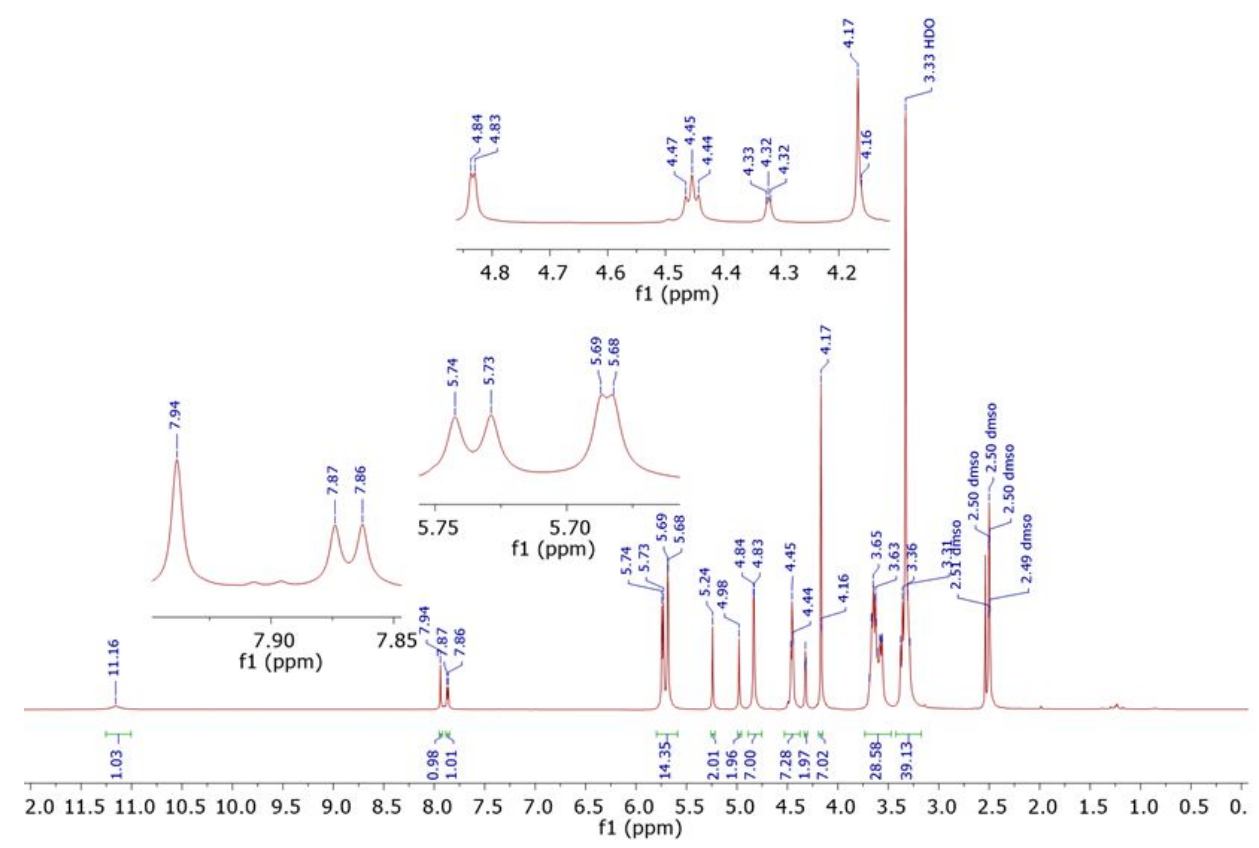

Figure S36. (a) Schematic representation of complex Fc-2@BCD, the selected insets of the spectra obtained from the ${ }^{1} \mathrm{H}$ NMR titration of compound Fc-2 with $\beta \mathrm{CD}$ (DMSO- $d_{6}$, $500 \mathrm{MHz}$ ) and the chemical shifts of signals shown in the insets (in ppm for the center of the signal). (b) The ${ }^{1} \mathrm{H}$ NMR spectrum of complex Fc-2@ $\beta C D$ (DMSO- $d_{6}, 500 \mathrm{MHz}$ ). 
a)

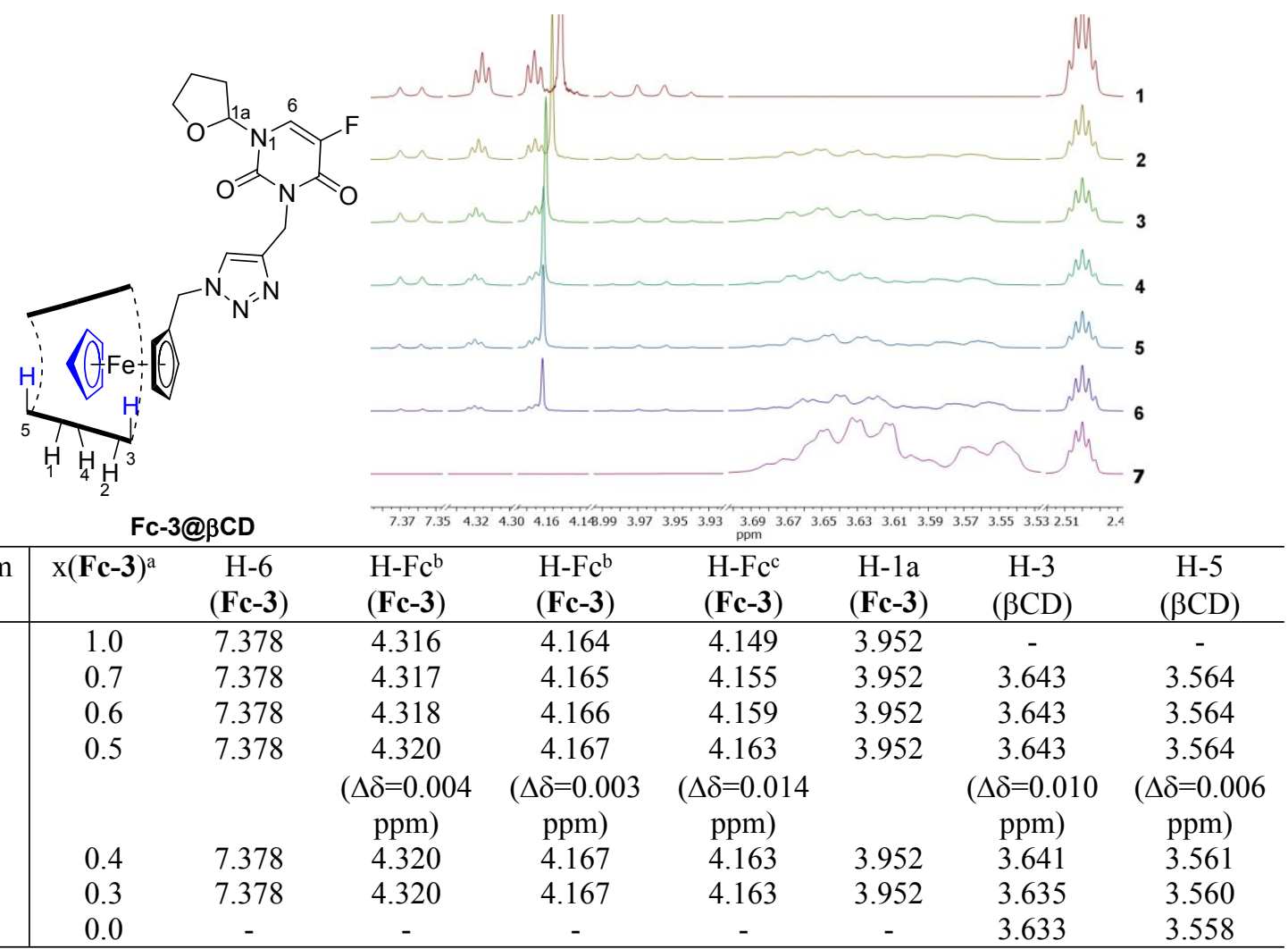

${ }^{a}$ Mole fraction of compound $\mathbf{F c - 3}$ in the examined sample. ${ }^{b}$ The chemical shift of signals assigned to the protons of the substituted cyclopentadienyl ring. ${ }^{\mathrm{c}}$ The chemical shift of signals assigned to the protons of the unsubstituted cyclopentadienyl ring (marked in blue). ${ }^{\mathrm{d}} \Delta \delta=\delta$ (entry 4$)$ - $\delta$ (entry 1 ) for signals of compound $\mathbf{F c}-\mathbf{3}$ or $\Delta \delta=\delta($ entry 4$)-\delta$ (entry 7$)$ for the $\beta C D$ signals.

b)

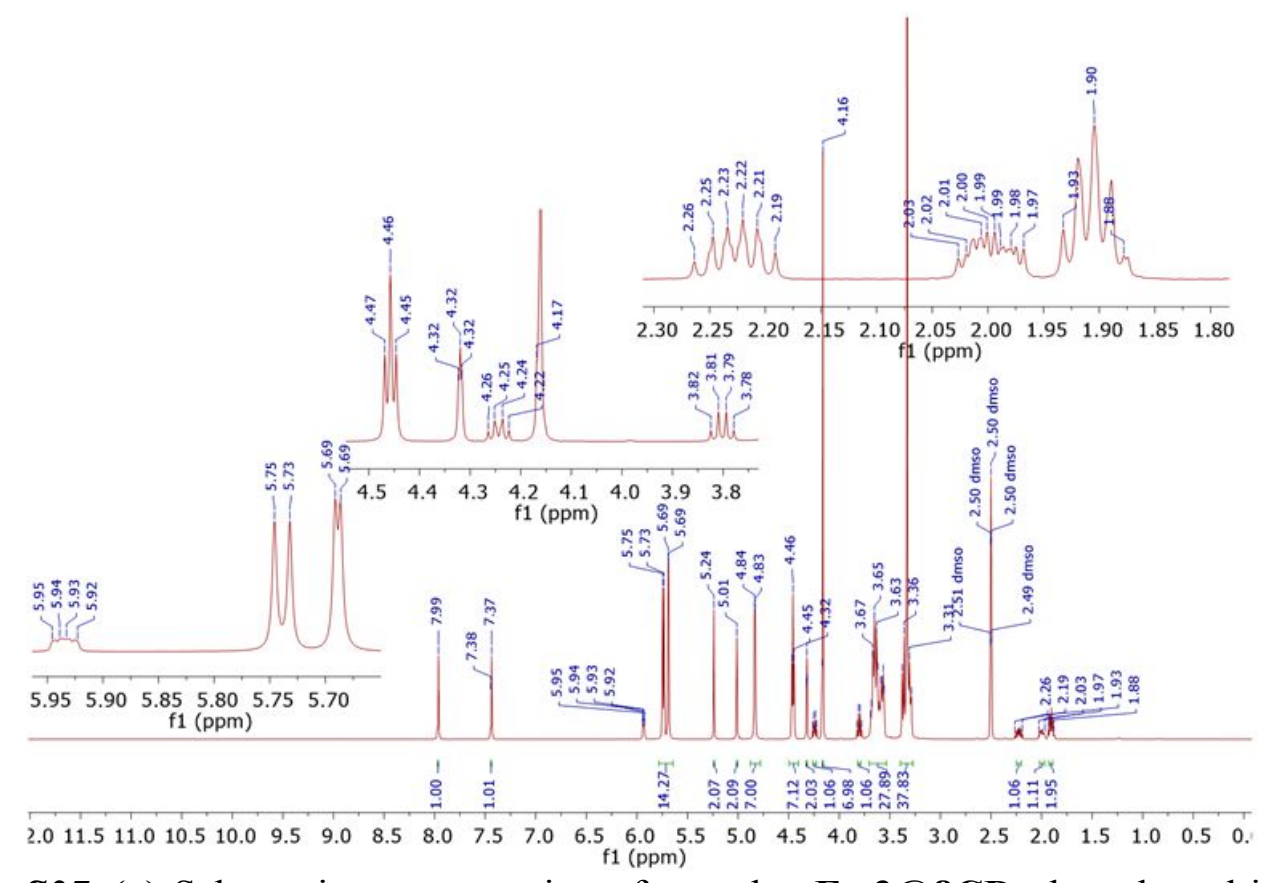

Figure S37. (a) Schematic representation of complex Fc-3@BCD, the selected insets of the spectra obtained from the ${ }^{1} \mathrm{H}$ NMR titration of compound Fc-3 with $\beta C D$ (DMSO- $d_{6}$, $500 \mathrm{MHz}$ ) and the chemical shifts of signals shown in the insets (in ppm for the center of the signal). (b) The ${ }^{1} \mathrm{H}$ NMR spectrum of complex Fc-3@ $@ \mathbf{\beta C D}$ (DMSO- $d_{6}, 500 \mathrm{MHz}$ ). 


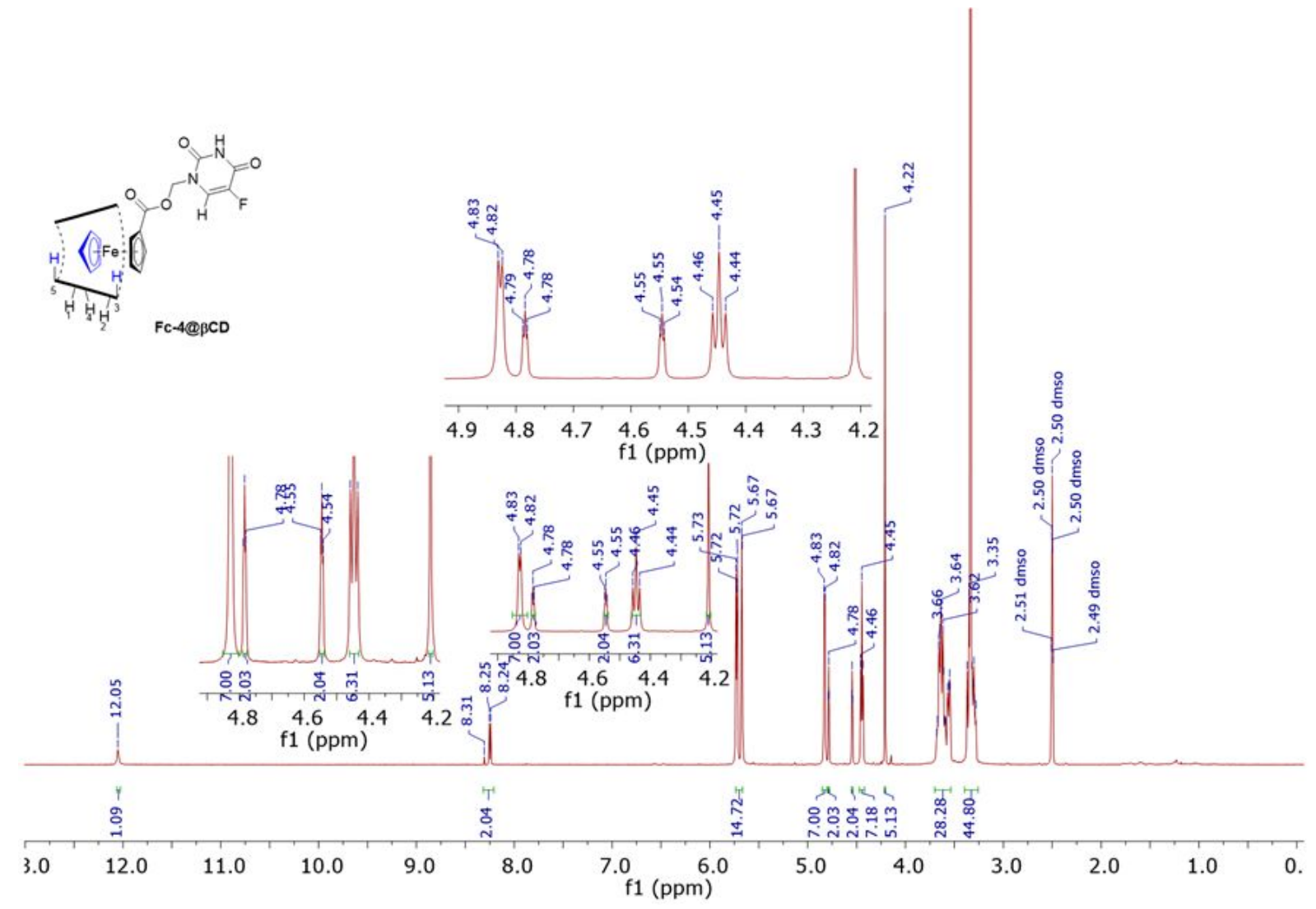

Figure S38. The ${ }^{1} \mathrm{H}$ NMR spectrum of complex Fc-4@BCD (DMSO- $d_{6}, 500 \mathrm{MHz}$ ).
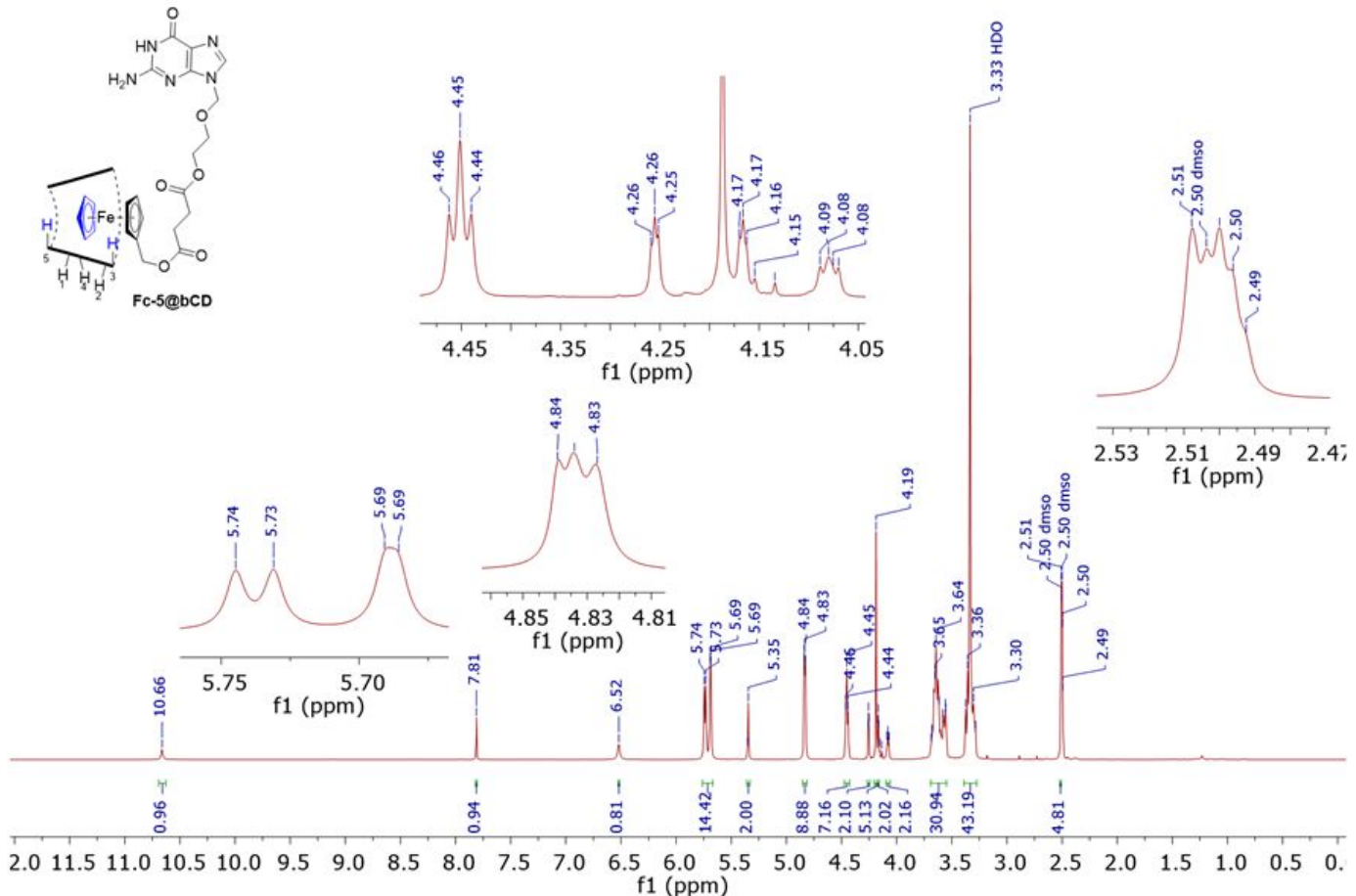

Figure S39. Full ${ }^{1} \mathrm{H}$ NMR spectrum of complex Fc-5@BCD (DMSO- $\left.d_{6}, 500 \mathrm{MHz}\right)$. 
a)

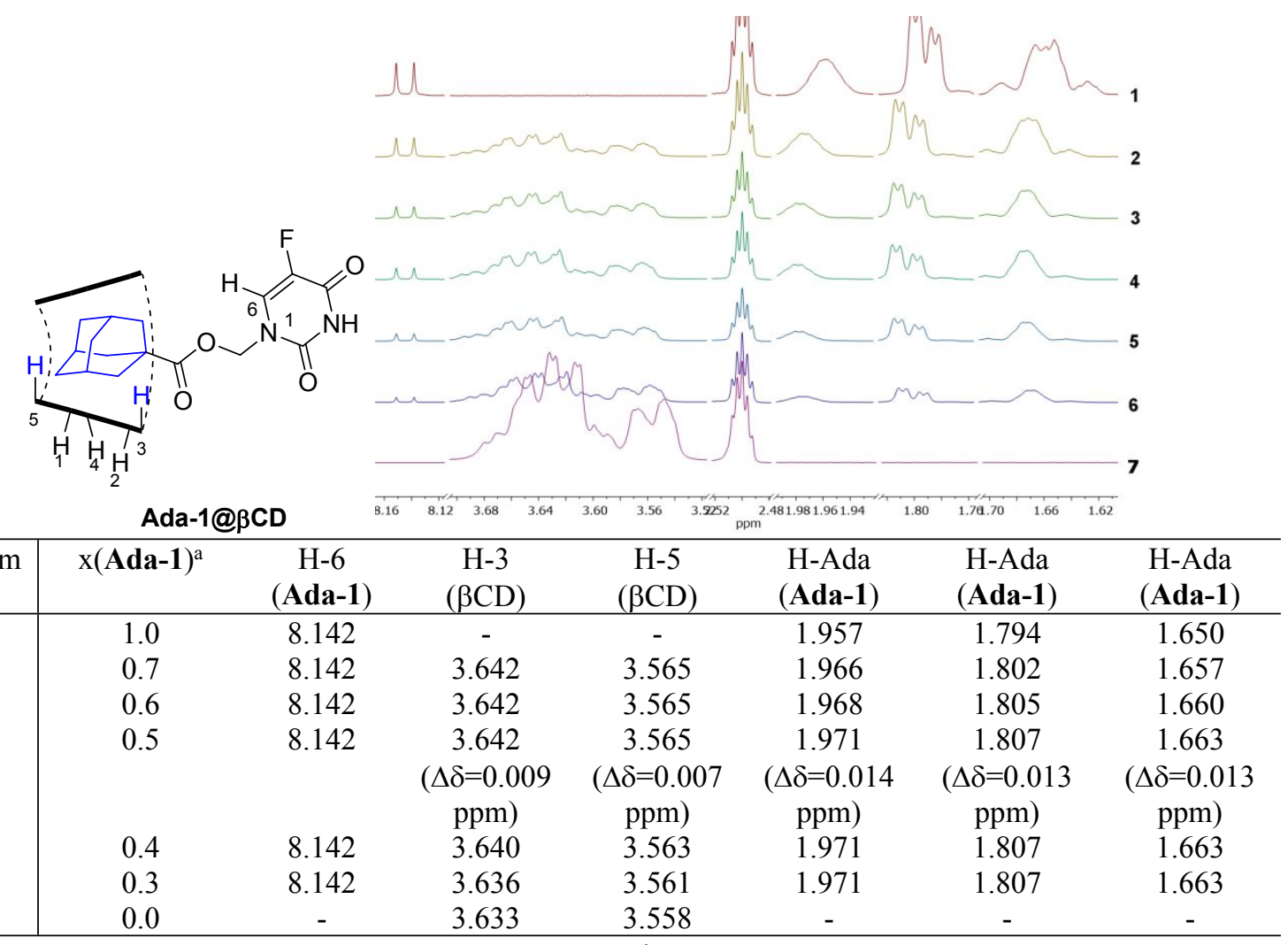

${ }^{\mathrm{a}}$ Mole fraction of compound Ada-1 in the examined sample. ${ }^{\mathrm{b}} \Delta \delta=\delta$ (entry 4$)-\delta$ (entry 1 ) for signals of compound $\mathbf{F} \mathbf{c}-\mathbf{3}$ or $\Delta \delta=\delta($ entry 4$)-\delta($ entry 7$)$ for the $\beta C D$ signals.

b)

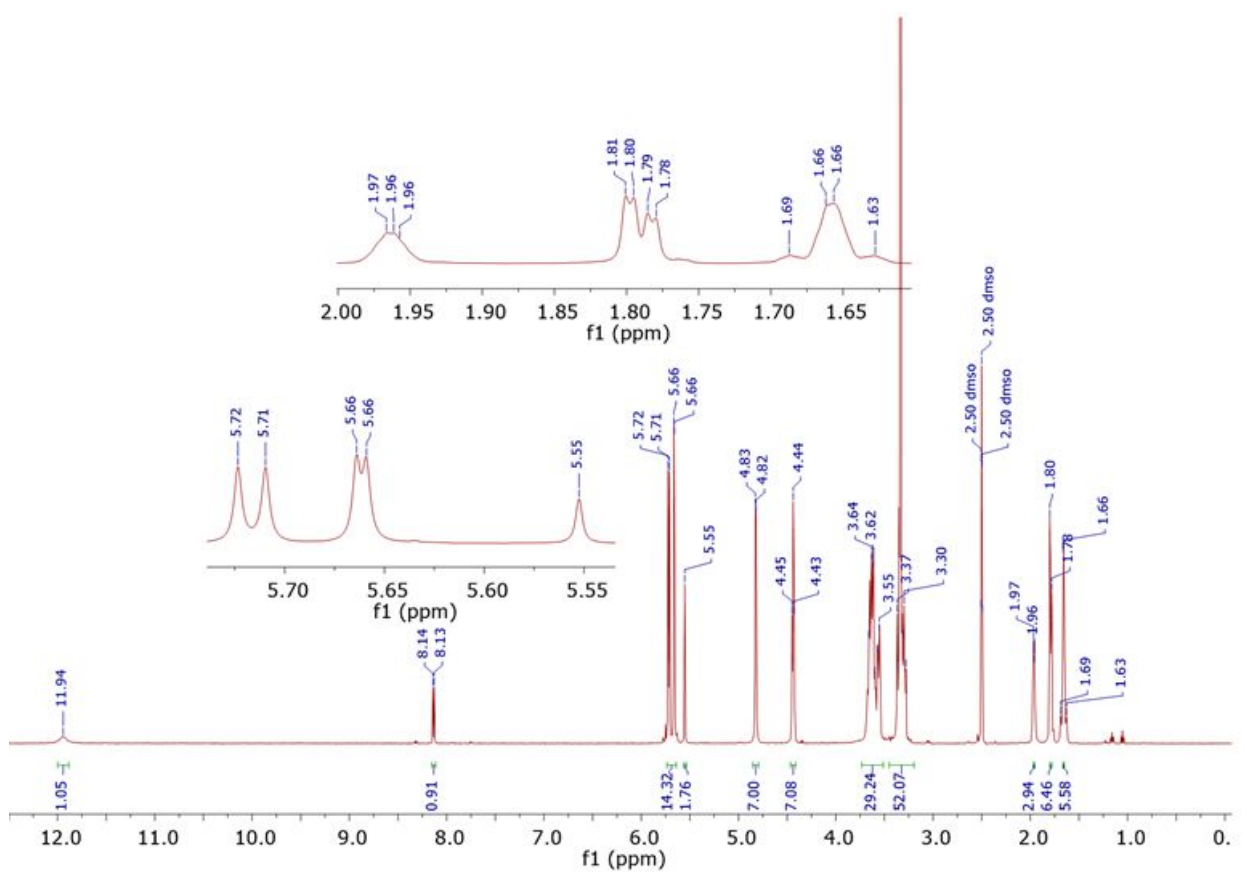

Figure S40. (a) Schematic representation of complex Ada-1@BCD, the selected insets of the spectra obtained from the ${ }^{1} \mathrm{H}$ NMR titration of compound Ada-1 with $\beta C D$ (DMSO$d_{6}, 500 \mathrm{MHz}$ ) and the chemical shifts of signals shown in the insets (in ppm for the center of the signal). (b) The ${ }^{1} \mathrm{H}$ NMR spectrum of complex Ada-1@ @CD (DMSO- $d_{6}, 500 \mathrm{MHz}$ ). 
S6. Complex stoichiometry analyses

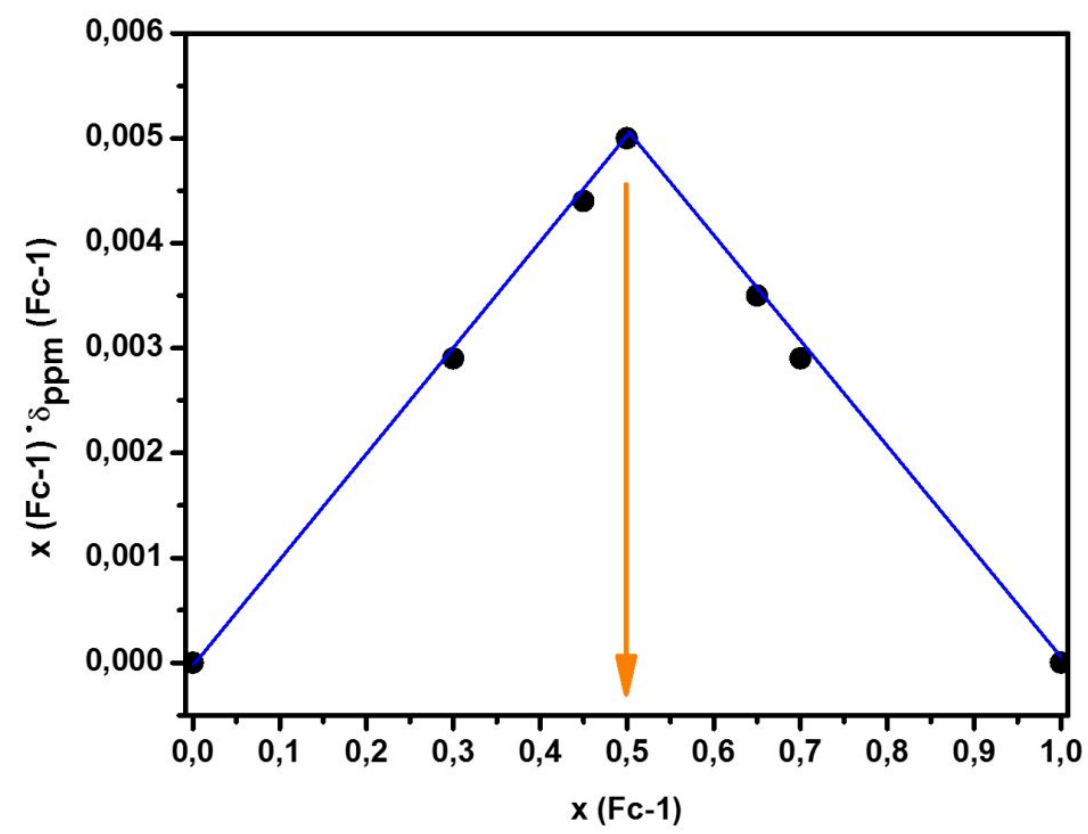

Figure S41. The plot enabling the estimation of the stoichiometry of complex Fc-1@ $\beta C D$ $\left({ }^{1} \mathrm{H}\right.$ NMR titration experiments).

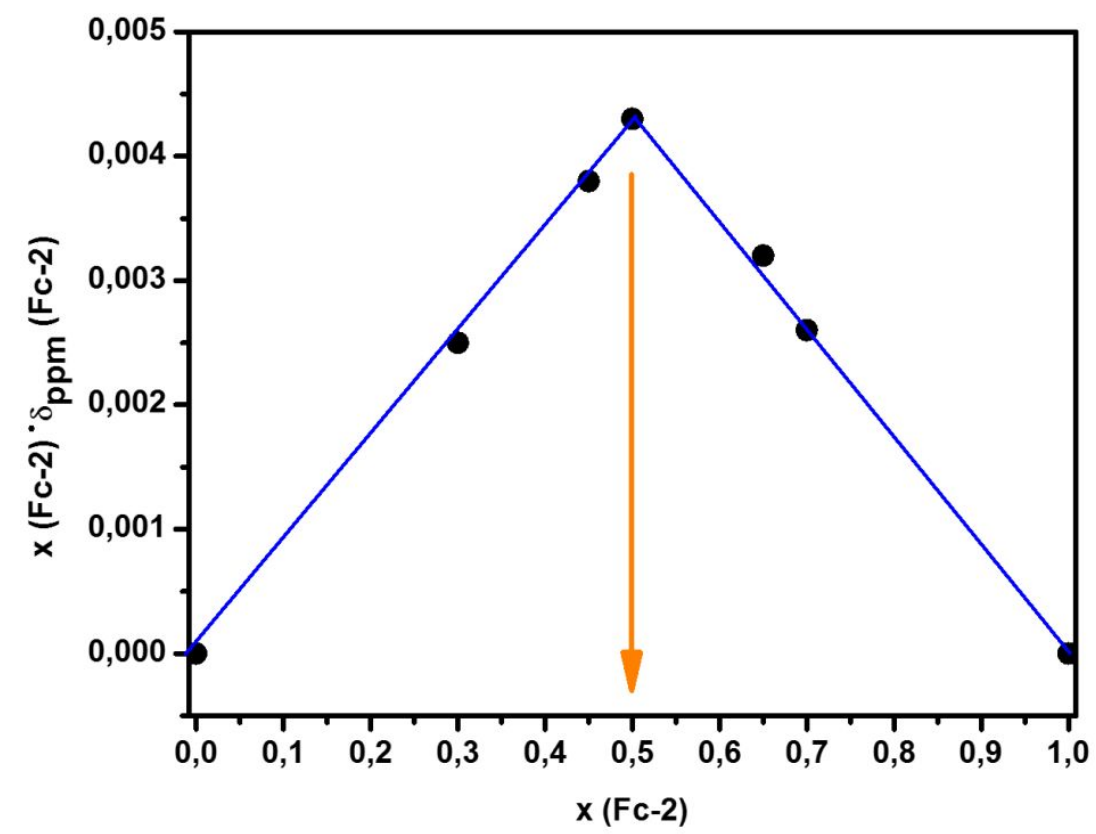

Figure S42. The plot enabling the estimation of the stoichiometry of complex Fc-2@ $\beta C D\left({ }^{1} \mathrm{H}\right.$ NMR titration experiments). 


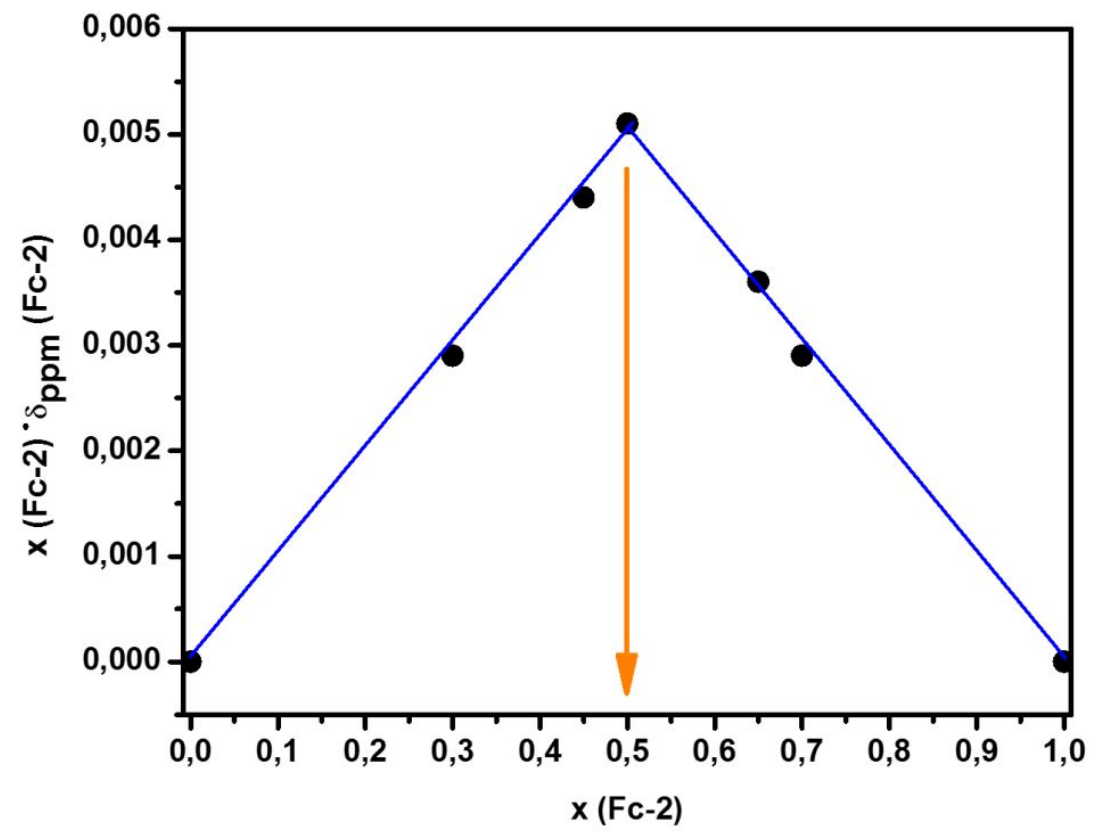

Figure $\mathbf{S 4 3}$. The plot enabling the estimation of the stoichiometry of complex Fc-3@ $\beta C D$ ( ${ }^{1} \mathrm{H}$ NMR titration experiments).

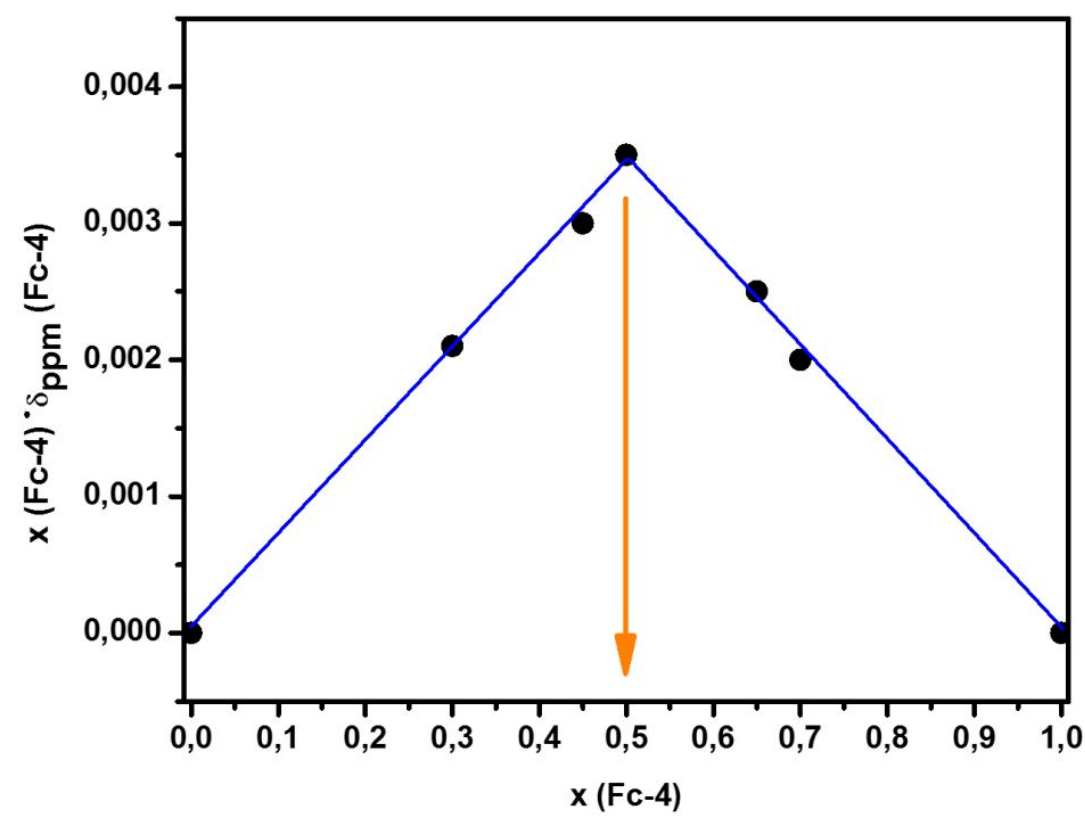

Figure S44. The plot enabling the estimation of the stoichiometry of complex Fc-4@ $\beta C D$ ( ${ }^{1} \mathrm{H}$ NMR titration experiments). 


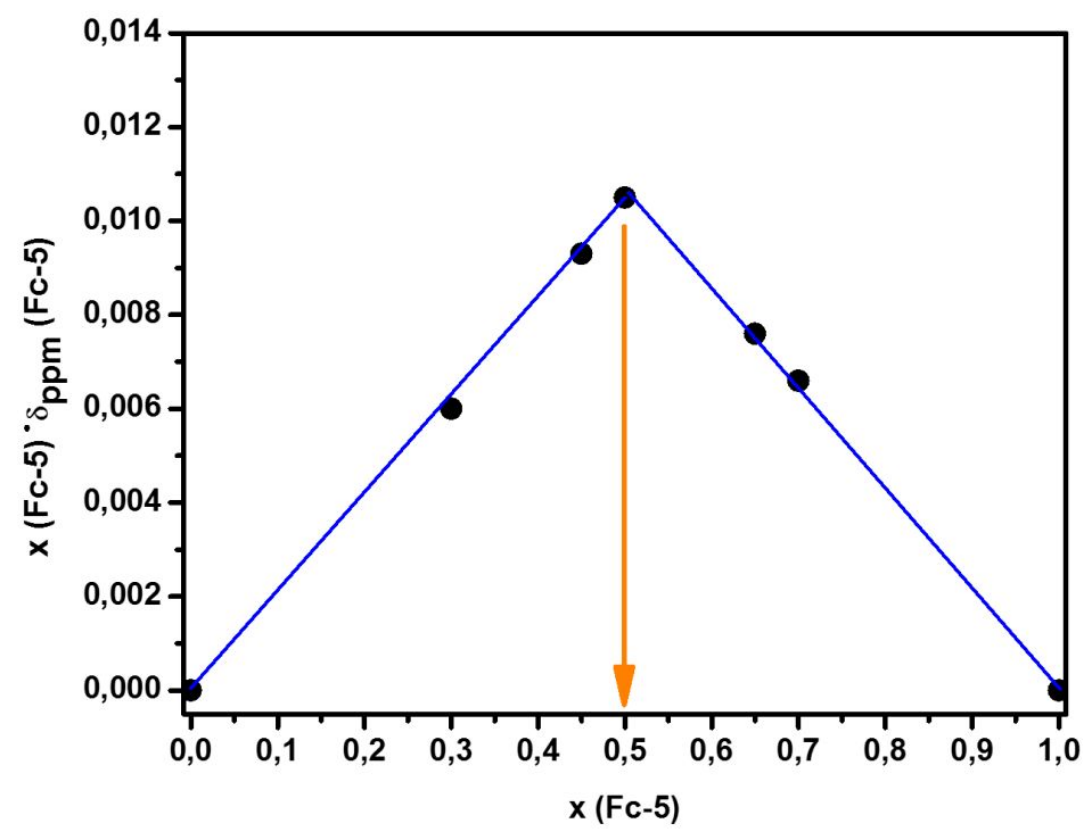

Figure S45. The plot enabling the estimation of the stoichiometry of complex Fc-5@ $\beta C D$ $\left({ }^{1} \mathrm{H}\right.$ NMR titration experiments).

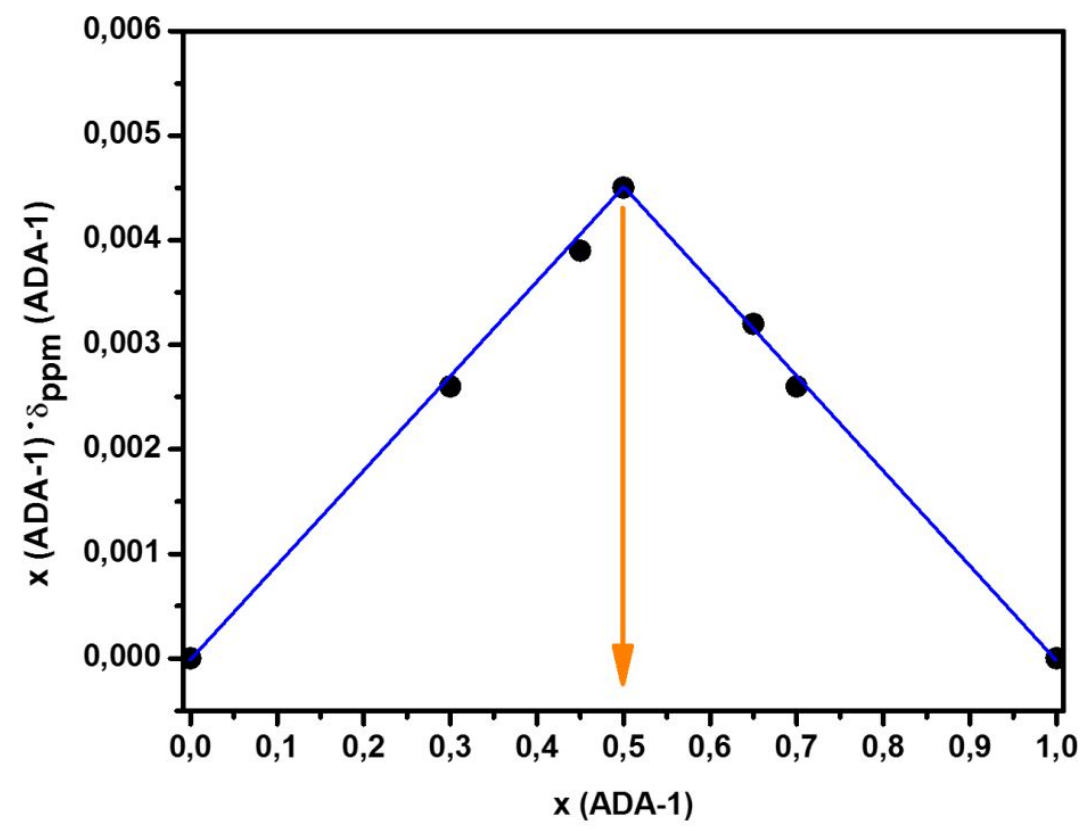

Figure S46. The plot enabling the estimation of the stoichiometry of complex Ada$1 @ \beta C D\left({ }^{1} \mathrm{H}\right.$ NMR titration experiments). 
S7. ${ }^{1} \mathrm{H}-{ }^{1} \mathrm{H}$ ROESY NMR spectra

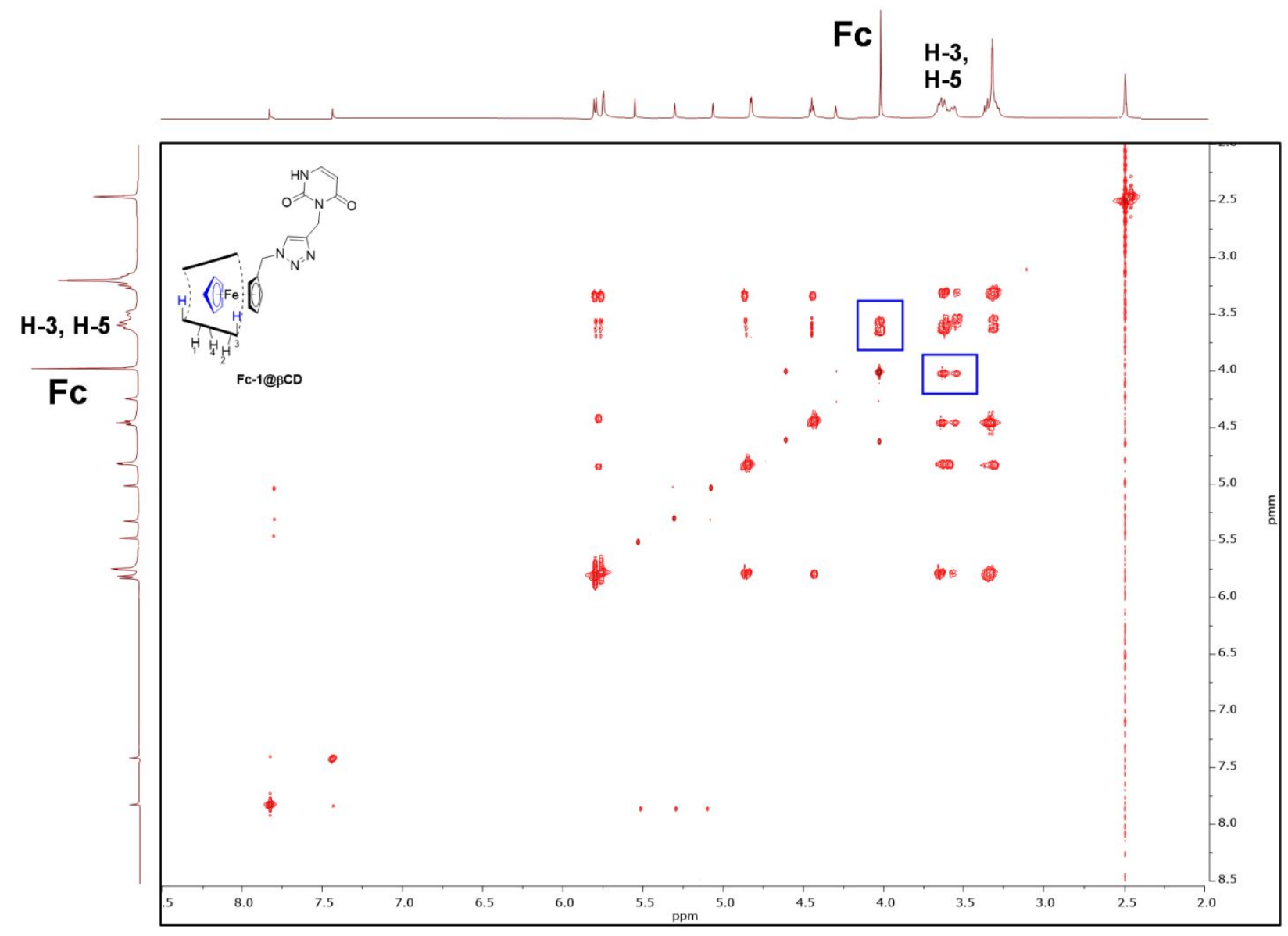

Figure S47. The ${ }^{1} \mathrm{H}_{-}{ }^{1} \mathrm{H}$ ROESY NMR spectrum of complex Fc-1@ $@ \mathrm{CD}$ (DMSO- $d_{6}, 500 \mathrm{MHz}$ ). The cross-correlations between the signals corresponding to the $\mathrm{Fc}$ and $\mathrm{H}-3, \mathrm{H}-5$ inner protons of $\beta \mathrm{CD}$ are marked in blue. 


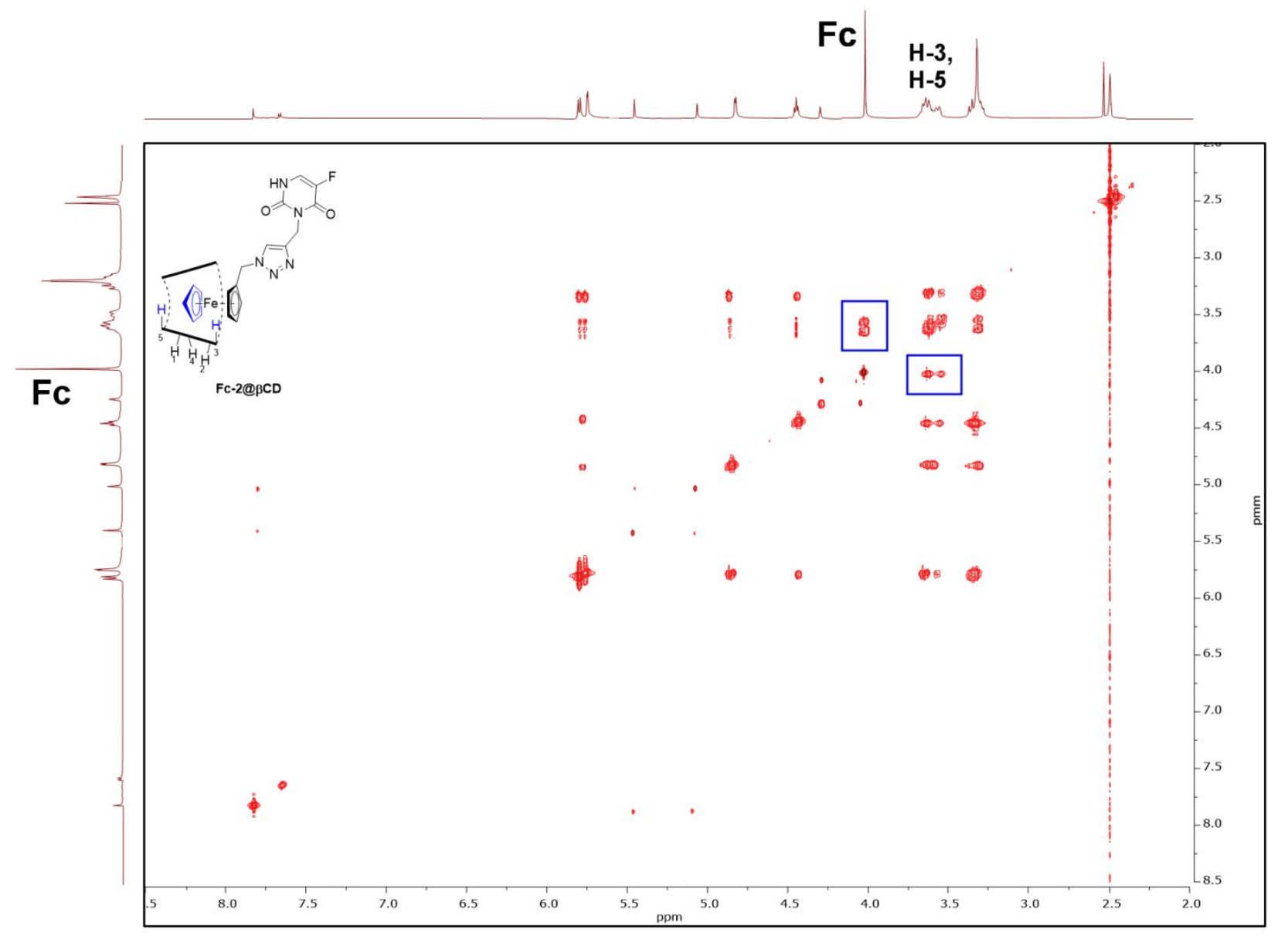

Figure S48. The ${ }^{1} \mathrm{H}_{-}{ }^{1} \mathrm{H}$ ROESY NMR spectrum of complex Fc-2@ $\beta \mathrm{CD}$ (DMSO- $d_{6}, 500 \mathrm{MHz}$ ). The cross-correlations between the signals corresponding to the $\mathrm{Fc}$ and $\mathrm{H}-3, \mathrm{H}-5$ inner protons of $\beta \mathrm{CD}$ are marked in blue. 


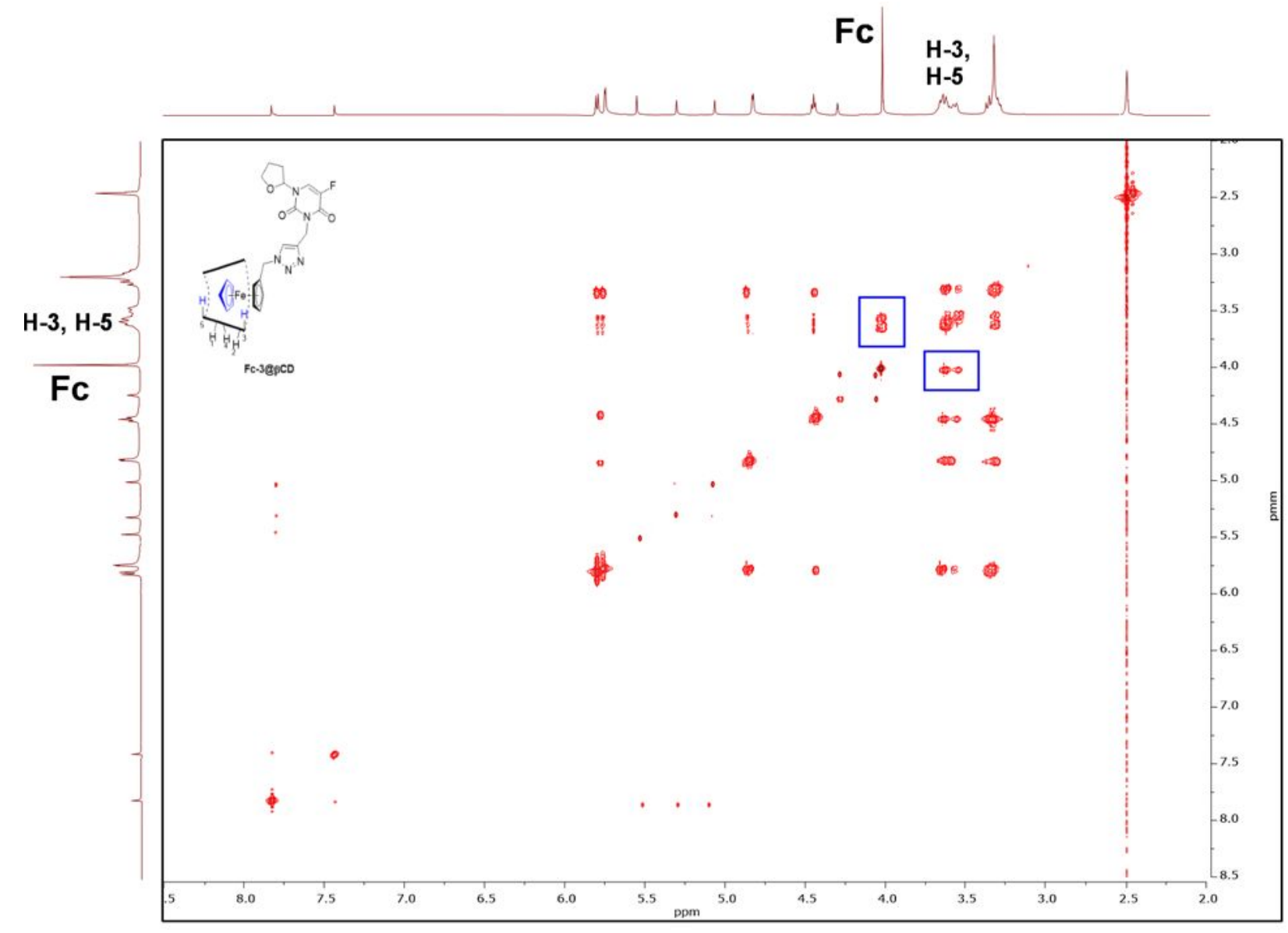

Figure S49. The ${ }^{1} \mathrm{H}^{1} \mathrm{H}$ ROESY NMR spectrum of complex Fc-3@ $\beta \mathrm{CD}$ (DMSO- $\left.d_{6}, 500 \mathrm{MHz}\right)$. The cross-correlations between the signals corresponding to the $\mathrm{Fc}$ and $\mathrm{H}-3, \mathrm{H}-5$ inner protons of $\beta \mathrm{CD}$ are marked in blue. 


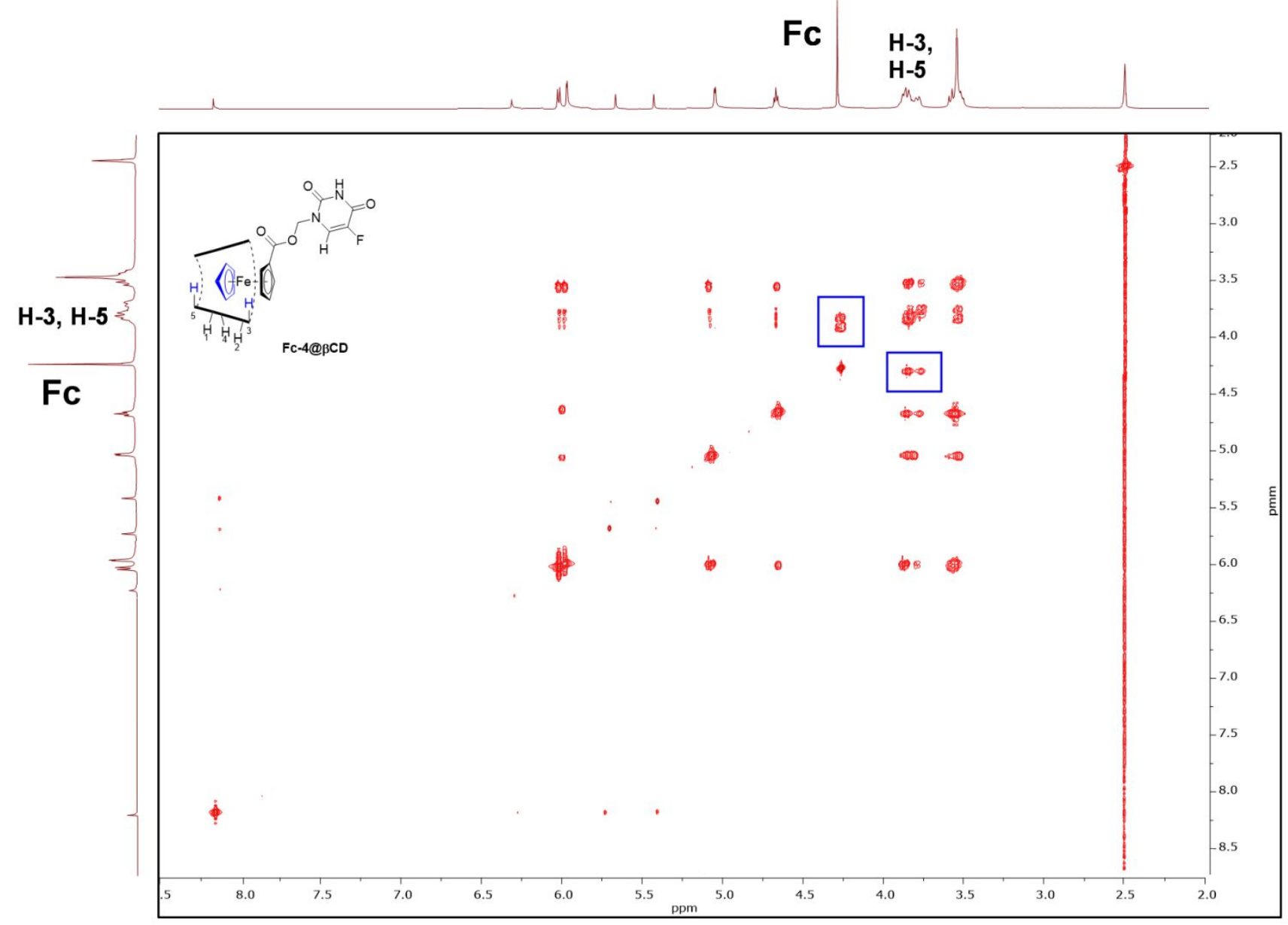

Figure S50. The ${ }^{1} \mathrm{H}_{-}{ }^{1} \mathrm{H}$ ROESY NMR spectrum of complex Fc-4@ $\beta \mathrm{CD}$ (DMSO- $d_{6}, 500 \mathrm{MHz}$ ). The cross-correlations between the signals corresponding to the $\mathrm{Fc}$ and $\mathrm{H}-3, \mathrm{H}-5$ inner protons of $\beta \mathrm{CD}$ are marked in blue. 


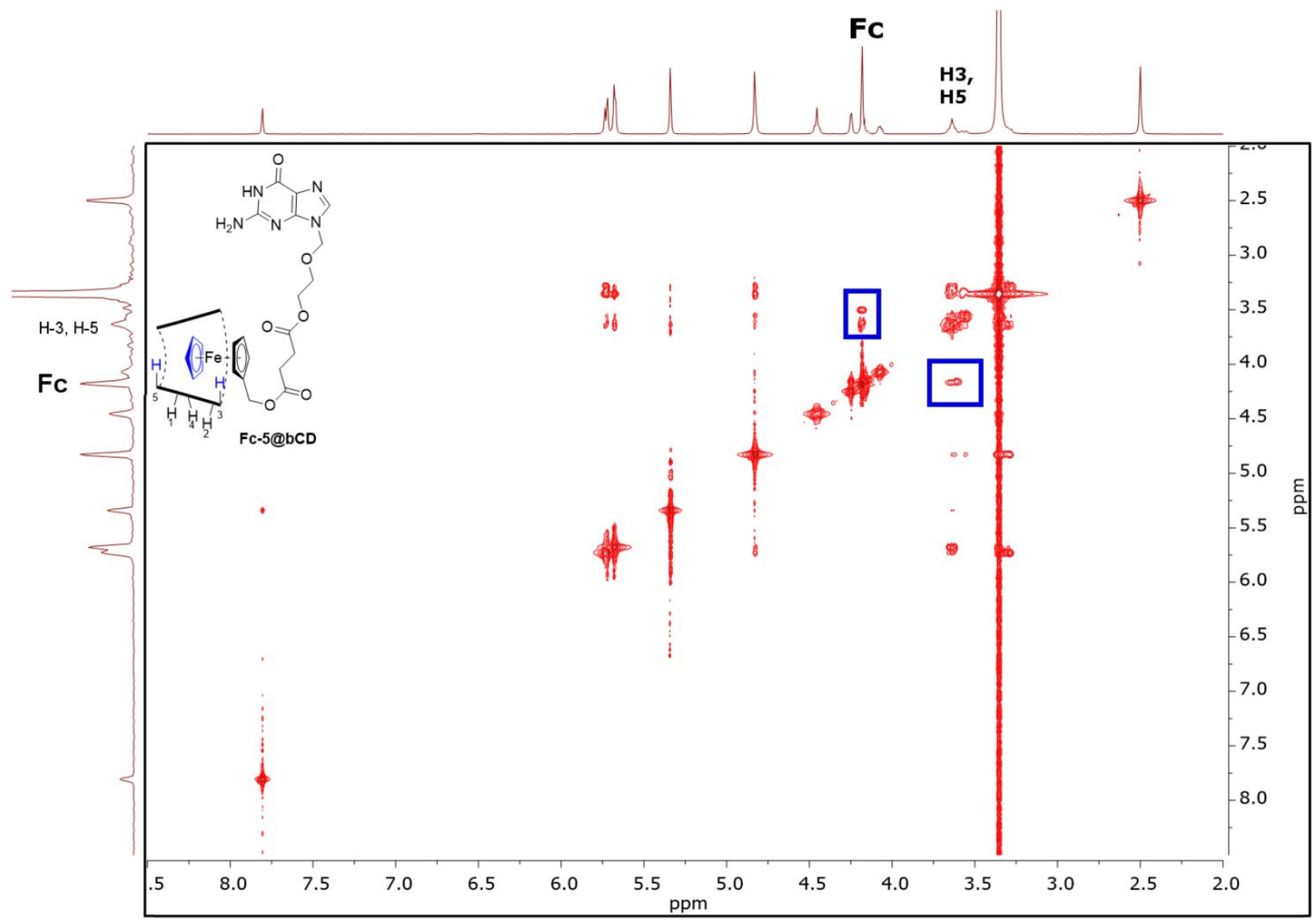

Figure S51. The ${ }^{1} \mathrm{H}_{-}{ }^{1} \mathrm{H}$ ROESY NMR spectrum of complex Fc-5@ßCD (DMSO- $d_{6}, 500 \mathrm{MHz}$ ). The cross-correlations between the signals corresponding to the $\mathrm{Fc}$ and $\mathrm{H}-3, \mathrm{H}-5$ inner protons of $\beta \mathrm{CD}$ are marked in blue. 


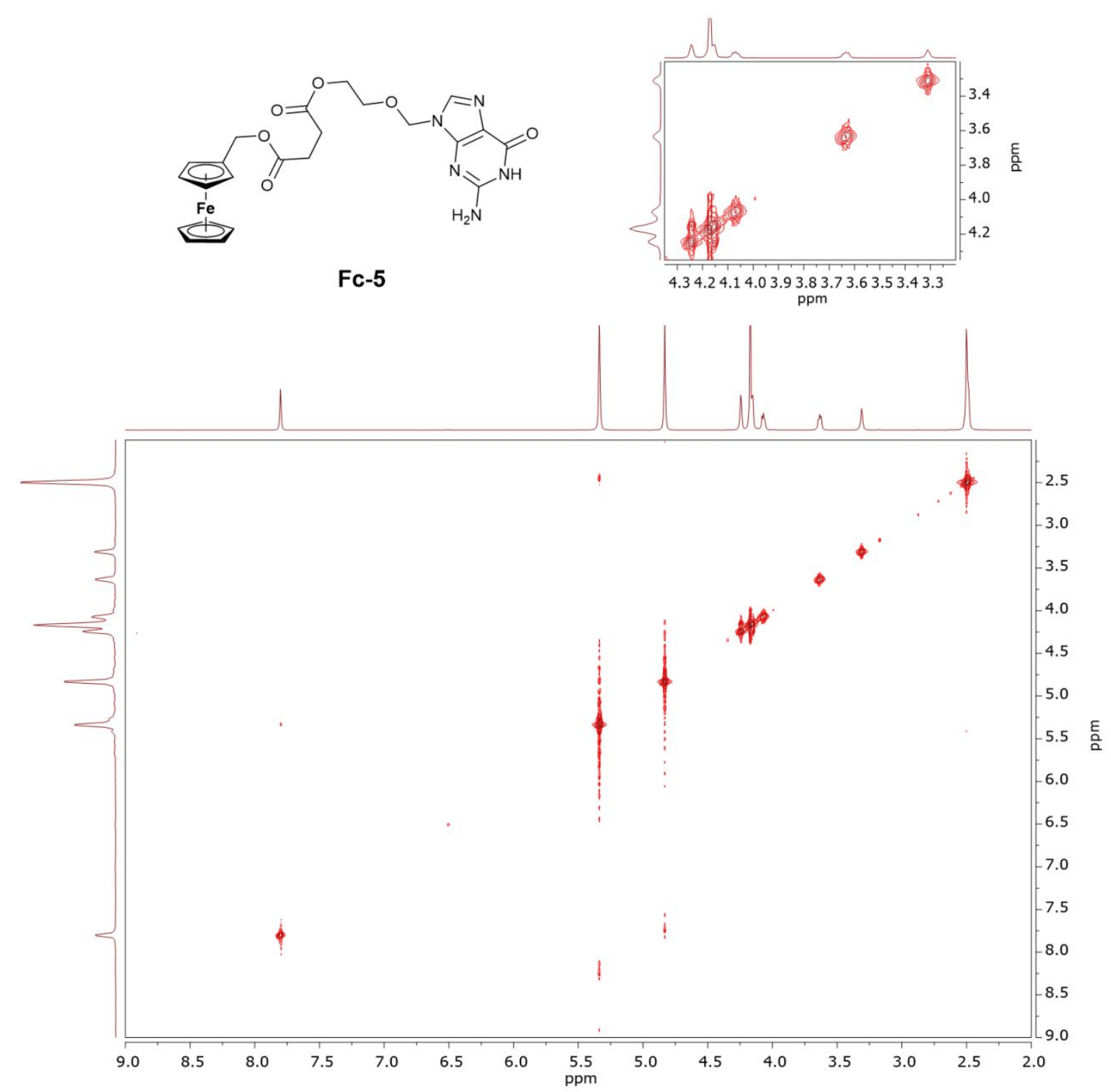

Figure S52. The ${ }^{1} \mathrm{H}-{ }^{1} \mathrm{H}$ ROESY NMR spectrum of compound Fc-5 (DMSO- $d_{6}, 500 \mathrm{MHz}$ ). The inset of the spectrum is also presented (top). 


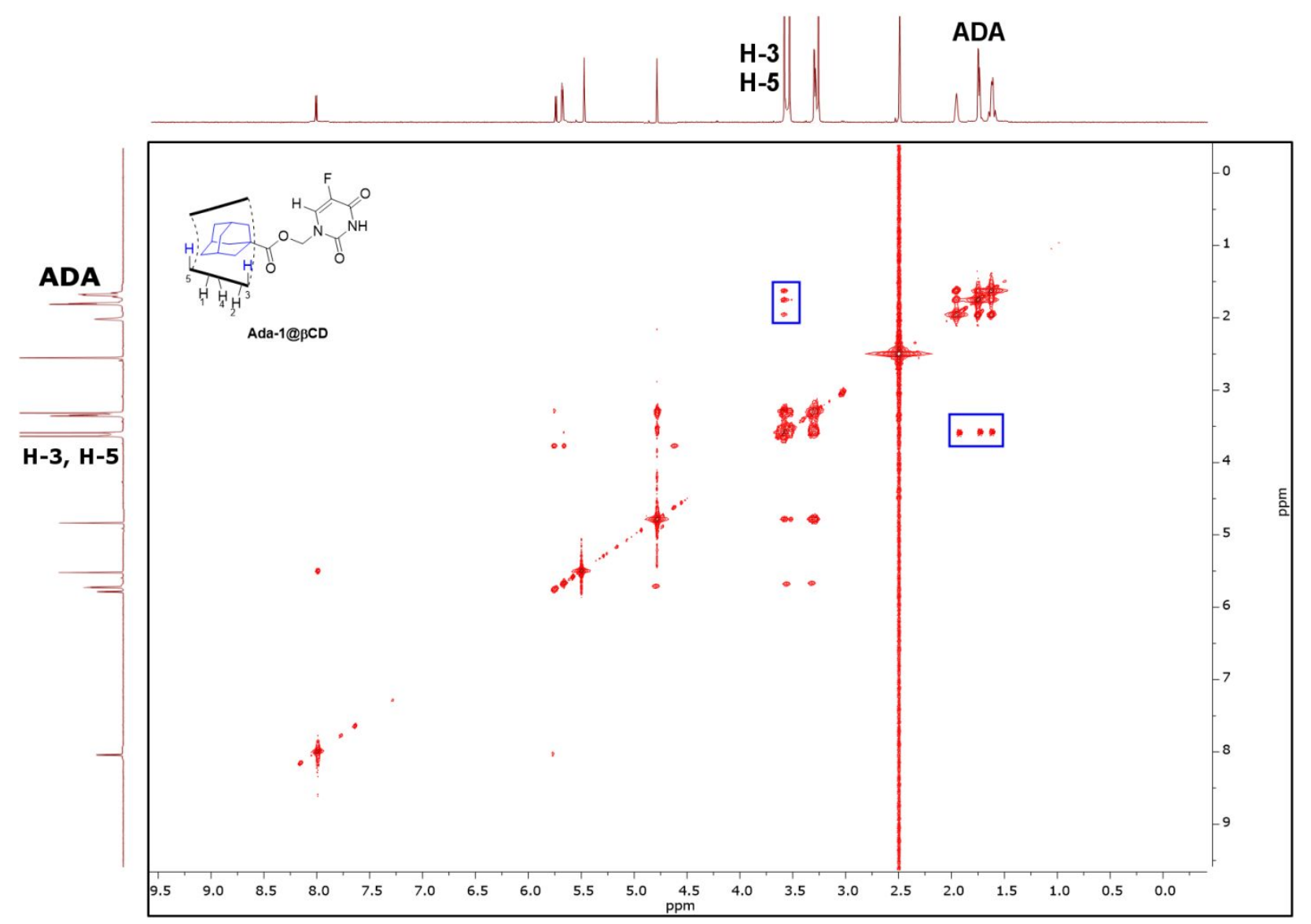

Figure S53. The ${ }^{1} \mathrm{H}^{-1} \mathrm{H}$ ROESY NMR spectrum of complex Ada-1@ $\beta \mathrm{CD}$ (DMSO- $d_{6}, 500 \mathrm{MHz}$ ). The cross-correlations between the signals corresponding to the $\mathrm{Fc}$ and $\mathrm{H}-3, \mathrm{H}-5$ inner protons of $\beta \mathrm{CD}$ are marked in blue. 


\section{S8. ${ }^{1}$ H DOSY NMR spectra}

The method of calculation of apparent binding constant $\left(K_{\text {app }}\right)$ and the data are presented in Table S4. The ${ }^{1} \mathrm{H}$ DOSY NMR spectra are presented below. The ${ }^{1} \mathrm{H}$ DOSY NMR spectra were measured for 1:1 mixtures of the guest and $\beta \mathrm{CD}$. For the calculation of the relative errors, see Section S9.

Table S4. Calculated apparent binding constant values $\left(K_{\text {app }}\right)$. Viscosity-corrected diffusion coefficient values are given in $10^{-10} \mathrm{~m}^{2} \mathrm{~s}^{-1}$ and were

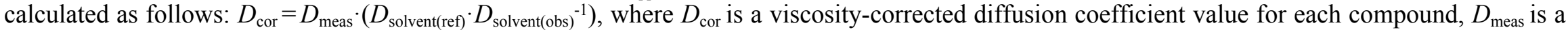
measured diffusion coefficient for each compound, $D_{\text {solvent(ref })}$ is a diffusion coefficient for the solvent in pure solution $\left(4.960 \cdot 10^{-10} \mathrm{~m}^{2} \mathrm{~s}^{-1}\right)$, and $D_{\text {solvent(obs }}$ stands for an observed diffusion coefficient for the solvent in the given sample. Molar fraction of the complexed guest $\left(x_{b}\right)$ was calculated as follows: $x_{\mathrm{b}}$ $=\left(D_{\text {free }}-D_{\text {obs }}\right) \cdot\left[\left(D_{\text {free }}-D_{\text {bound }}\right)^{-1}\right]$, where $x_{\mathrm{b}}$ is a molar fraction value of the complexed guest, $D_{\text {free }}$ is a diffusion coefficient value for the native guest, $D_{\text {obs }}$ stands for a diffusion coefficient value for the guest in the complex, $D_{\text {bound }}$ is a diffusion coefficient value for $\beta C D$ in the complex. $K_{\text {app }}$ values were calculated as follows: $K_{\text {app }}=x_{\mathrm{b}} \cdot\left[\left(1-x_{\mathrm{b}}\right) \cdot\left(0.01 \mathrm{M}-x_{\mathrm{b}} \cdot 0.01 \mathrm{M}\right)\right]^{-1}$, where $K_{\text {app }}\left[\mathrm{M}^{-1}\right]$ is an apparent binding constant, $x_{\mathrm{b}}$ is a molar fraction of the guest in the system, $0.01 \mathrm{M}$ is a concentration of $\beta C D$ and a guest in the sample. Viscosity-corrected diffusion coefficient value $\left(D_{\text {cor }}\right)$ for the native $\beta C D$ is $1.821 \cdot 10^{-10} \mathrm{~m}^{2} \mathrm{~s}^{-1}$, according to Kasprzak, A.; Grudzinski, I. P.; Bamburowicz-Klimkowska, M.; Parzonko, A.; Gawlak, M.; Poplawska, M. Macromol. Biosci. 2018, No. $170028,1-7$.

\begin{tabular}{|c|c|c|c|c|c|c|}
\hline \multicolumn{7}{|c|}{ Inclusion complexes } \\
\hline Inclusion complex & Component & $D_{\text {free }}$ & $D_{\text {obs }}$ & $D_{\text {bound }}$ & $x_{\mathrm{b}}$ & $\boldsymbol{K}_{\text {app }}\left[\mathbf{M}^{-1}\right]$ \\
\hline \multirow{2}{*}{ Fc-1@ $\beta C D$} & $\beta C D$ & N/A & $\mathrm{N} / \mathrm{A}$ & $0.948 \pm 0.008$ & \multirow{2}{*}{$0.280 \pm 0.004$} & \multirow{2}{*}{$53.9 \pm 1.4$} \\
\hline & Fc-1 & $1.729 \pm 0.016$ & $1.508 \pm 0.013$ & $\mathrm{~N} / \mathrm{A}$ & & \\
\hline \multirow[b]{2}{*}{ Fc-2@ $\beta C D$} & $\beta C D$ & N/A & N/A & $1.047 \pm 0.009$ & \multirow{2}{*}{$0.308 \pm 0.005$} & \multirow{2}{*}{$64.4 \pm 1.7$} \\
\hline & Fc-2 & $1.598 \pm 0.015$ & $1.426 \pm 0.012$ & $\mathrm{~N} / \mathrm{A}$ & & \\
\hline \multirow{2}{*}{ Fc-3@ $@ \beta C D$} & $\beta C D$ & N/A & N/A & $0.771 \pm 0.007$ & \multirow{2}{*}{$0.351 \pm 0.005$} & \multirow{2}{*}{$83.2 \pm 2.2$} \\
\hline & Fc-3 & $1.688 \pm 0.015$ & $1.366 \pm 0.011$ & $\mathrm{~N} / \mathrm{A}$ & & \\
\hline \multirow{2}{*}{ Fc-4@BCD } & $\beta C D$ & N/A & $\mathrm{N} / \mathrm{A}$ & $0.887 \pm 0.008$ & \multirow{2}{*}{$0.332 \pm 0.005$} & \multirow{2}{*}{$74.2 \pm 2.0$} \\
\hline & Fc-4 & $1.791 \pm 0.016$ & $1.491 \pm 0.013$ & $\mathrm{~N} / \mathrm{A}$ & & \\
\hline \multirow{2}{*}{ Fc-5@ $\beta C D$} & $\beta C D$ & $\mathrm{~N} / \mathrm{A}$ & N/A & $0.844 \pm 0.008$ & \multirow{2}{*}{$0.374 \pm 0.006$} & \multirow{2}{*}{$95.2 \pm 2.5$} \\
\hline & Fc-5 & $1.630 \pm 0.015$ & $1.336 \pm 0.011$ & $\mathrm{~N} / \mathrm{A}$ & & \\
\hline \multirow{2}{*}{ Ada-1@ $@ \beta C D$} & $\beta C D$ & N/A & N/A & $0.806 \pm 0.007$ & \multirow{2}{*}{$0.321 \pm 0.005$} & \multirow{2}{*}{$69.4 \pm 1.9$} \\
\hline & Ada-1 & $1.908 \pm 0.017$ & $1.555 \pm 0.013$ & $\mathrm{~N} / \mathrm{A}$ & & \\
\hline
\end{tabular}



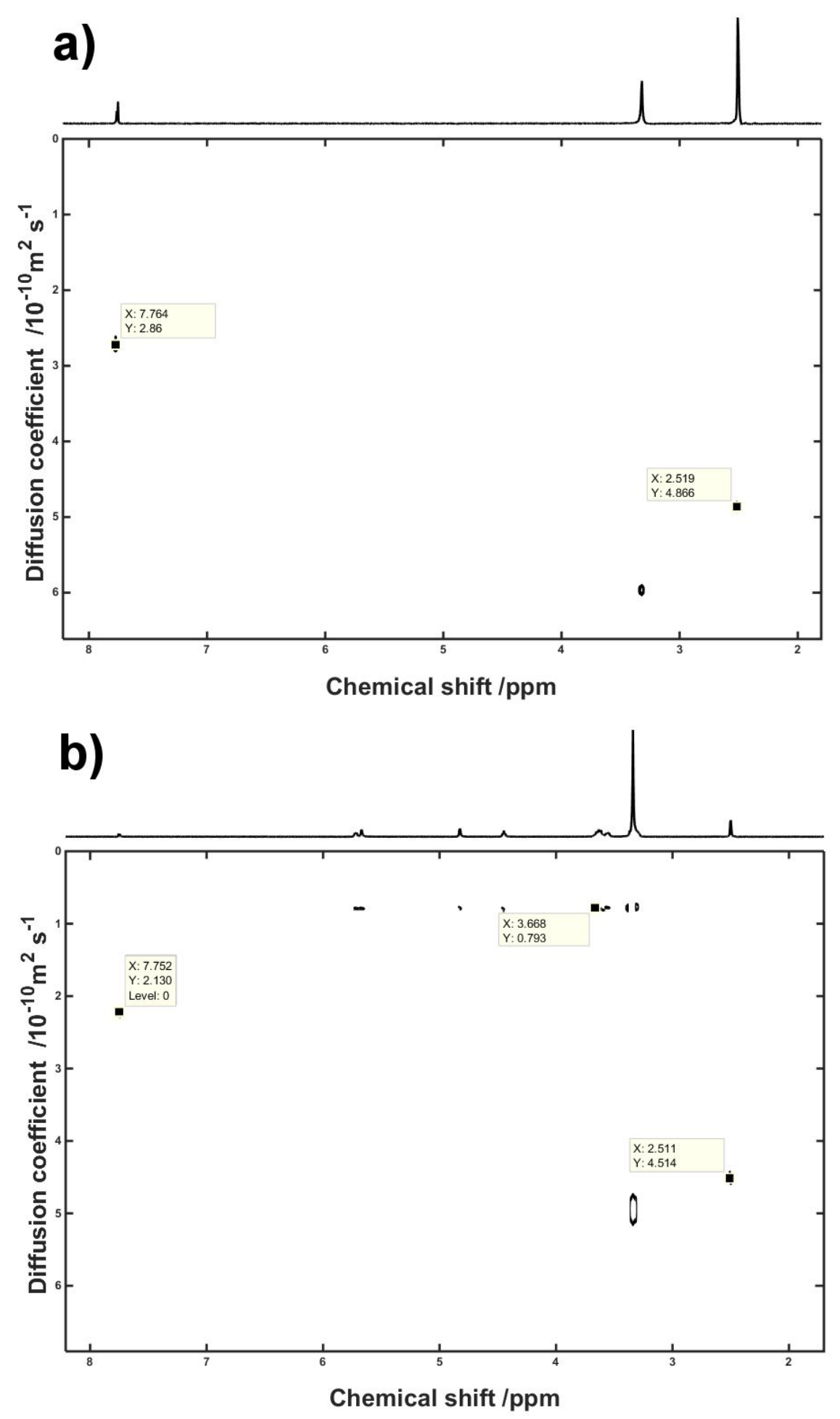

Figure S54. The ${ }^{1} \mathrm{H}$ DOSY NMR spectra (DMSO- $\left.d_{6}, 500 \mathrm{MHz}\right)$ of (a) 5-FUr, and (b) complex 5-FUra $@ \beta C D\left(D_{\text {free }}=2.915 \pm 0.026 \cdot 10^{-10} \mathrm{~m}^{2} \mathrm{~s}^{-1},\left(D_{\mathrm{obs}}=2.340 \pm 0.020 \cdot 10^{-10}\right.\right.$ $\mathrm{m}^{2} \mathrm{~s}^{-1}, D_{\text {bound }}=0.871 \pm 0.008 \cdot 10^{-10} \mathrm{~m}^{2} \mathrm{~s}^{-1}, x_{\mathrm{b}}=0.281 \pm 0.005, \boldsymbol{K}_{\text {app }}=\mathbf{5 2 . 4} \pm \mathbf{1 . 4} \mathbf{M}^{-\mathbf{1}}$; for the calculation method, see Table S1). For calculation of the relative errors, see Section S9. 

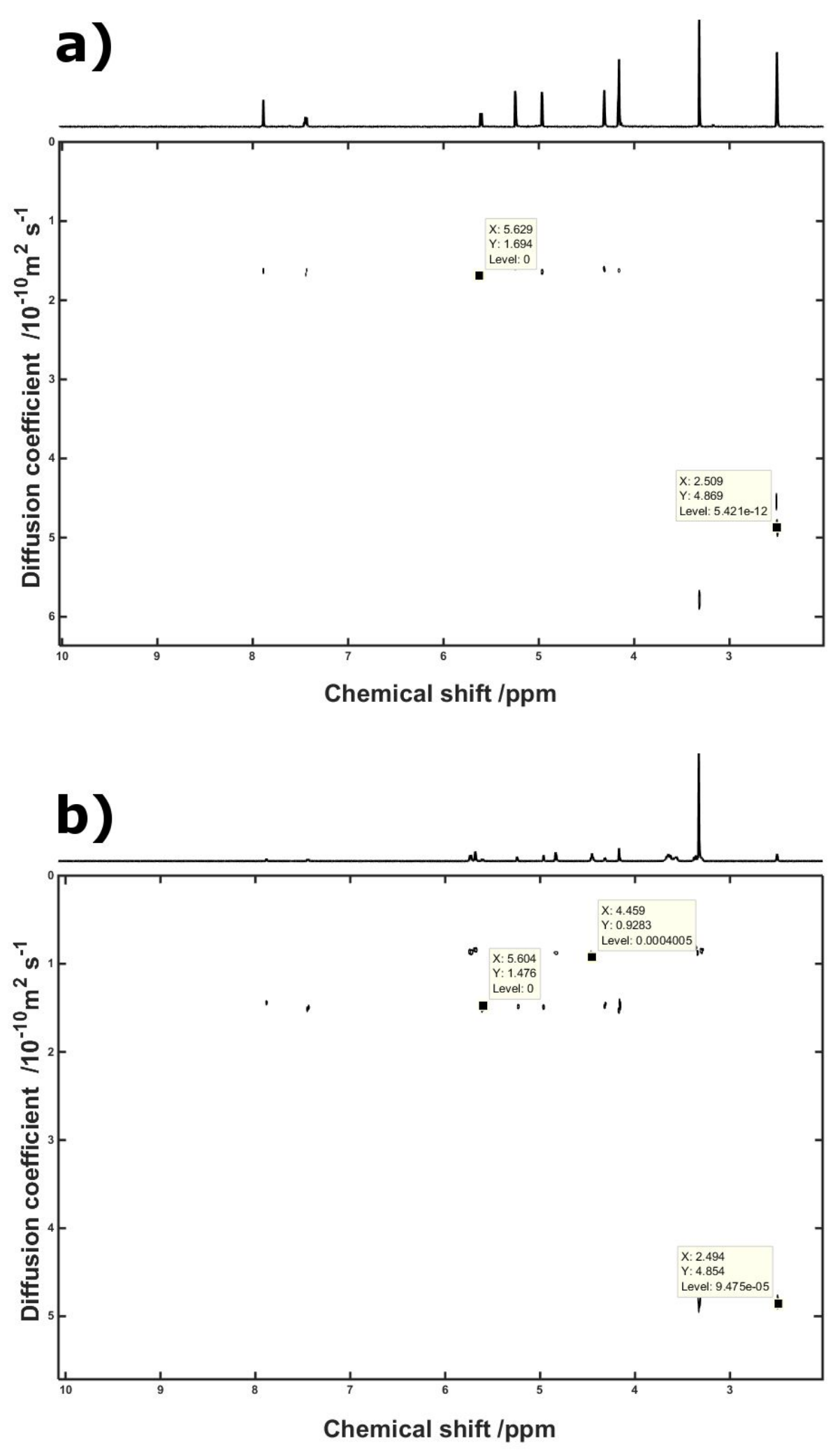

Figure S55. The ${ }^{1} \mathrm{H}$ DOSY NMR spectra (DMSO- $d_{6}, 500 \mathrm{MHz}$ ) of (a) compound Fc-1 and (b) complex Fc-1@ $\beta C D$. 

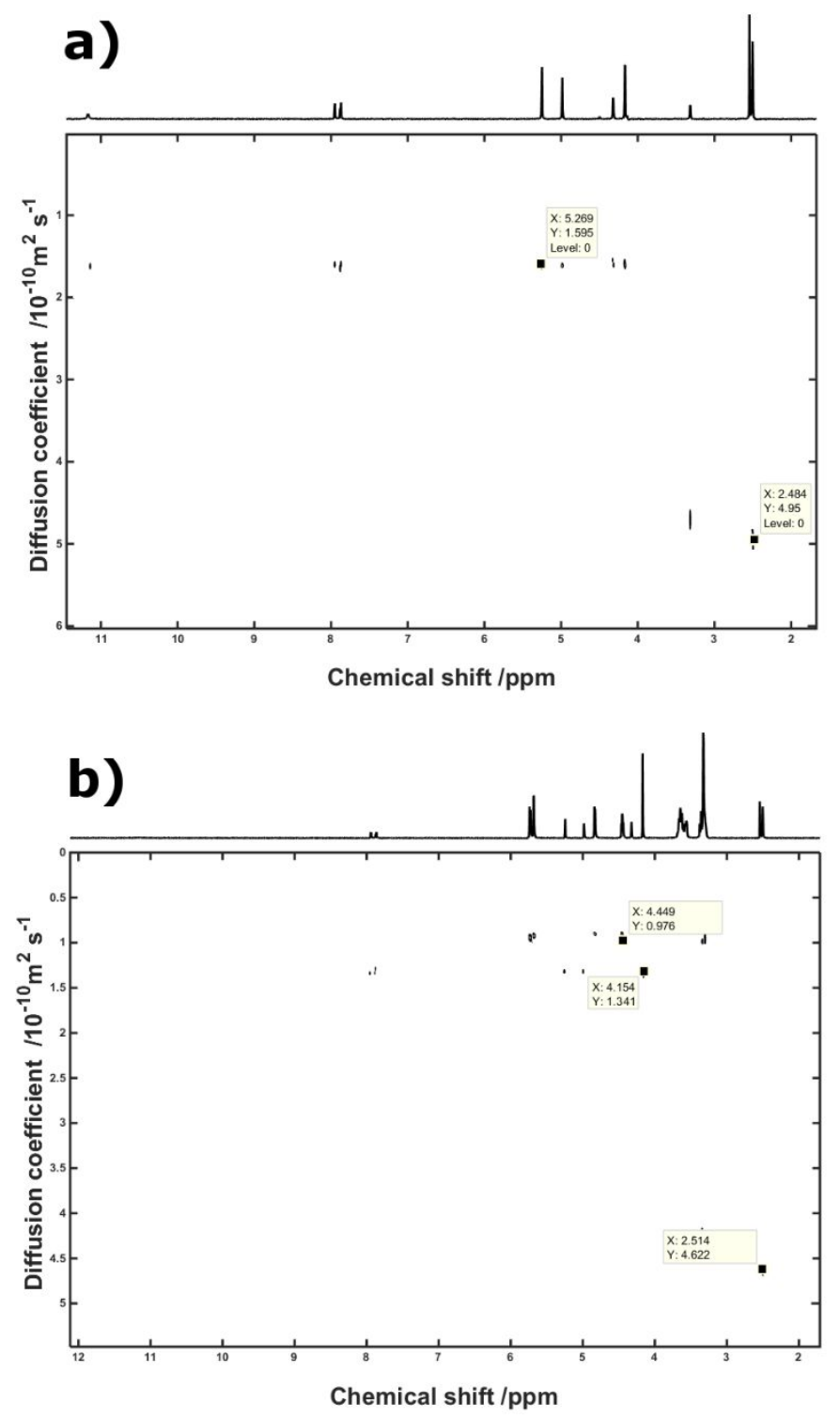

Figure S56. The ${ }^{1} \mathrm{H}$ DOSY NMR spectra (DMSO- $d_{6}, 500 \mathrm{MHz}$ ) of (a) compound Fc-2, and (b) complex Fc-2@ßCD. 

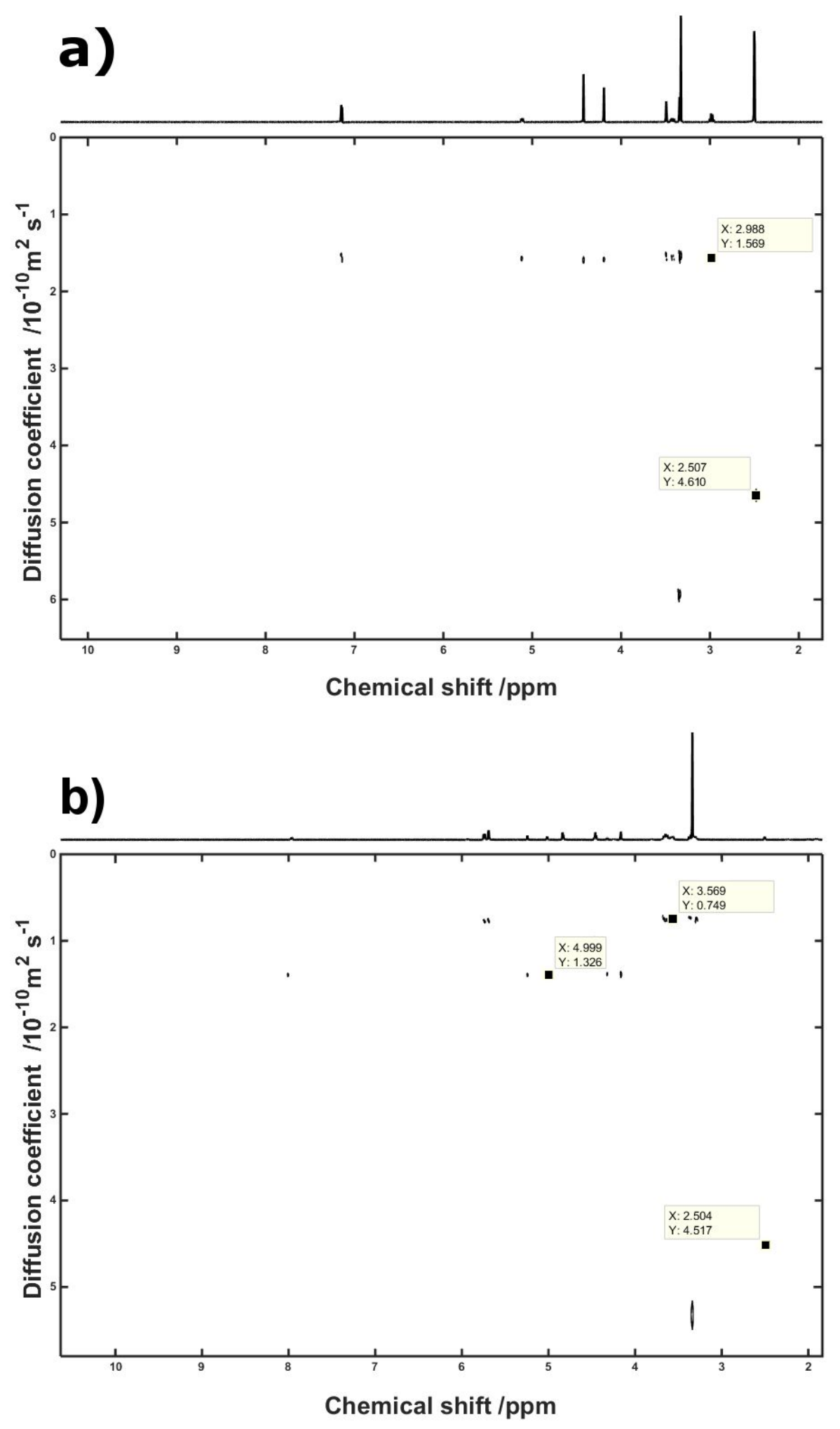

Figure S57. The ${ }^{1} \mathrm{H}$ DOSY NMR spectra (DMSO- $d_{6}, 500 \mathrm{MHz}$ ) of (a) compound Fc-3, and (b) complex Fc-3@ $\beta C D$. 

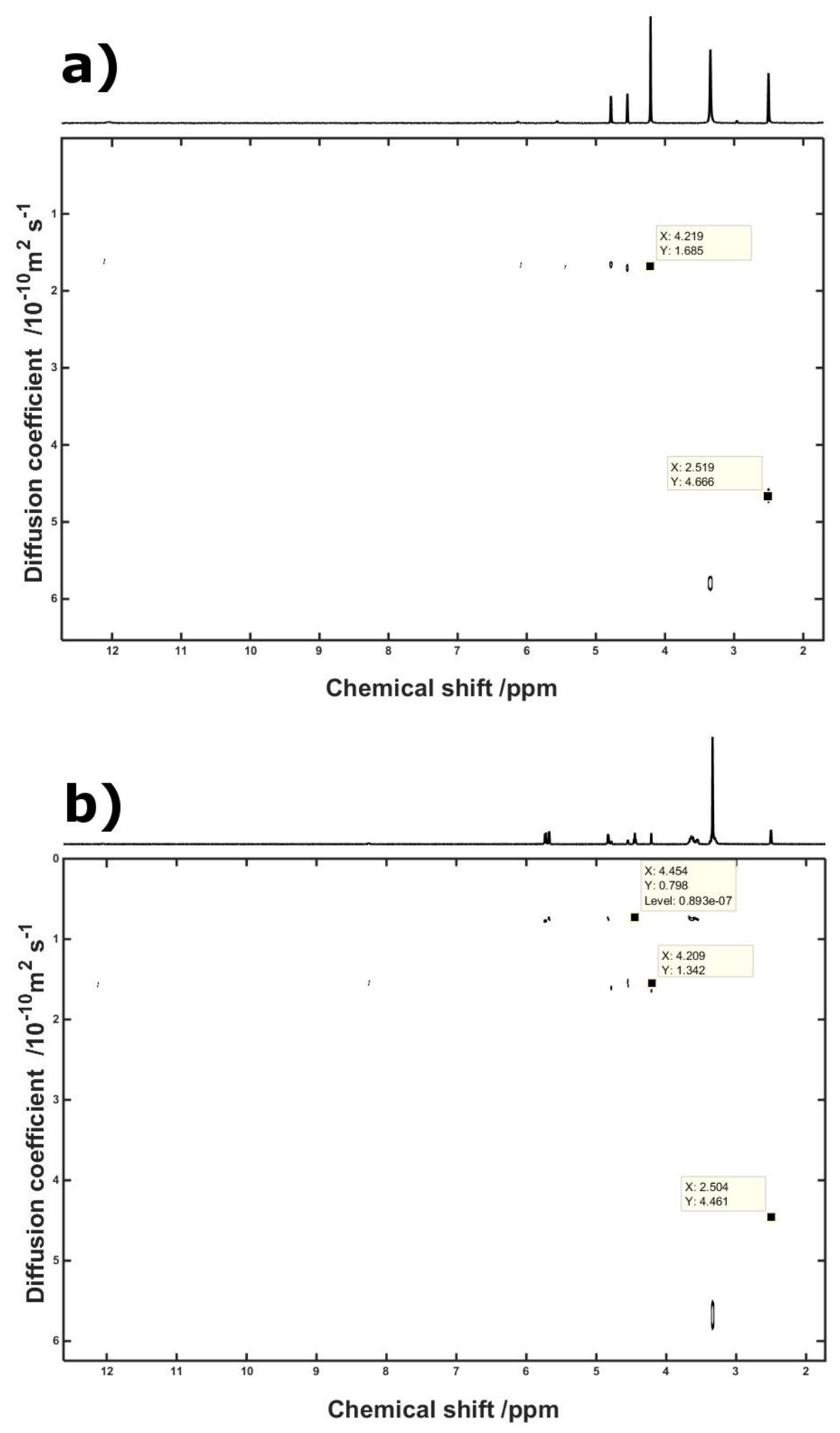

Figure S58. The ${ }^{1} \mathrm{H}$ DOSY NMR spectra (DMSO- $d_{6}, 500 \mathrm{MHz}$ ) of (a) compound Fc-4, and (b) complex Fc-4@ $@$ CD. 

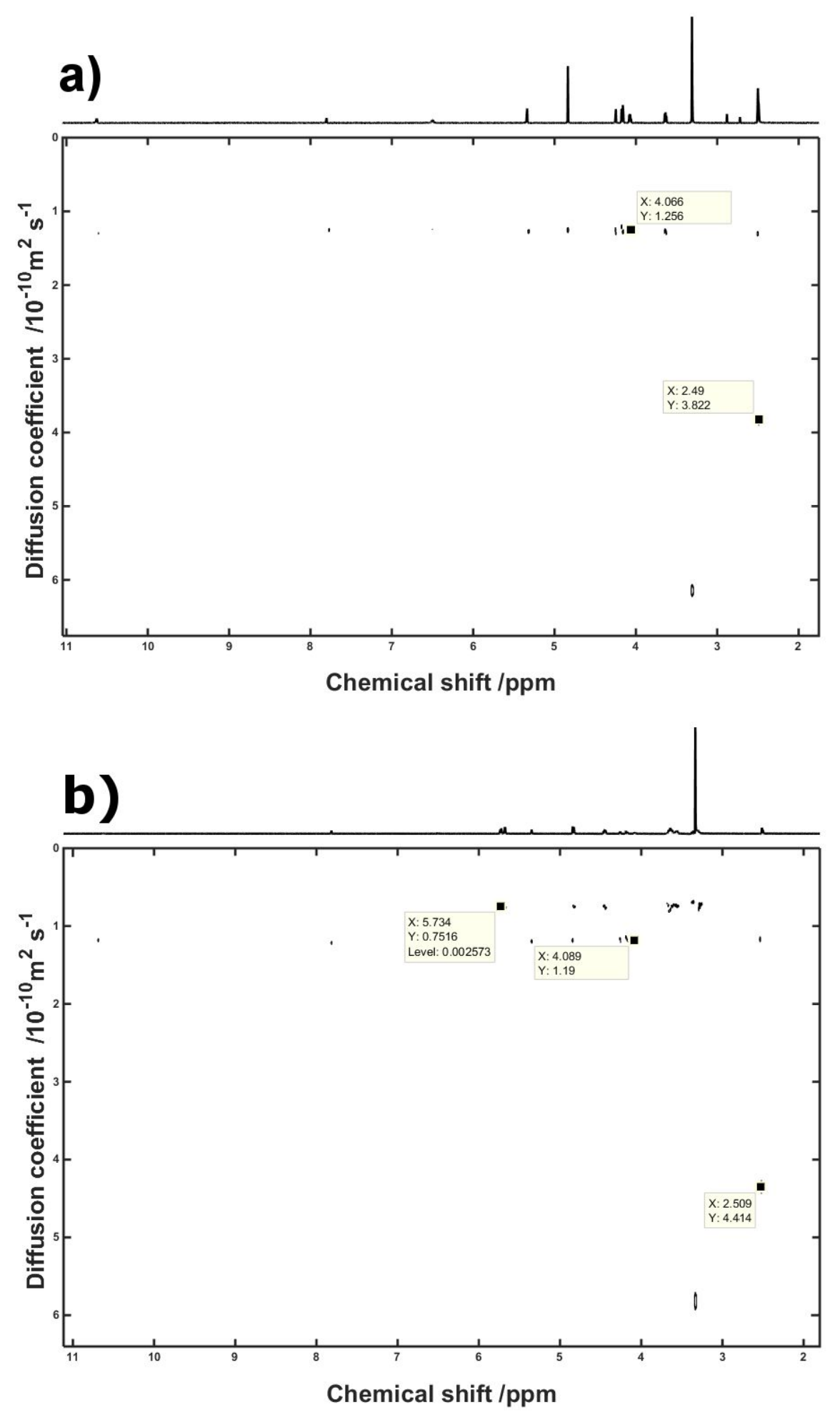

Figure S59. The ${ }^{1} \mathrm{H}$ DOSY NMR spectra (DMSO- $d_{6}, 500 \mathrm{MHz}$ ) of (a) compound Fc-5, and (b) complex Fc-5@ $@$ CD. 

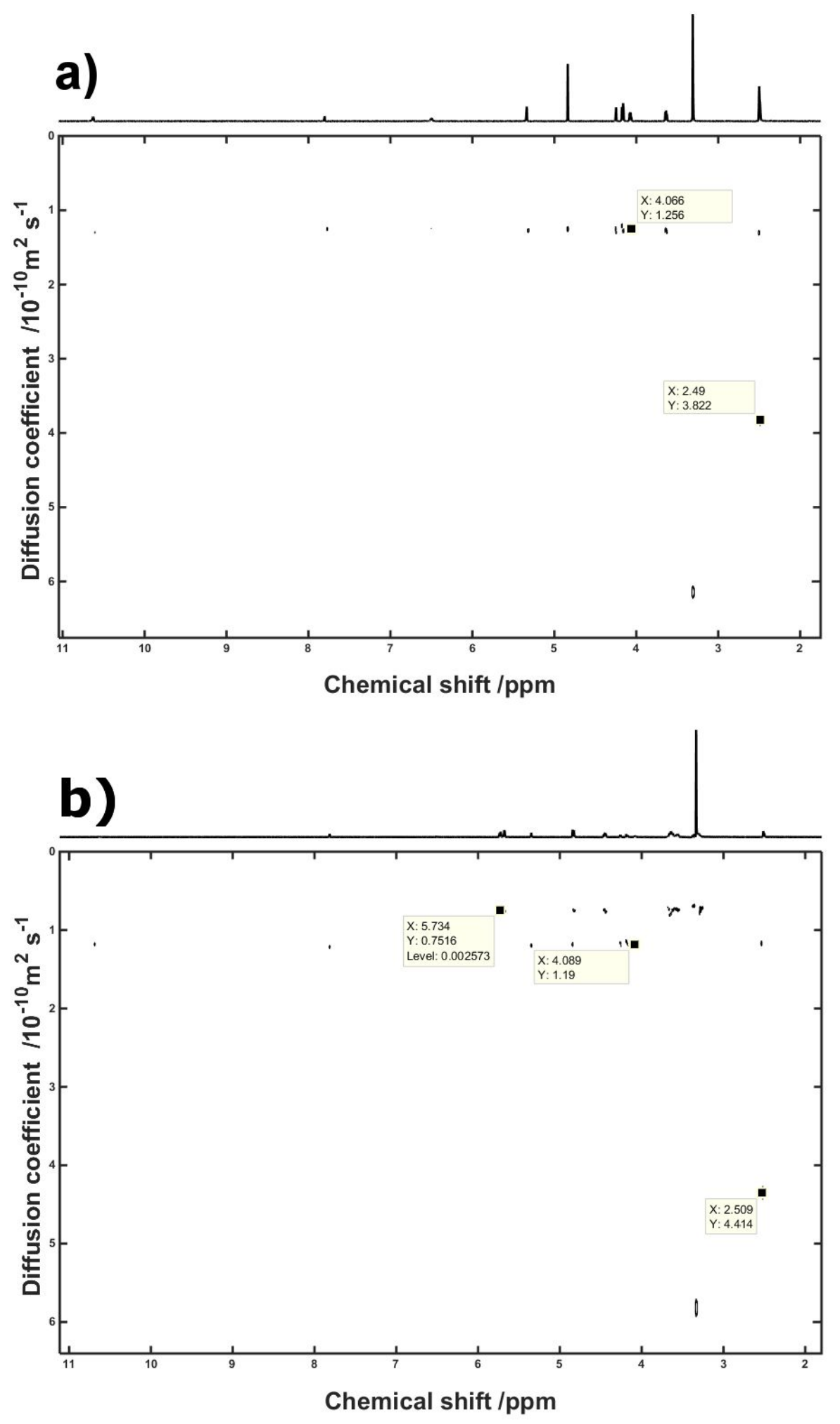

Figure S60. The ${ }^{1} \mathrm{H}$ DOSY NMR spectra (DMSO- $d_{6}, 500 \mathrm{MHz}$ ) of (a) compound Ada-1, and (b) complex Ada-1@ $@ \beta C D$. 


\section{S9. Calculation method for errors of measured diffusion coefficients and association constant values}

The protocol for calculating errors of measured diffusion coefficients and association constant was as follows ${ }^{4}$ :

1) Linear fit to $\ln$ (intensity) versus (gradient field strength) ${ }^{2}$ was performed for the reference samples (solvent: DMSO- $d_{6}, \beta C D$ in DMSO- $\mathrm{d}_{6}, \mathbf{F c}-1$ in DMSO- $d_{6}$ as the representative conjugate) and representative complex (Fc-1@ $\beta \mathrm{CD}$ in DMSO- $\left.d_{6}\right)$. This fir was performed for the data for $2.50 \mathrm{ppm}$ signal (residual solvent), $5.69 \mathrm{ppm}$ signal (for the samples that contain $\beta C D$ ) and 4.46 ppm (for the samples that contain Fc-1). See Figs. S60-S64.

2) Data on the error of parameter $a$ in the linear fit $y=a x+b$ were collected with reglinp function, yielding $\Delta a$. See data in Table S5.

3) Relative error of diffusion coefficient ( $\delta[\%])$ corresponded to error of parameter $a$. This error was calculated as follows: $\left.\delta[\%]=\frac{\Delta a}{a} \cdot 100 \%\right)$.

4) Standard root-mean-square error approach was used to calculate relative errors of viscosity-corrected diffusion coefficients, and relative errors of parameter $x_{\mathrm{b}}$ and association constant $\left(\mathrm{K}_{\mathrm{a}}\right)$.

5) The obtained data were assumed to be the same for the latter compounds and complexes. ${ }^{4}$ 
Table S5. Calculated measurement errors.

\begin{tabular}{|c|c|c|c|c|c|}
\hline Sample & Component & $\begin{array}{l}\text { Relative error } \\
\text { for diffusion } \\
\text { coefficient } \\
\left(\delta_{D, \text { meas }}\right)[\%]\end{array}$ & $\begin{array}{l}\text { Relative error for } \\
\text { viscosity-corrected } \\
\text { diffusion } \\
\text { coefficient }\left(\delta_{D, \text { cor }}\right) \\
{[\%]} \\
\end{array}$ & $\begin{array}{l}\text { Relative error } \\
\text { for molar } \\
\text { fraction }\left(\delta_{\mathrm{x}}\right) \\
{[\%]}\end{array}$ & $\begin{array}{l}\text { Relative error } \\
\text { for } \\
\text { association } \\
\text { constant }\left(\delta_{\mathrm{Ka}}\right) \\
{[\%]}\end{array}$ \\
\hline DMSO- $d_{6}$ & DMSO & $0.21^{4}$ & N.A. & N.A. & N.A. \\
\hline \multirow{2}{*}{$\beta C D$} & DMSO & $0.65^{4}$ & N.A. & N.A. & N.A. \\
\hline & $\beta C D$ & $0.61^{4}$ & 0.92 & N.A. & N.A. \\
\hline \multirow{2}{*}{ Fe-1 } & DMSO & 0.65 & N.A. & N.A. & N.A. \\
\hline & Fc-1 & 0.61 & 0.91 & N.A. & N.A. \\
\hline \multirow{3}{*}{$\begin{array}{l}\text { Fc-1@ } \\
\text { BCD }\end{array}$} & DMSO & 0.47 & N.A. & N.A. & N.A. \\
\hline & Fc-1 & 0.67 & 0.84 & \multirow{2}{*}{1.53} & \multirow{2}{*}{2.66} \\
\hline & $\beta C D$ & 0.73 & 0.89 & & \\
\hline
\end{tabular}

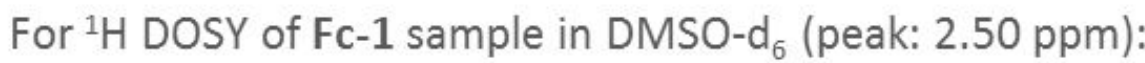

$$
a=-3,31039 \mathrm{E}-09 ; \Delta a=2,14074 \mathrm{E}-11
$$

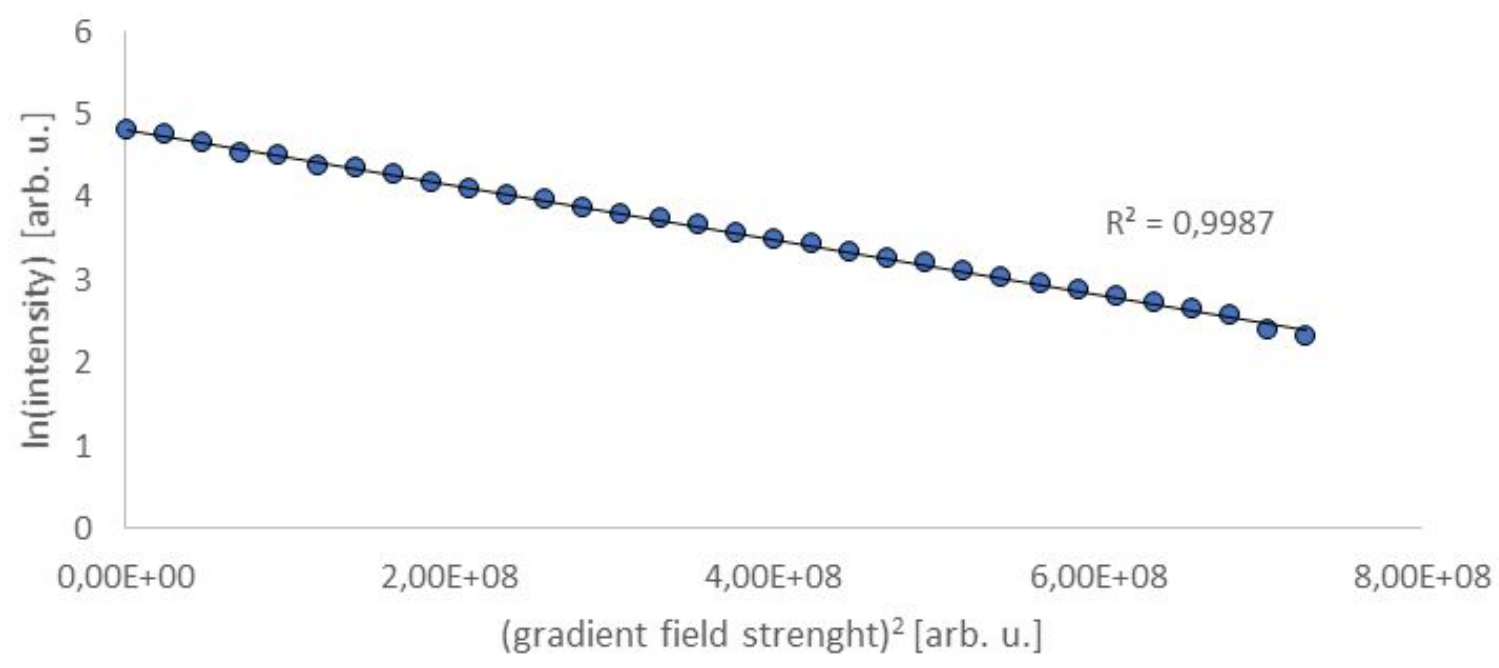

Figure S61. Linear fit for $2.50 \mathrm{ppm}$ peak in ${ }^{1} \mathrm{H}$ DOSY NMR spectrum (500 MHz, DMSO- $\left.d_{6}\right)$ of Fc-1 sample. Data on $a$ parameter and $\Delta a$ in $y=a x+b$ linear fit are also given. 
For ${ }^{1} \mathrm{H}$ DOSY of Fc-1 sample in DMSO-d $\mathrm{d}_{6}$ (peak: $4.46 \mathrm{ppm}$ ):

$a=-3,31634 \mathrm{E}-09 ; \Delta a=2,00149 \mathrm{E}-11$

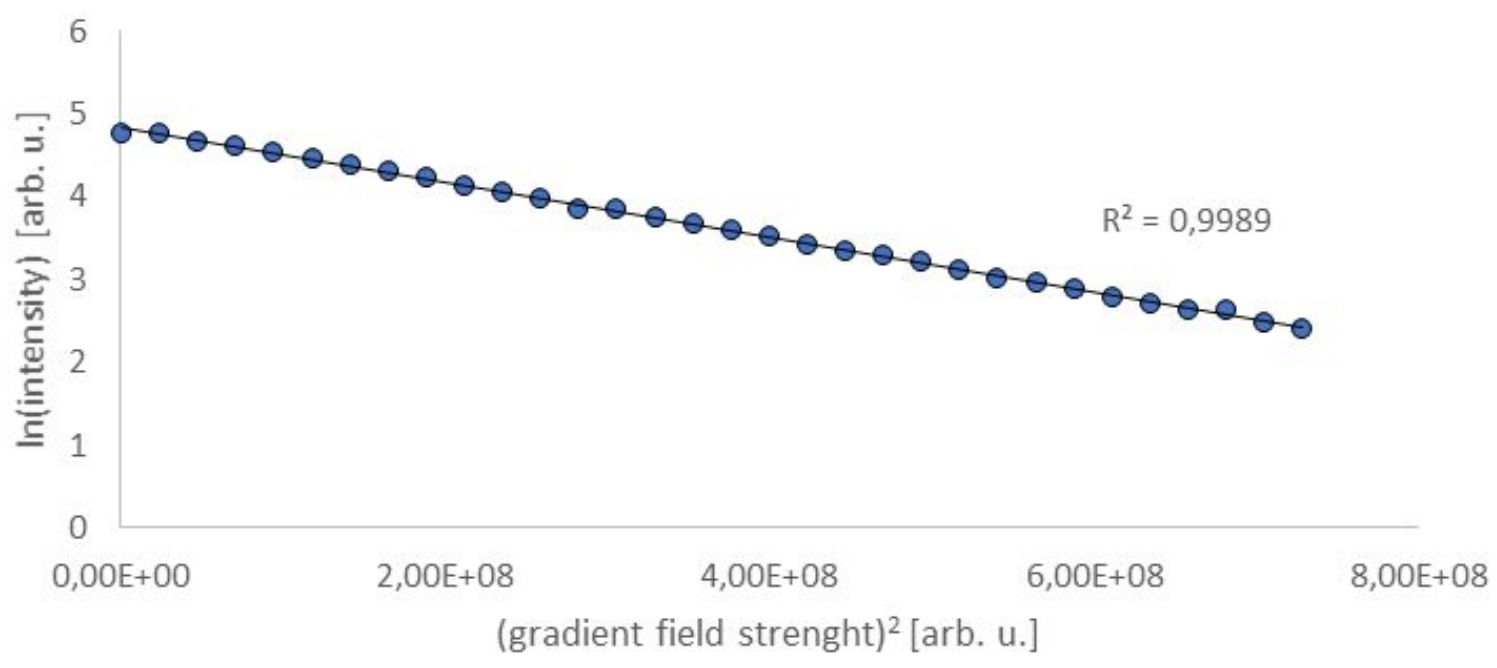

Figure S62. Linear fit for $4.46 \mathrm{ppm}$ peak in ${ }^{1} \mathrm{H}$ DOSY NMR spectrum $\left(500 \mathrm{MHz}\right.$, DMSO- $\left.d_{6}\right)$ of Fc-1 sample. Data on $a$ parameter and $\Delta a$ in $y=a x+b$ linear fit are also given.

For ${ }^{1} \mathrm{H}$ DOSY of Fc-1@ßCD sample in DMSO- $\mathrm{d}_{6}$

(peak: $2.50 \mathrm{ppm}$ ):

$a=-3,34439 \mathrm{E}-09 ; \Delta a=1,57945 \mathrm{E}-11$

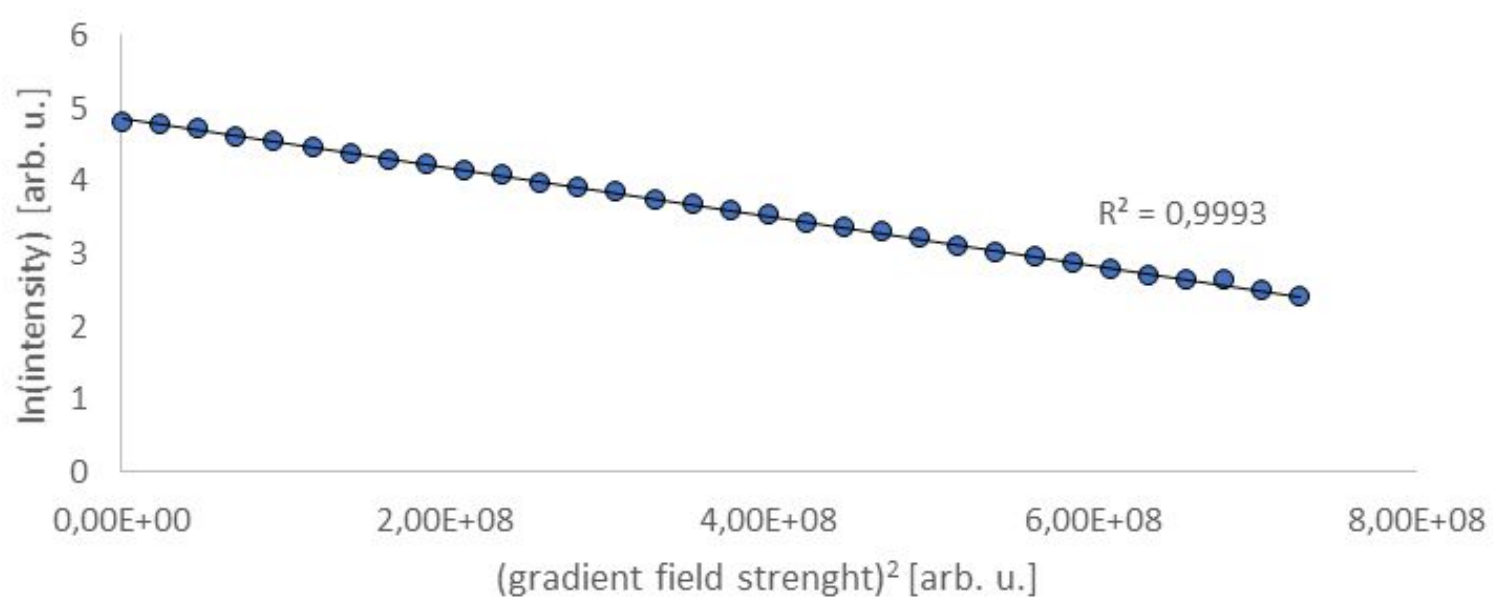

Figure S63. Linear fit for $2.50 \mathrm{ppm}$ peak in ${ }^{1} \mathrm{H}$ DOSY NMR spectrum (500 MHz, DMSO- $\left.d_{6}\right)$ of Fc-1@ $@ C D$ sample. Data on $a$ parameter and $\Delta a$ in $y=a x+b$ linear fit are also given. 


\section{For ${ }^{1} \mathrm{H}$ DOSY of Fc-1@ßCD sample in DMSO- $\mathrm{d}_{6}$}

(peak: $4.46 \mathrm{ppm}$ ):

$a=-3,37422 \mathrm{E}-09 ; \Delta a=2,90806 \mathrm{E}-11$

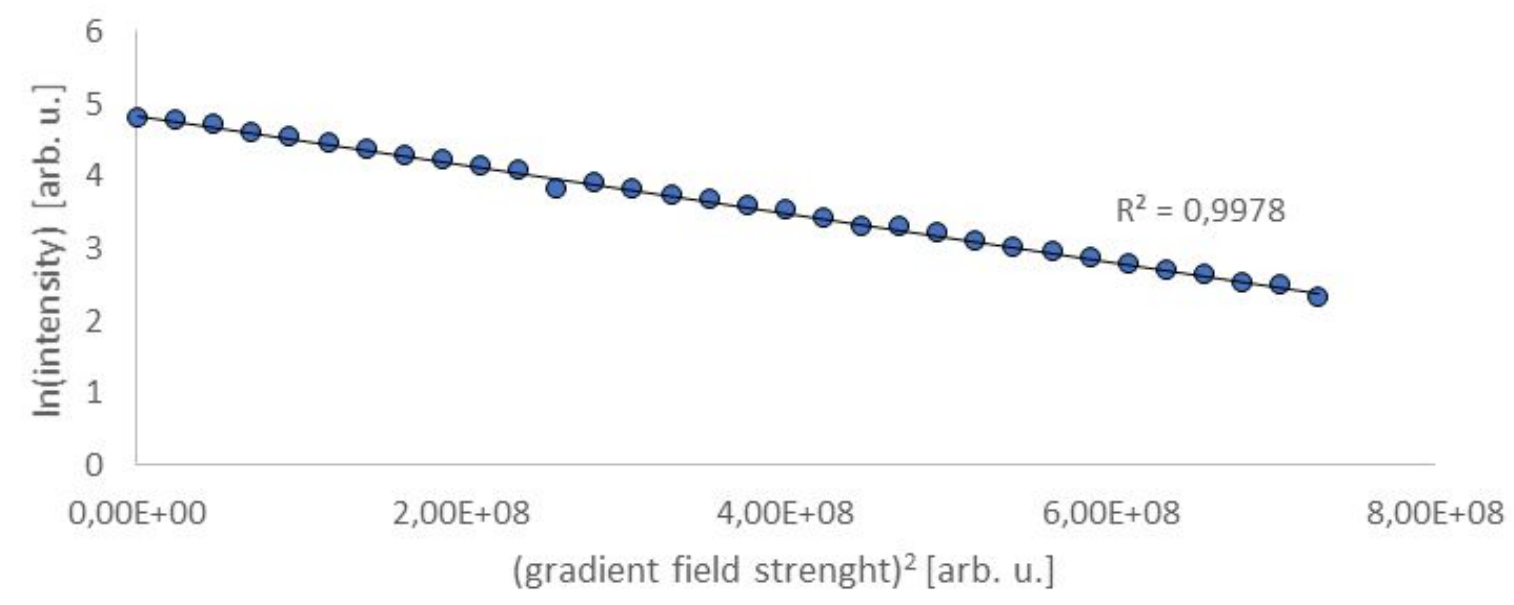

Figure S64. Linear fit for 4.46 ppm peak in ${ }^{1} \mathrm{H}$ DOSY NMR spectrum (500 MHz, DMSO- $\left.d_{6}\right)$ of Fc-1@ $@ \beta C D$ sample. Data on $a$ parameter and $\Delta a$ in $y=a x+b$ linear fit are also given.

For ${ }^{1} \mathrm{H}$ DOSY of Fc-1@ßCD sample in DMSO- $\mathrm{d}_{6}$

(peak: $5.69 \mathrm{ppm}$ ):

$a=-3,33692 \mathrm{E}-09 ; \Delta a=2,44436 \mathrm{E}-11$

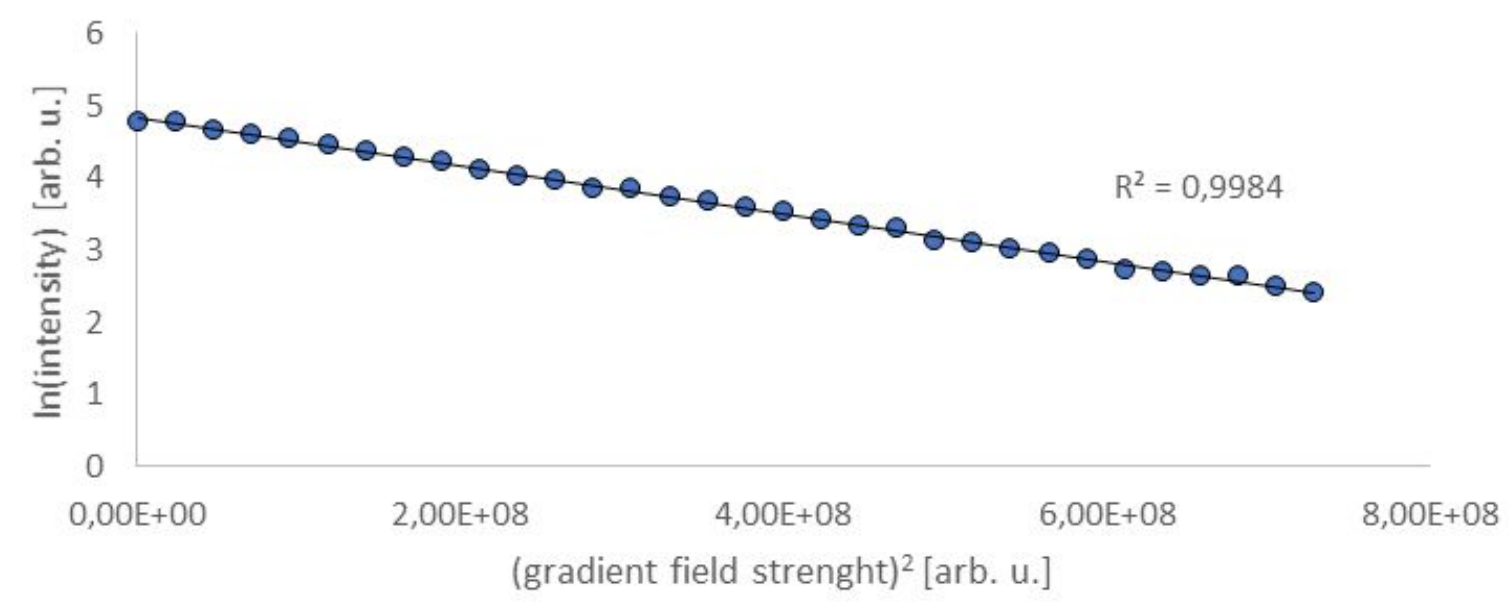

Figure S65. Linear fit for 5.69 ppm peak in ${ }^{1} \mathrm{H}$ DOSY NMR spectrum (500 MHz, DMSO- $\left.d_{6}\right)$ of Fc-1@ $@$ CD sample. Data on $a$ parameter and $\Delta a$ in $y=a x+b$ linear fit are also given. 
S10. Fluorescence spectra titration

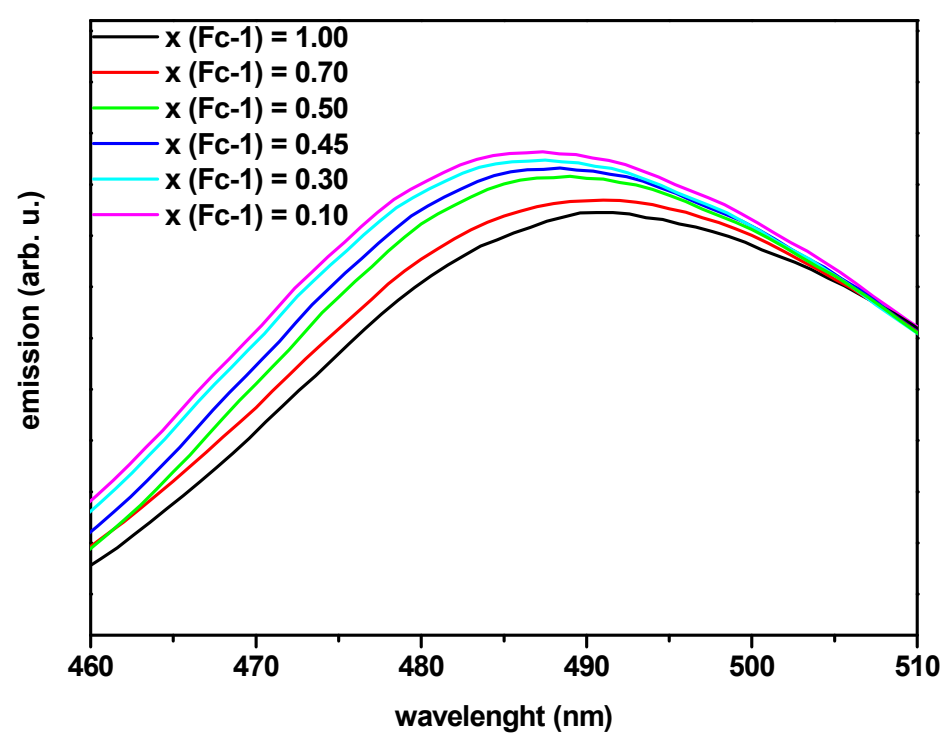

Figure S66. Fluorescence spectra measured for a titration of the DMSO solution of compound Fc-2 with $\beta C D ; \mathbf{x}(\mathbf{F c}-1)$ denotes the mole fraction of compound $\mathbf{F c - 1}$ in the examined solution.

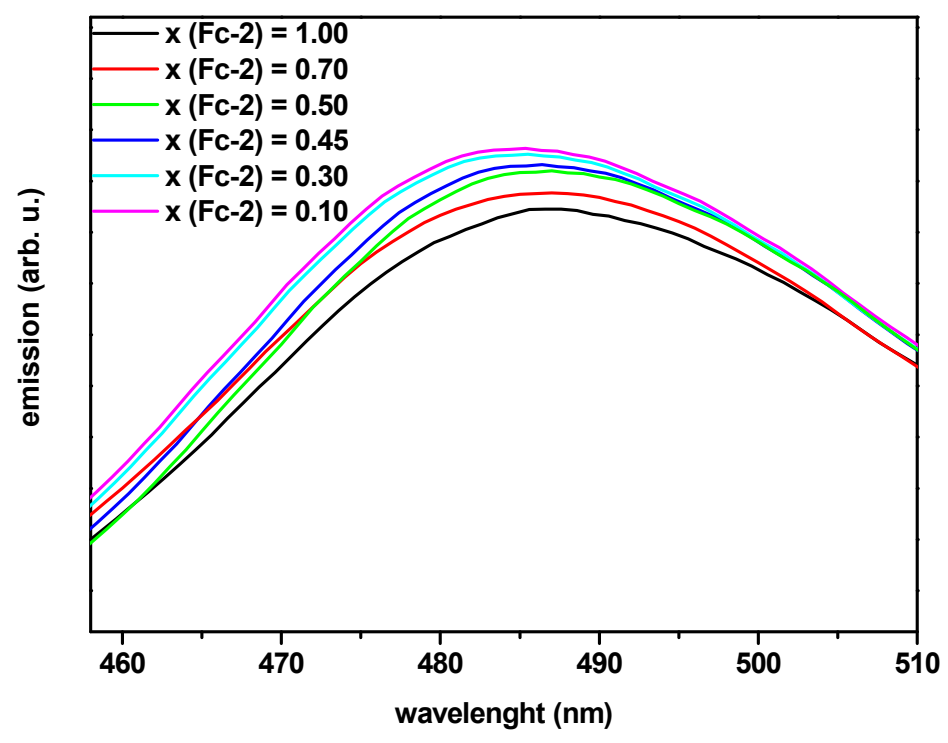

Figure S67. Fluorescence spectra measured for a titration of the DMSO solution of compound Fc-2 with $\beta C D ; \mathbf{x}(\mathbf{F c}-2)$ denotes the mole fraction of compound $\mathbf{F c - 2}$ in the examined solution. 


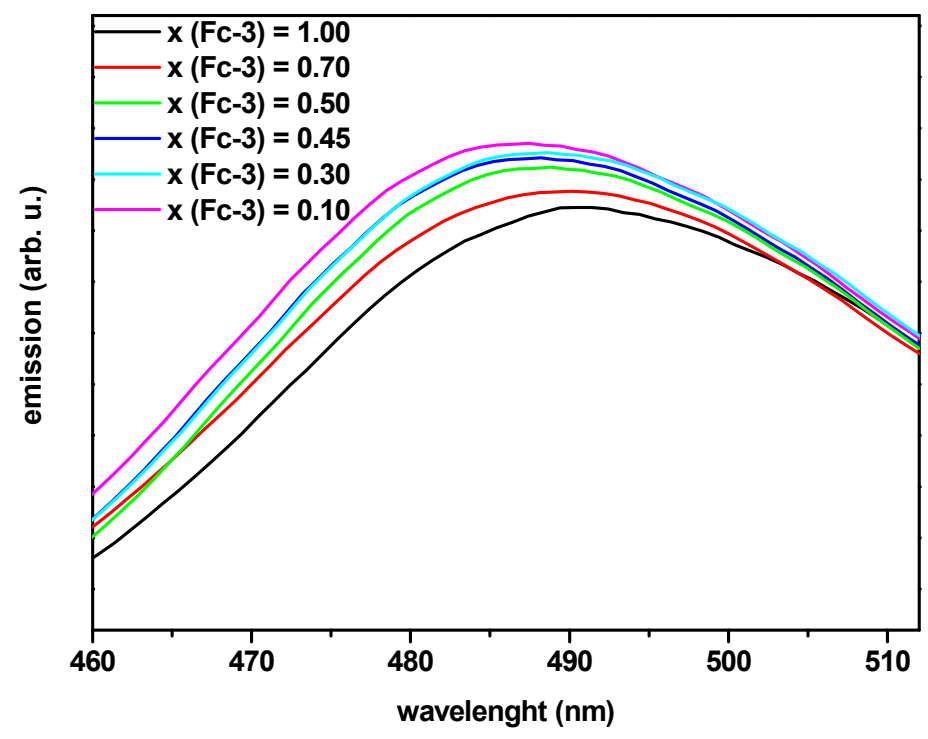

Figure S68. Fluorescence spectra measured for a titration of the DMSO solution of compound Fc-3 with $\beta C D ; x(\mathbf{F c}-3)$ denotes the mole fraction of compound $\mathbf{F c - 3}$ in the examined solution.

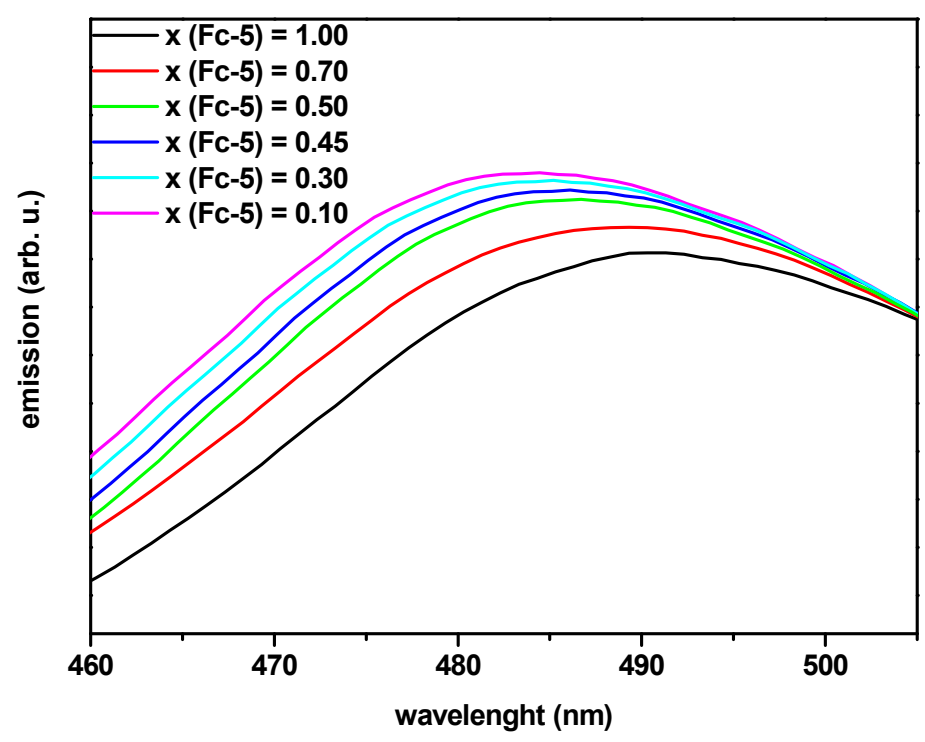

Figure S69. Fluorescence spectra measured for a titration of the DMSO solution of compound Fc-5 with $\beta \mathrm{CD}$; $\mathbf{x}(\mathbf{F c}-5)$ denotes the mole fraction of compound $\mathbf{F c}-5$ in the examined solution. 


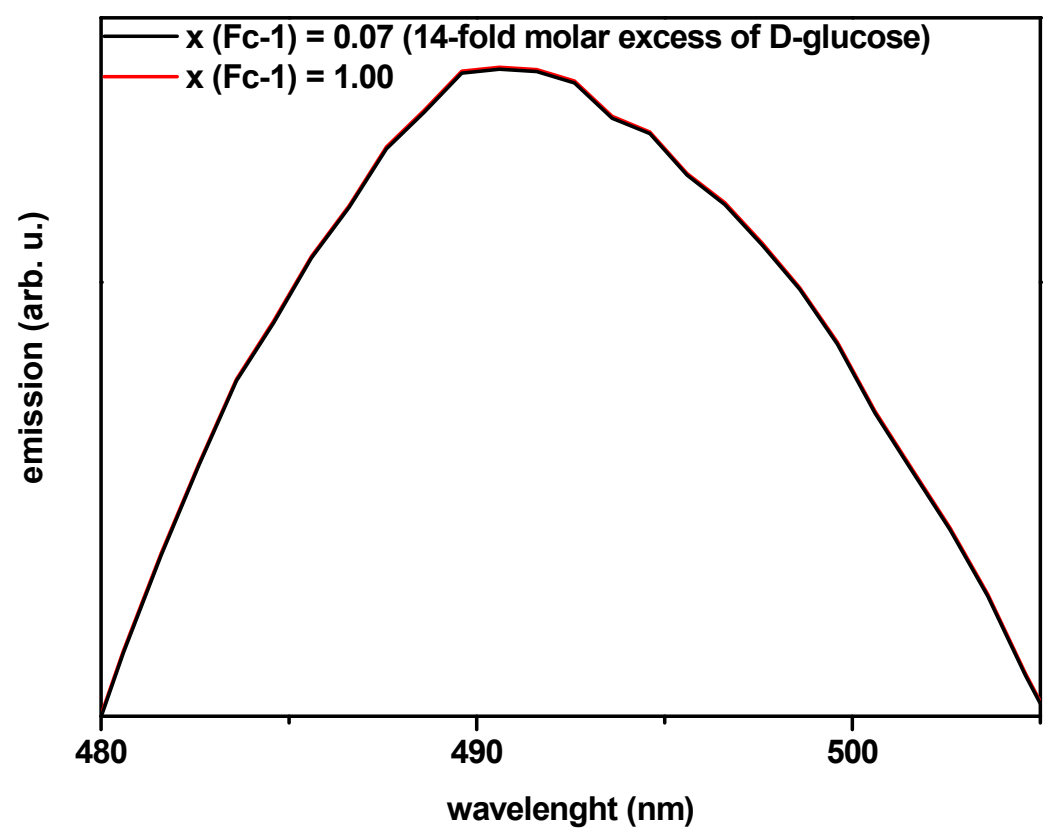

Figure S70. Fluorescence spectra titration experiments with compound Fc-1 and the excess of D-glucose.

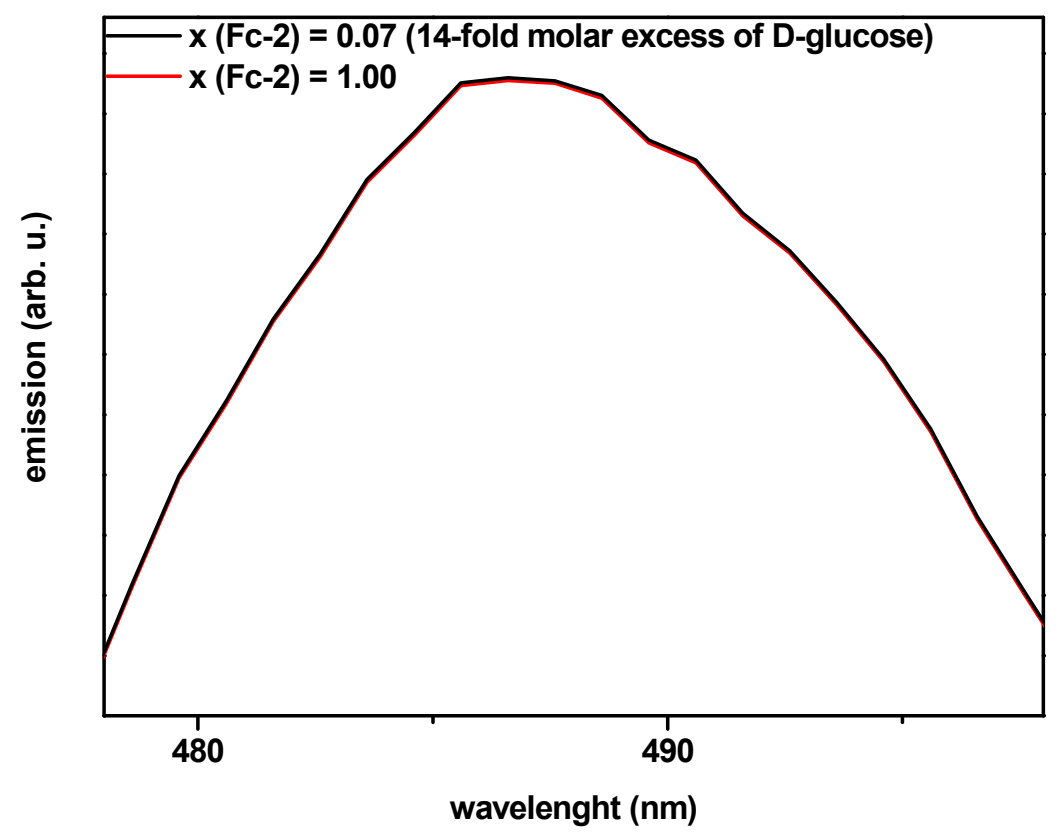

Figure S71. Fluorescence spectra titration experiments with compound Fc-2 and the excess of D-glucose. 


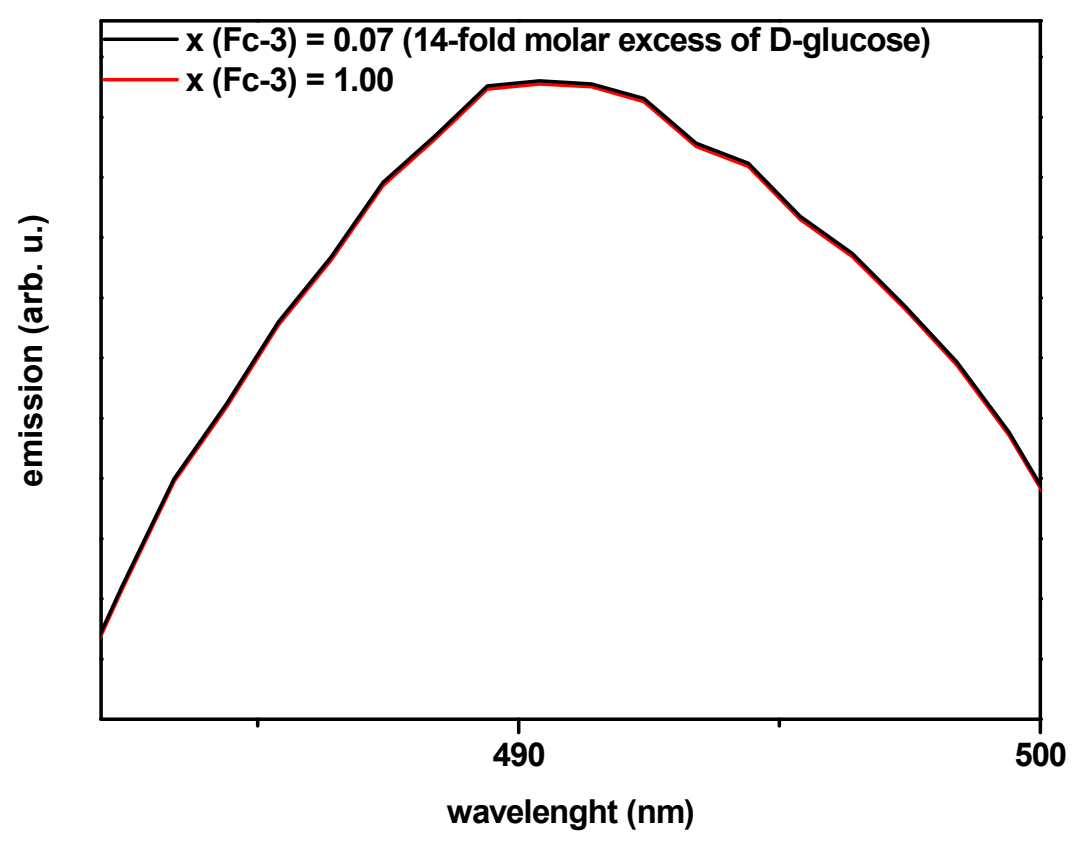

Figure S72. Fluorescence spectra titration experiments with compound Fc-3 and the excess of D-glucose.

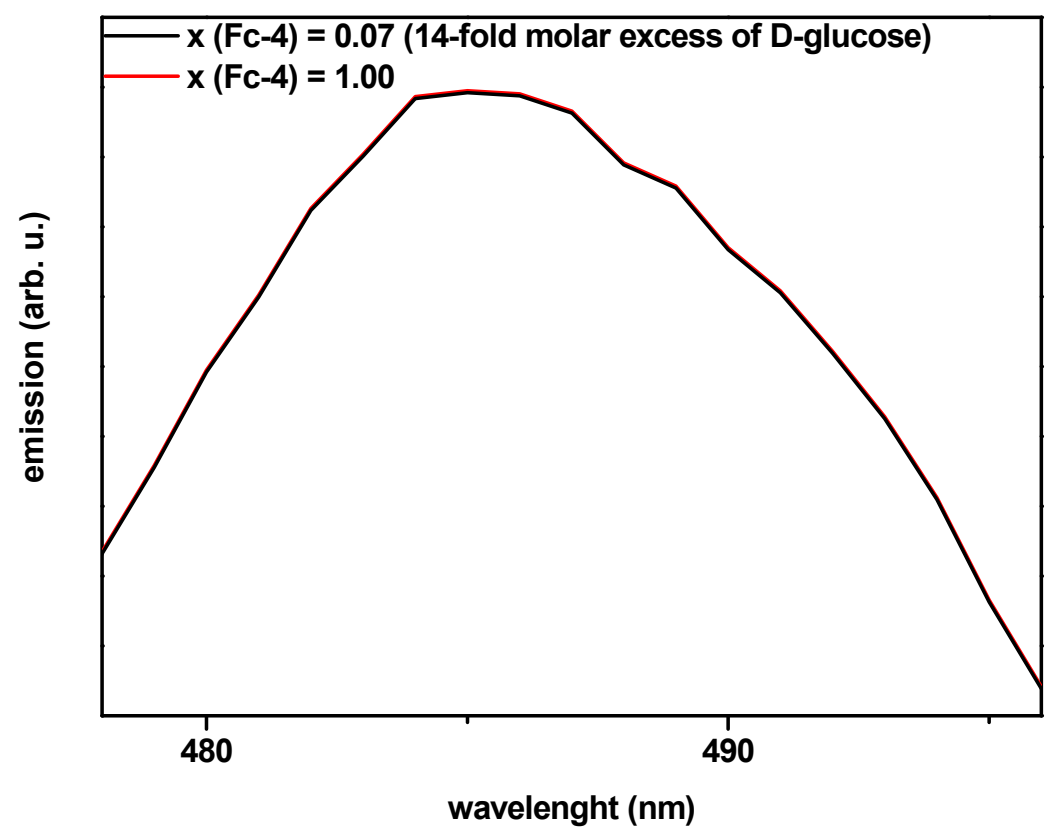

Figure S73. Fluorescence spectra titration experiments with compound Fc-4 and the excess of D-glucose. 


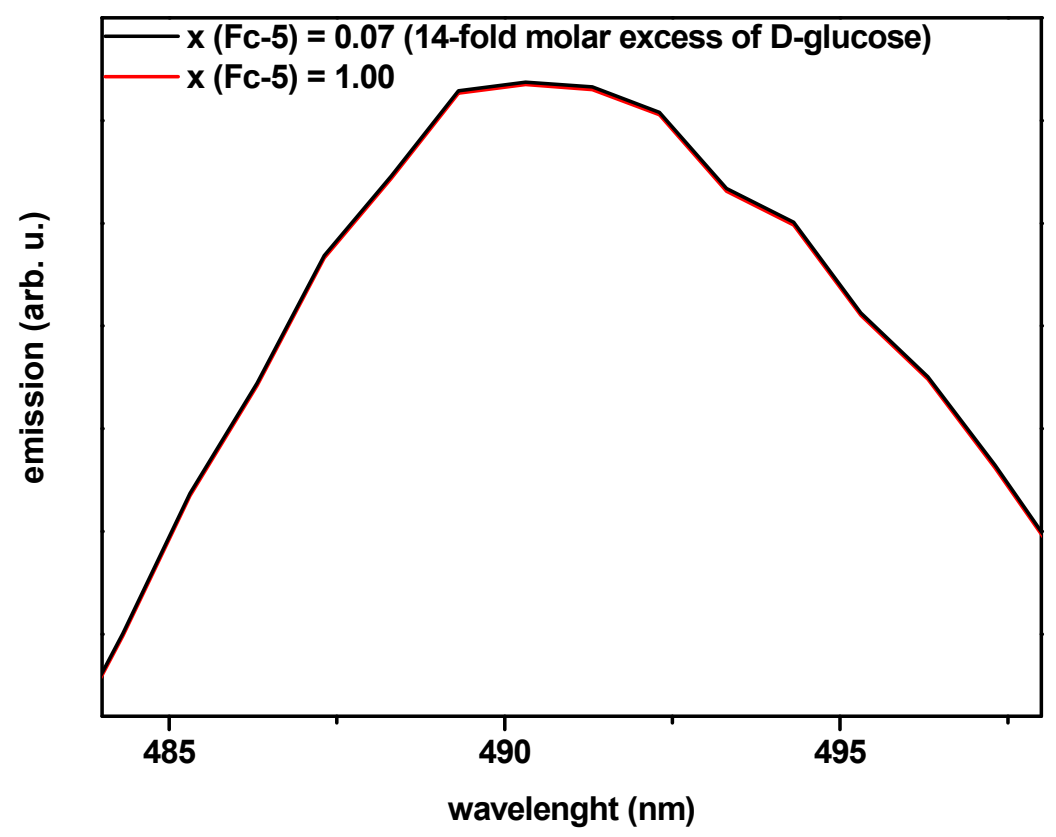

Figure S74. Fluorescence spectra titration experiments with compound Fc-5 and the excess of D-glucose. 
S11. Tracking the complexation phenomenon with FT-IR

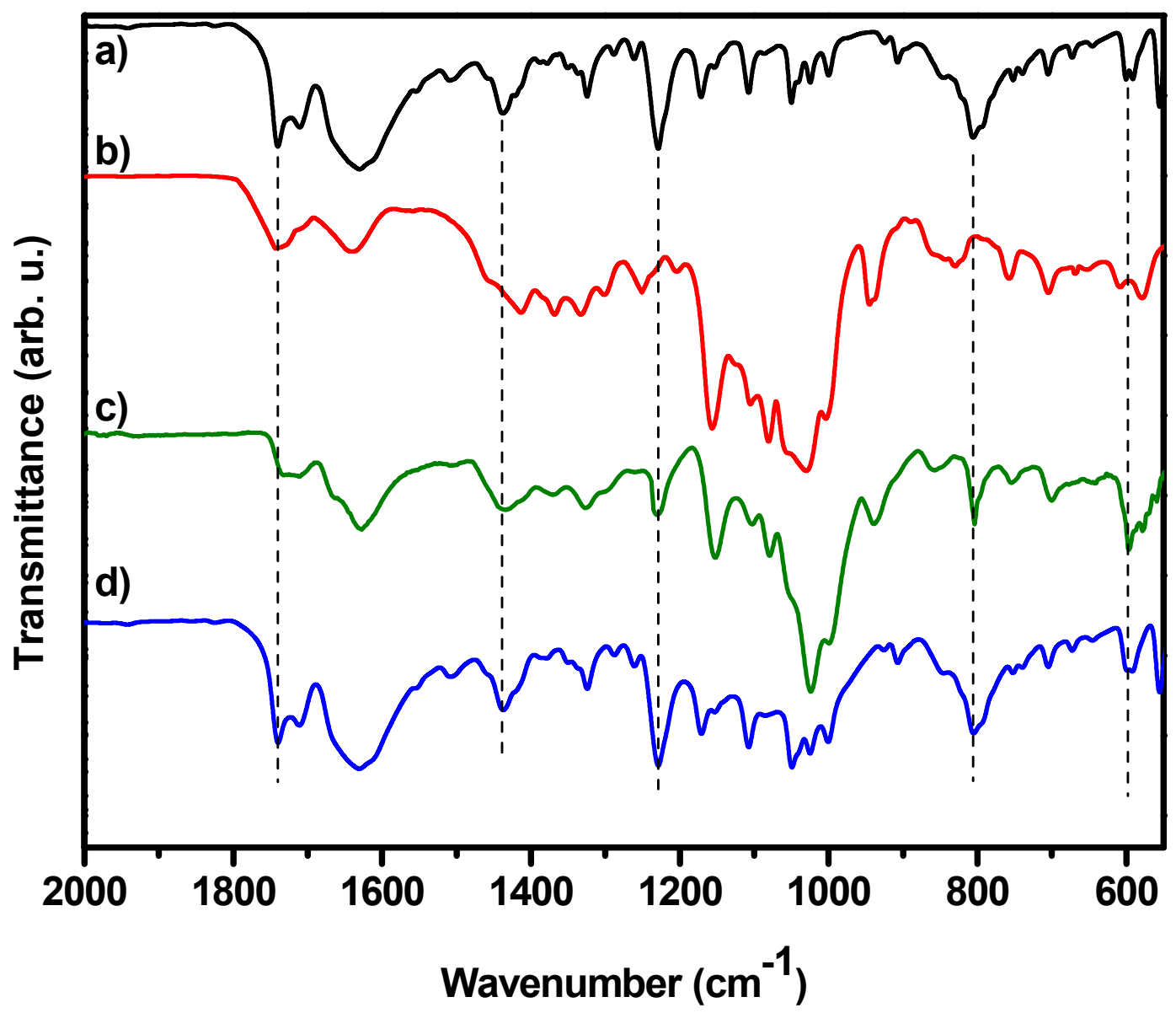

Figure S75. Comparison of the FT-IR spectra of (a) native compound Fc-1, (b) inclusion complex Fc-1@ $\beta C D$, (c) physical mixture of Fc-1 and $\beta C D(x(\mathbf{F c}-1)=0.50),(\mathbf{d})$ physical mixture of compound Fc-1 and D-glucose $(x(\mathbf{F c}-1)=0.125)$. 


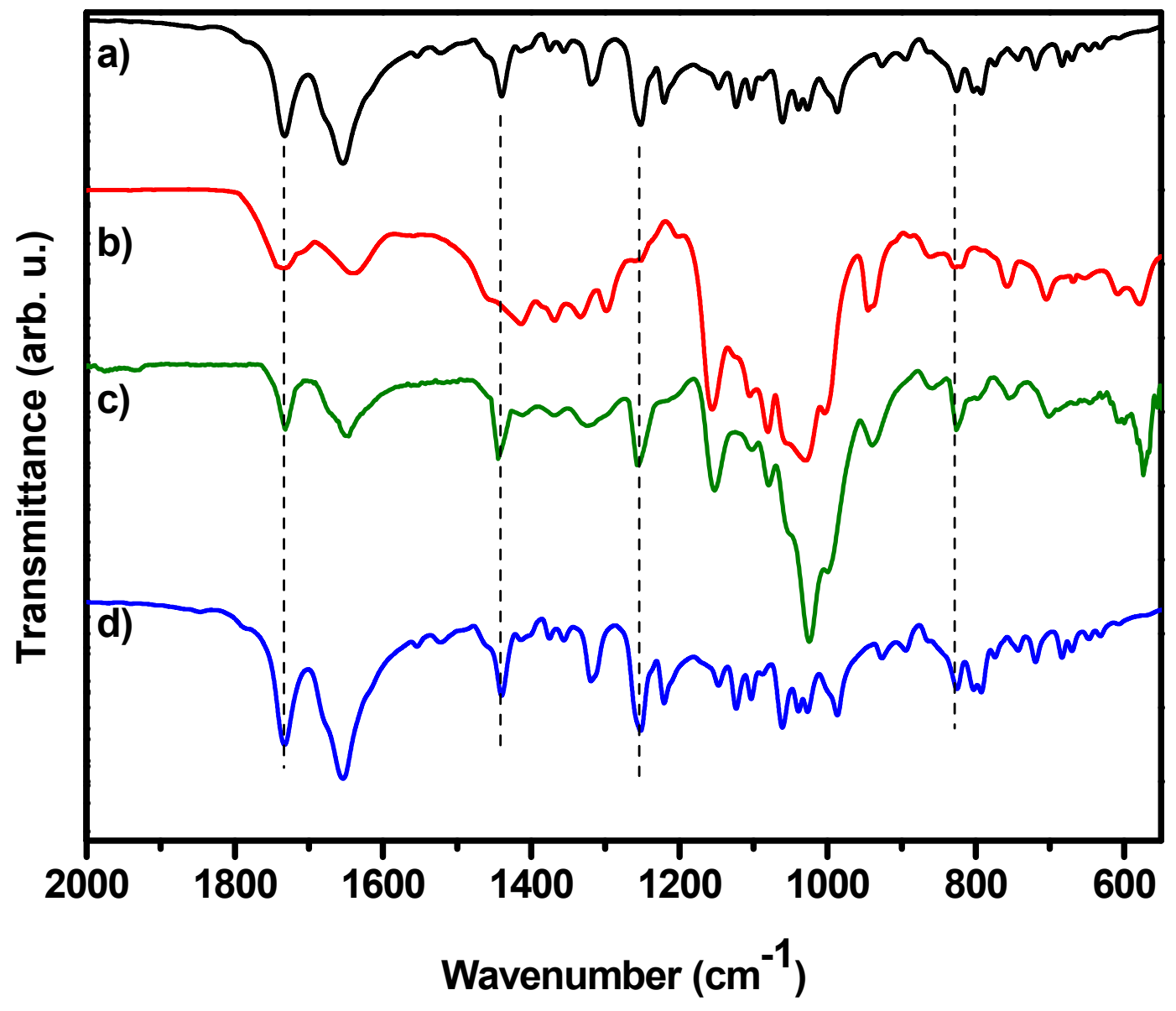

Figure S76. Comparison of the FT-IR spectra of (a) native compound Fc-2, (b) inclusion complex Fc-2@ $\beta C D$, (c) physical mixture of Fc-2 and $\beta C D(x(\mathbf{F c}-2)=0.50),(\mathbf{d})$ physical mixture of compound Fc-2 and D-glucose $(x(\mathbf{F c}-2)=0.125)$. 


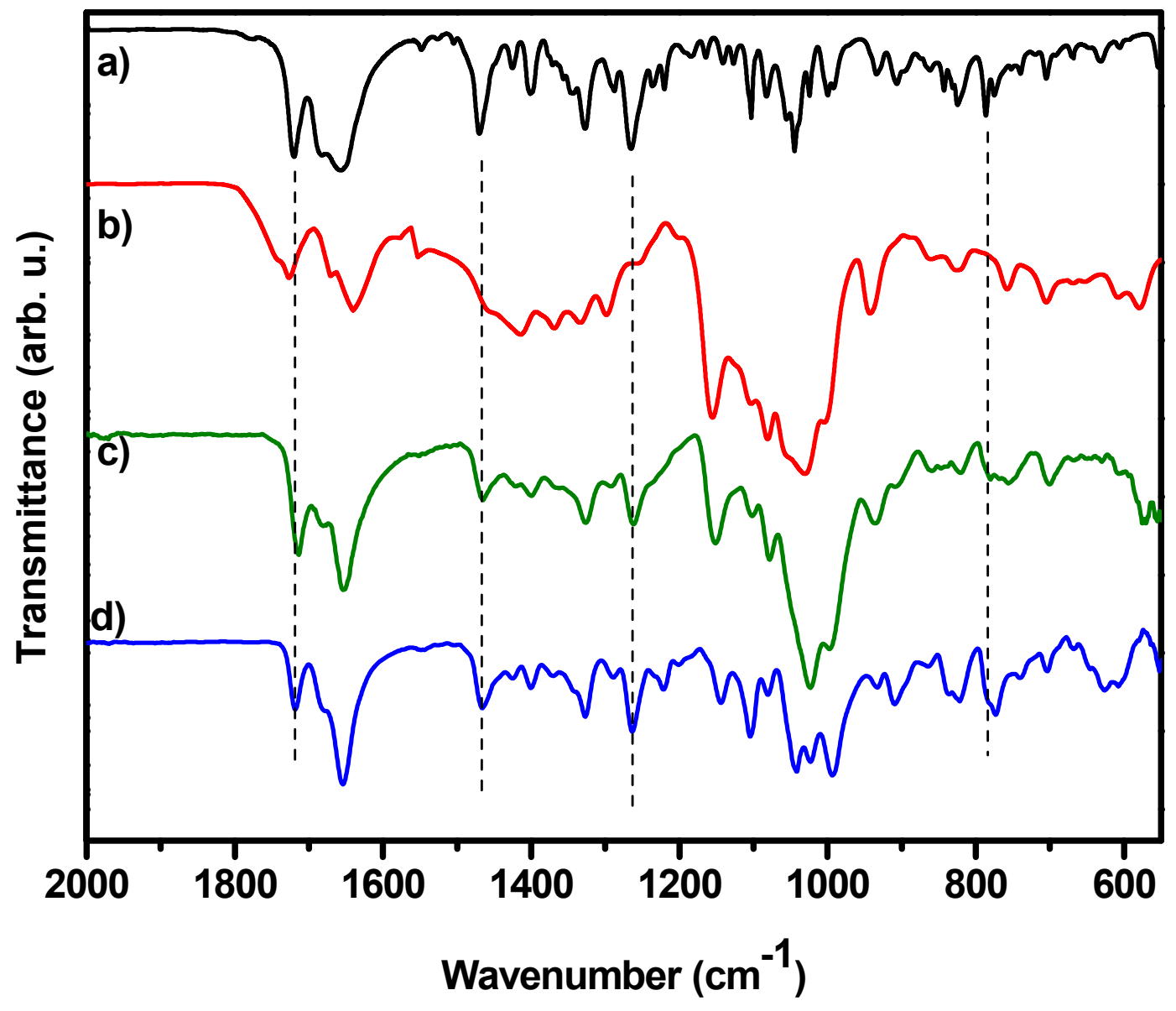

Figure S77. Comparison of the FT-IR spectra of (a) native compound Fc-3, (b) inclusion complex Fc-3@ $\beta C D$, (c) physical mixture of Fc-3 and $\beta C D(x(\mathbf{F c}-3)=0.50)$, (d) physical mixture of compound Fc-3 and D-glucose $(x(\mathbf{F c}-3)=0.125)$. 


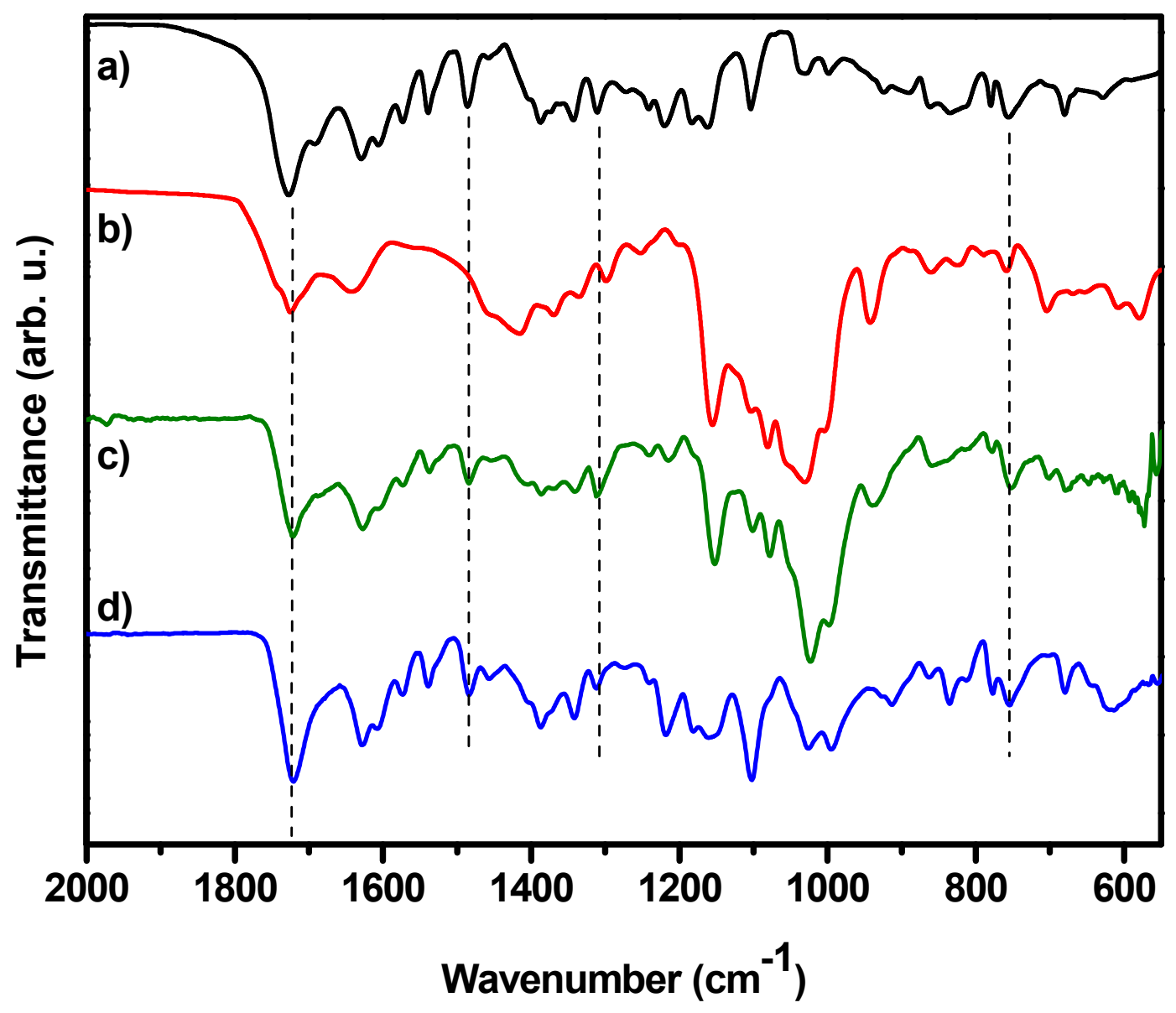

Figure S78. Comparison of the FT-IR spectra of (a) native compound Fc-5, (b) inclusion complex Fc-5@ $\beta C D$, (c) physical mixture of Fc-5 and $\beta C D(x(\mathbf{F c}-5)=0.50),(\mathbf{d})$ physical mixture of compound Fc-45and D-glucose $(x(\mathbf{F c}-5)=0.125)$. 


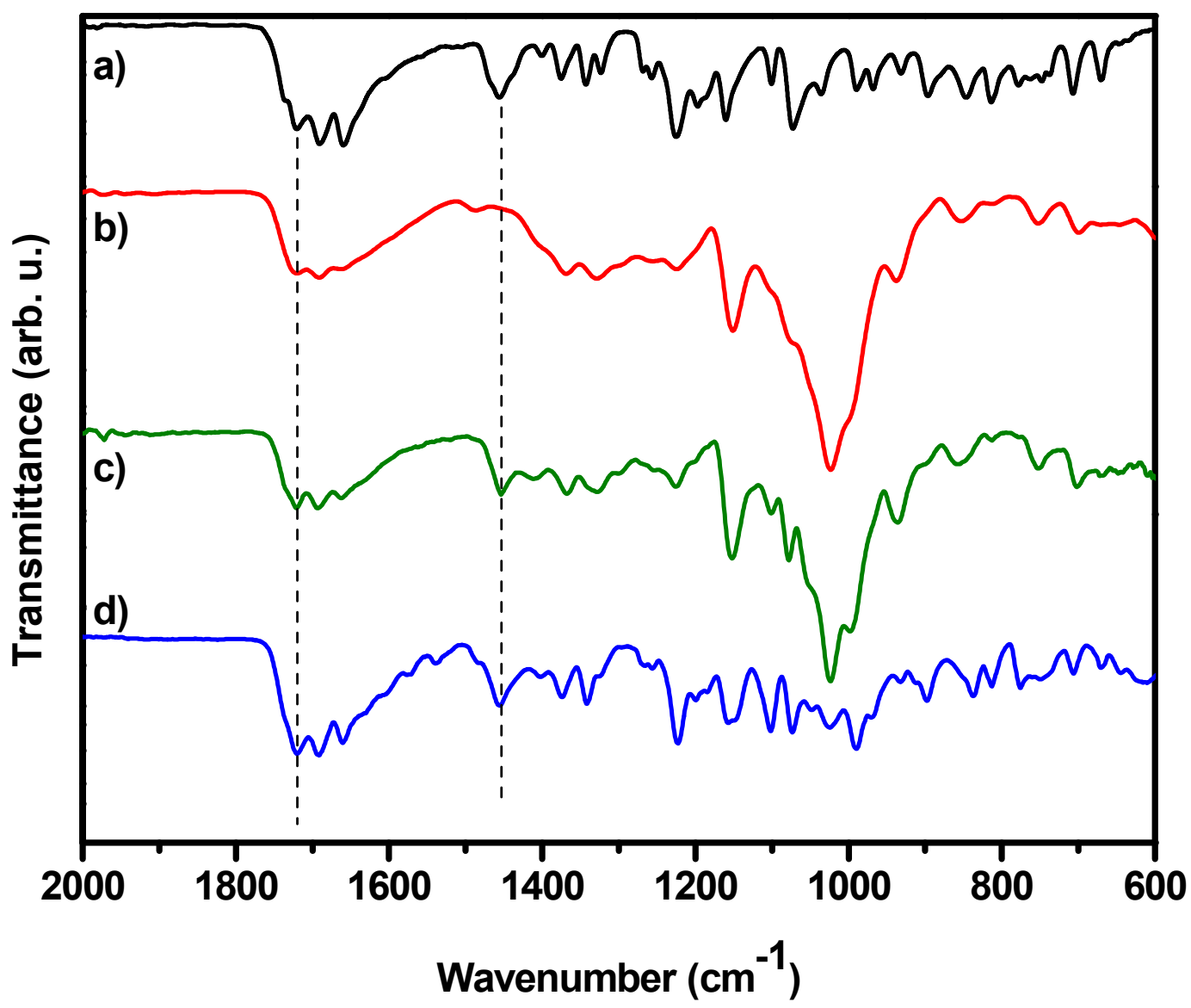

Figure S79. Comparison of the FT-IR spectra of (a) native compound Ada-1, (b) inclusion complex Ada-1@ $\beta C D,(\mathbf{c})$ physical mixture of Ada-1 and $\beta C D(x($ Ada-1 $)=0.50),(\mathbf{d})$ physical mixture of compound Ada-1 and D-glucose $(x($ Ada-1 $)=0.125)$. 


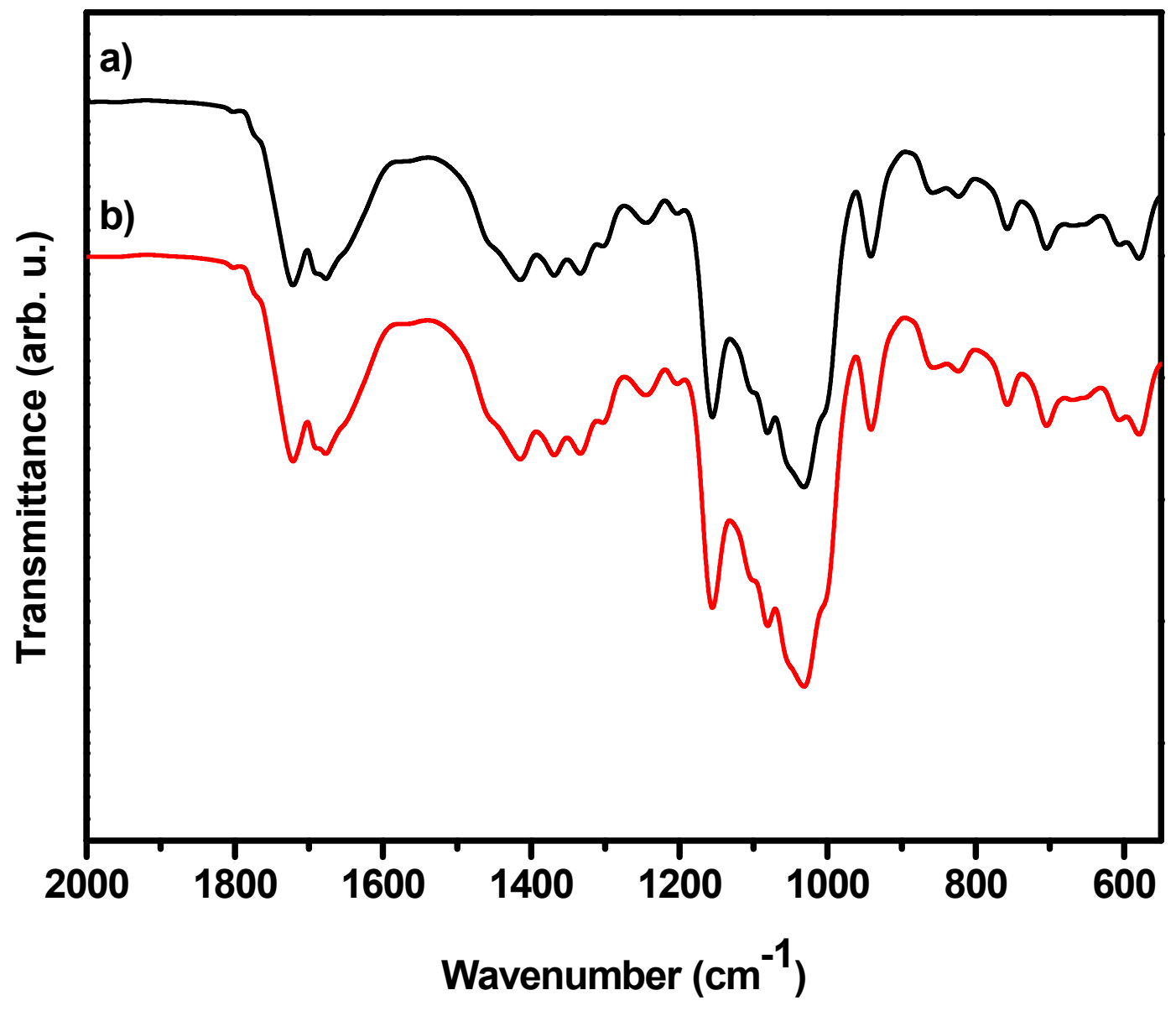

Figure S80. Comparison of the FT-IR spectra of the representative Fc-4@ $\beta C D$ inclusion complex measured in a (a) transmission mode, (b) ATR mode. In the case of the measurement of the sample in the ATR mode, $\mathrm{KBr}$ was not added and the sample was not formed into a pellet. 


\section{References}

(1) Katritzky, A.; Ramsden, C.; Joule, J.; Zhdankin, V. In: Handbook of Heterocyclic Chemistry, Third Edit.; Elsevier, 2010.

(2) Popenoe, D. D.; Deinhammer, R. S.; Porter, M. D. Infrared Spectroelectrochemical Characterization of Ferrocene-Terminated Alkanethiolate Monolayers at Gold.

Langmuir 1992, 8 (10), 2521-2530.

(3) SDBSWeb: Https://Sdbs.Db.Aist.Go.Jp (National Institute of Advanced Industrial Science and Technology, Date of Access - 07.11.2018).

(4) Kasprzak, A.; Borys, K. M.; Molchanov, S.; Adamczyk-Woźniak, A. Spectroscopic Insight into Supramolecular Assemblies of Boric Acid Derivatives and $\beta$-Cyclodextrin. Carbohydr. Polym. 2018, 198, 294-301. 